Review

\title{
Application of Metal-Organic Framework-Based Composites for Gas Sensing and Effects of Synthesis Strategies on Gas-Sensitive Performance
}

\author{
Bo Huang ${ }^{1}$, Yanqiong $\mathrm{Li}^{2}$ and Wen Zeng ${ }^{1, *}$ \\ 1 College of Materials Science and Engineering, Chongqing University, Chongqing 400030, China; \\ 20162974@cqu.edu.cn \\ 2 School of Electronic Information \& Electrical Engineering, Chongqing University of Arts and Sciences, \\ Chongqing 400030, China; 20170031@cqwu.edu.cn \\ * Correspondence: wenzeng@cqu.edu.cn
}

Citation: Huang, B.; Li, Y.; Zeng, W. Application of Metal-Organic

Framework-Based Composites for Gas Sensing and Effects of Synthesis Strategies on Gas-Sensitive Performance. Chemosensors 2021, 9 , 226. https://doi.org/10.3390/ chemosensors 9080226

Academic Editor: Jana Drbohlavová

Received: 16 June 2021

Accepted: 7 August 2021

Published: 14 August 2021

Publisher's Note: MDPI stays neutral with regard to jurisdictional claims in published maps and institutional affiliations.

Copyright: (c) 2021 by the authors. Licensee MDPI, Basel, Switzerland. This article is an open access article distributed under the terms and conditions of the Creative Commons Attribution (CC BY) license (https:/ / creativecommons.org/licenses/by/ $4.0 /)$.

\begin{abstract}
Gas sensing materials, such as semiconducting metal oxides (SMOx), carbon-based materials, and polymers have been studied in recent years. Among of them, SMOx-based gas sensors have higher operating temperatures; sensors crafted from carbon-based materials have poor selectivity for gases and longer response times; and polymer gas sensors have poor stability and selectivity, so it is necessary to develop high-performance gas sensors. As a porous material constructed from inorganic nodes and multidentate organic bridging linkers, the metal-organic framework (MOF) shows viable applications in gas sensors due to its inherent large specific surface area and high porosity. Thus, compounding sensor materials with MOFs can create a synergistic effect. Many studies have been conducted on composite MOFs with three materials to control the synergistic effects to improve gas sensing performance. Therefore, this review summarizes the application of MOFs in sensor materials and emphasizes the synthesis progress of MOF composites. The challenges and development prospects of MOF-based composites are also discussed.
\end{abstract}

Keywords: metal-organic framework; semiconducting metal oxides; carbon-based materials; polymers; gas sensing; composites

\section{Introduction}

Human beings live in the world and perceive nature through a variety of senses. The use of senses cannot always provide the information needed, which prevents humans from understanding nature perfectly, so we have begun to use some natural materials to extend our senses as well as scientific aids to create devices to obtain information in the field of nature and production. The invention of sensors allows people to detect the existence of various substances or phenomena that cannot be naturally sensed. These tools dramatically facilitate the production of human life. Many toxic, harmful, flammable, and explosive gases in energy production are colorless and tasteless, or at certain concentrations develop these characteristics. Therefore, people have made gas-sensitive sensors, which are used to detect the composition or concentration of these gas tools.

To date, there have been many studies regarding gas sensing, and researchers have discovered a variety of materials that can be used to detect gases. Semiconducting metal oxides (SMOx, such as $\mathrm{SnO}_{2}, \mathrm{ZnO}, \mathrm{NiO}, \mathrm{CuO}$, etc.) are popular materials and widely applied in gas sensing [1-4]. Semiconductor metal oxides-based sensors can detect a wide range of gases due to their higher sensitivity, shorter response/recovery times, relatively lower cost, and higher level of reliability compared to other sensing materials [5]. However, the sensing performance of semiconducting metal oxide-based sensors is poor due to the influence of specific surface area, surface defects, morphological characteristics, and adsorption capacity of semiconductor materials [6-11]. Meanwhile, some SMOx may suffer 
from cross-sensitivity to other gases (especially water vapor) although they are highly sensitive to certain low concentrations of inorganic gases and volatile organic compounds (VOCs) $[12,13]$. Furthermore, the sensors usually require high operating temperatures $\left(200-600{ }^{\circ} \mathrm{C}\right)$, which means that they require high energy and high power to use and are not suitable for real-life production applications [14]. In addition to SMOx, there are other materials used for gas sensing applications, such as carbon-based materials with both a larger specific surface area and the ability to prepare devices that can operate at room temperature, but they are less selective and have longer response times for gases as well as poorer reproducibility [15]. Two-dimensional transition metal dichalcogenides (TMDs) have a high specific surface area and unique semiconductor properties with a tunable bandgap. Nonetheless, the response times of the prepared gas sensors are slow and usually reverting to the reference resistance [16]. Its surface may be partially covered by oxygen or moisture in the surrounding atmosphere, resulting in poor sensing performance and long-term stability [17]. Conducting polymers with active functional groups in their structure and their complexes with other polymers have also been used as active layers for gas sensors [18]. Conductive polymers have many interesting sensing properties, including high sensitivity and short response times at room temperature, thus reducing energy consumption [19]. However, the poor processing properties of conductive polymer material limits the use in practical applications, while a single conductive polymer gas sensor has disadvantages such as poor stability and selectivity. In 2011, Michael Naguib et al. [20] synthesized a layered transition metal carbide or nitride (MXenes). The MXene has a high surface area and adjustable morphology and chemical properties that are suitable for the adsorption of various gas molecules [21,22]. However, compared to metal oxide semiconductors, its sensitivity is lower and easily restacked; thus, it is currently receiving less attention.

In 1995, scientists proposed the term metal-organic frameworks (MOFs), which are porous coordination polymers composed of metal ions and organic linking groups. MOFs not only have high porosity, large specific surface area, and multiple coordination sites, but they also have tunable structures and diverse functions [23]. These features allow MOFs to be used in a variety of applications, including gas storage and separation [24], catalysis [25,26], energy applications [27], etc. Among them, the unique gas storage and separation properties of MOFs make selective chemical sensors possible [28]. Due to the unique porous structure of MOFs, gas molecules can be easily accessed and transported. Gas molecules can be adsorbed on the active sites of MOF, including metal ions and functional groups in organic ligands [28]. The sensors can also exhibit high molecular transport rates and are easily modified, and most importantly, many of the sensors prepared in the current study can be used at lower temperatures. For example, Valeriya et al. [29] synthesized a capacitive sensor that can detect $\mathrm{SO}_{2}$ at room temperature. Although MOFs have excellent properties, there is not much research on the use of MOFs in gas sensing, and the author found that the main reason is that there are several problems with the use of pure MOFs.

(1) Most pure MOFs are not stable, and some of them are sensitive to link-displacement reactions (LDRs) when treated with solvents for a long time, so they cannot be used in chemically extreme conditions [23]. Due to the organic content, the decomposition temperatures of MOFs typically range from 300 to $500{ }^{\circ} \mathrm{C}$ [30]. Due to the fragile nature of the metal/ligand junction, some MOFs have poor water stability, and water vapor can destroy their structure [31-33].

(2) MOFs are limited in the types of gases they can detect and only respond to some specific gases [28].

(3) Sensors based on resistance changes are the most straightforward sensors. However, the inherent conductivity of most pure MOFs is low, which limits their application in the field of electronic sensors [34-41]. This is due to the way they are constructed. The metal ions in MOF are hard, and redox inert organic ligands connected with metal ions do not promote electron transfer. As such, most pure MOFs cannot provide free charge carriers 
and charge transport paths [42]. However, in recent years, some strategies have been adopted to improve the electrical conductivity of MOFs. There have been many reports to improve the electrical conductivity of MOFs by increasing the conduction pathway. Twodimensional (2D) electrically conductive MOFs (EC-MOFs) can be synthesized, which have better conductivity because of the facilitated charge transfer between layers. Moreover, EC-MOFs have high porosity, which provides a possible platform for the development of chemosensitive sensors [41]. It is also possible to use some redox active ligands in MOFs to establish $\pi-\pi$ stacking channels, thereby enhancing conductivity $[43,44]$. Apart from modifying the structure of the MOF, donor-acceptor interactions, mixed valence, and other methods can also be used [45]. Although a large number of conductive MOFs have been synthesized and reported, it is still necessary to consider whether these conductive MOFs are feasible in practical applications. Most MOFs have poor water stability [46,47]. If we want to use MOF for gas sensing, we have to consider the effect of water vapor, so we need to ensure its chemical stability. However, it is obvious that many conductive MOFs are not suitable for such applications. For those MOFs with excellent water stability, their electrical conductivity is still low, so it is still a challenge to develop conductive MOFs as gas-sensitive materials [48].

(4) The MOF powders are generally obtained in conventional synthesis, which have low mechanical strength and poor processability [49-51]. Moreover, the sensitivity of the sensor obtained from the powder for gas detection is low, so it needs to be made into thin films (MOF membranes) for sensing [52].

(5) Although the problems associated with poor selectivity of chemical sensors can be solved through the introduction of MOF membranes, gas sensors prepared from pure MOF membranes have some limitations, and their synthesis may require more stringent and harsh growth conditions. Additionally, MOF membranes are generally processable [52]. There have been many breakthroughs in these issues; however, more research and systematic summaries are needed.

Although it is challenging to use MOFs directly as sensing layers due to their usually poor electrical conductivity, their unique porous structures, and large specific surface area they can be used to facilitate gas adsorption and diffusion, and the pore size and morphology of MOF materials can also be adjusted by selecting different metal ions [53]. Additionally, some MOF materials have good structural stability, and organic ligands can be easily decomposed into gases by high-temperature calcination, which not only retains the original structure, but also can more effectively form porous and hollow structures [54]. Therefore, many materials such as metal oxides or carbon composites can often use MOF materials as sacrificial templates, while materials prepared by pyrolysis or calcination of MOF have a porous structure and can be used for gas detection [20,55]. However, these improved materials still have poor detection performance for low concentrations of VOC gases, especially undetectable ppb or sub-ppm detection responses, and have severe signal drift as well as relatively low selectivity [56-59]. In addition, the calcination temperature of the MOF porous structure needs be controlled to avoid the collapse of the structure after calcination [60].

The design of microporous and conductive materials requires the obtaining of efficient gas sensors [61]. Since MOF can provide microporosity, we can develop different platforms based on MOF composites to overcome this challenge, such as solving the various drawbacks of MOF, enhancing the conductivity, and improving the sensing performance for gases by the synergy between the materials [30]. Compared with conductive MOF, MOF-based composites have outstanding advantages. MOF in the composites still retains its own advantages, including a large surface area, high porosity, and tunability of frameworks [62]. At the same time, the properties of the other material remain in the composite materials, such as stability.

In addition, due to the large specific surface area and the high porosity of the MOF, there are many studies on gas-phase adsorption of MOF materials, which can be used to remove certain gases. The advantage is that the adsorption can be performed at low 
temperatures; thus, it exhibits low energy consumption, low cost, easy operation, and less harmful by-products. The problems that still need to be solved are how to improve the selectivity of the MOF material and the adsorption capacity of the target gas. It is found that by combining MOF materials with suitable materials that the gas removal and storage and separation capacity - especially the carbon dioxide capture capacity-can be improved, which is one of the key applications of MOF composite materials [63]. We speculate that if detection can be performed when these composites selectively adsorb gases, sensing and adsorption of gases can be achieved at the same time, which can be a double benefit for some industrial productions.

MOFs have been successfully compounded with SMOx [64,65], metal nanoparticles [66,67], carbon-based materials [68,69], polymers [70,71], silica [72,73], and quantum dots [74,75]. Figure 1 summarizes the number of publications on gas sensing of MOFbased composites and MOF-derived composites in recent years. It can be seen that this is a developing field. This review summarizes the sensing properties of MOF composites for gas sensing. The composites that are summarized combine MOF with inherently capable materials of gas sensing, including MOF-metal oxides, MOF-carbon based materials, and MOF-polymers. Additionally, this paper considers the enhanced properties and problems in gas sensing and gas adsorption of the above-mentioned materials when compounded with MOF. It should be noted that the literature corresponding to these composites in gas sensing is relatively limited at present, so some conclusions are only inferences based on the existing literature and may not be extensive; more experiments are needed to justify the inferences in the future. We hope that the information in this review related to the preparation and application of MOF composites as gas sensors can provide ideas and directions for other groups' research.

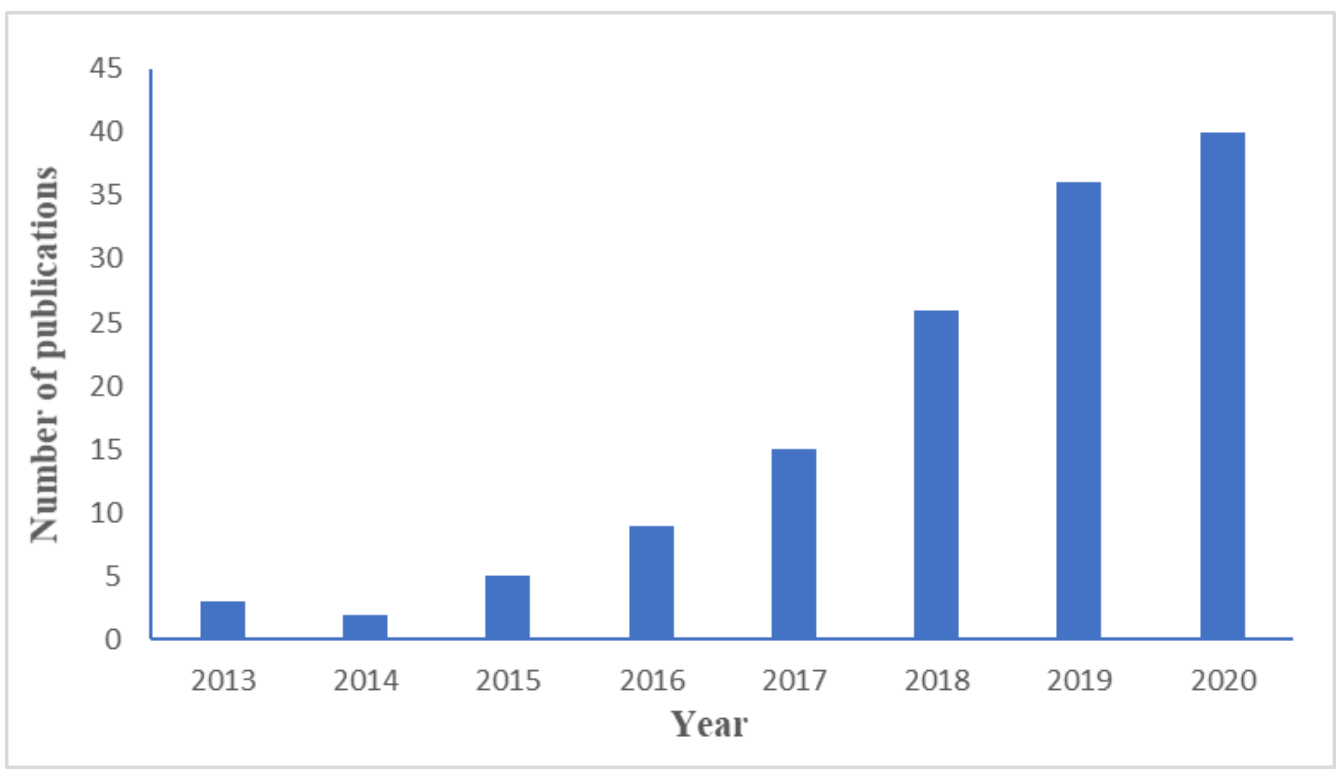

Figure 1. Number of publications on gas sensing of MOF-based composites and MOF-derived composites in recent years (data from ISI Web of Science up to 31 December 2020).

\section{MOFs-Semiconducting Metal Oxides Composites}

\subsection{Sensing Mechanism of SMOx and Limitations}

$\mathrm{SMOx}$, such as $\mathrm{SnO}_{2}, \mathrm{ZnO}, \mathrm{In}_{2} \mathrm{O}_{3}, \mathrm{WO}_{3}, \mathrm{NiO}, \mathrm{CuO}$, etc., are the main materials that are currently well studied and used in gas sensing [76]. The chemical resistance sensing mechanism of most constant valence metal oxides is roughly as follows: the SMOx is placed into the air, the oxygen molecules in the air are adsorbed on the surface of the material, and the electrons of the oxygen molecules are captured by the oxide and simultaneously form chemisorbed reactive oxygen $\mathrm{O}_{2}{ }^{-}, \mathrm{O}^{-}$, and $\mathrm{O}^{2-}$. Note that when reactive oxygen is formed, 
it generally depends on the temperature: $\mathrm{O}_{2}{ }^{-}$generates below $150{ }^{\circ} \mathrm{C}, \mathrm{O}^{-}$develops in the range of 150 to $400{ }^{\circ} \mathrm{C}$, and $\mathrm{O}^{2-}$ generates above $400{ }^{\circ} \mathrm{C}$, which leads to a change in conductivity in the near electron-withdrawal region of the surface [77]. Additionally, when exposed to a reduction or oxidation, the target gas adsorbs on the surface of the SMOx and reacts with oxygen on the charged surface and the conductivity of the SMOx is changed by varying the carrier concentration in the space charge layer. The response is reflected according to the change in conductivity before and after the exposure of the target gas [78].

SMOx sensors are widely used to detect a wide range of gases with relatively low cost and high reliability [3]. However, sensitivity, selectivity, response and recovery times, detection limits, and long-term stability of the sensing material are more important for gas sensors, which are usually influenced by the composition, structure, and morphology of the material. SMOx-based sensors currently suffer from several limitations: (i) Their sensing performance is not high enough due to the influence of specific surface area, surface defects, morphological characteristics, and limited adsorption capacity [79]. (ii) Their selectivity is poor due to their sensing mechanism, which may have multiple gas molecules with similar sensing activity resulting in resistance changes and thus making a single sensor unable to identify a gas correctly [80]. (iii) Although MOX gas sensors are sensitive to some inorganic gases and volatile organic compounds (VOCs), water vapor is usually present in the air and is one of the main combustion products of combustible gases. Water molecules will interact with oxygen adsorbed on the surface of the oxide by forming hydroxyl groups, which due to the sensing principle, will change the carrier concentration and thus the conductivity as well as creating cross-sensitivity [78]. (iv) Since low temperatures are not sufficient to overcome thermal barriers and trigger gas induction reactions, the operating temperatures required are generally high $\left(200-600^{\circ} \mathrm{C}\right)$, indicating that high energy and high power are required for practical life production applications [14].

In response to these existing problems, various solutions have been explored in the past decades. The mechanism of gas sensing of SMOx materials is a resistive response process occurring on the surface. The surface properties of the sensor, such as composition, crystal structure, morphology, and microstructure (e.g., roughness, porosity, grain size, etc.), are the key parameters that affect the sensing response. These parameters affect the sensitivity, selectivity, and response recovery time of the sensor, as well as the stability of the sensing material over time [79]. Therefore, it can be speculated that increasing the specific surface area is one of the effective ways to improve the gas sensing properties of the material. It has been found that porous SMOx possess improved gas-sensitive properties due to their large specific surface area, so the preparation of porous nano-metal oxides with large specific surface area and abundant reactive sites is also a promising approach. The preparation of SMOx by thermal decomposition of precursors has attracted much attention because of its high efficiency and low cost [23]. However, this material cannot address other limitations and cannot detect responses at the ppb or sub-ppm level [81]. In addition, experimental studies have found that methods including ion doping [82], modification using noble metals [83], hybridization with catalysts, and functionalization with sensing probes $[84,85]$ or the use of heterostructures [86] can also improve gas sensing performance. Remaining challenges include the ability to further enhance selectivity for molecules with a similar sensing activity and dealing with interference with water vapor. This has inspired the idea of improving gas sensing performance by developing composite materials, i.e., using gas-sensitive metal oxides combined with other materials to improve the limitations of a single material [78].

As described above, MOF materials have high porosity and large specific surface area. The unique gas storage and separation properties of MOFs can improve the selectivity. Nevertheless, many MOFs have relatively low conductivity, meaning that single MOF materials cannot directly apply for resistive sensing applications [38]. Therefore, combining the advantages and disadvantages of SMOx and MOFs in sensing performance, composite structures of SMOx and MOFs are designed, and a sensor with excellent performance is 
developed by using the sensing characteristics of SMOx and the molecular sieve effect of MOF, which is extremely attractive [87].

\subsection{Selection of Composite Materials with SMOx and MOF}

There are many sources and preparation methods of SMOx that can be used as active sensing materials, so we will not explain in much detail. The metal ion source and organic ligand source are essential for the preparation of MOF, thus the metal source of MOF is crucial for the successful synthesis of SMOx and MOF composites [88]. At present, few studies on SMOx and MOF composites have been reported because there are only a few sources of metals used for the initial conversion of MOF. This review summarizes the sensing performance of some sensors based on SMOx and MOF composites for certain gases in recent years, as shown in Table 1. Most SMOx materials are $\mathrm{ZnO}$ with a small number of other oxides, while MOF materials are from the ZIF family. According to the literature, some reasons are summarized as follows.

Table 1. A brief summary of the gas-sensitive properties of gas sensors prepared from composites of MOF and MO.

\begin{tabular}{|c|c|c|c|c|c|c|c|}
\hline Material & $\begin{array}{c}\text { Target Gas, } \\
\text { Concentration (ppm) }\end{array}$ & $\begin{array}{l}\text { Topt } \\
\left({ }^{\circ} \mathrm{C}\right)\end{array}$ & Response & $\begin{array}{c}\text { Response/Recovery } \\
\text { Time (s) }\end{array}$ & $\operatorname{BET}\left(\mathrm{m}^{2} / \mathrm{g}\right)$ & $\begin{array}{l}\text { Detection } \\
\text { Limit }\end{array}$ & Ref. \\
\hline ZnO@ZIF-8 & $\mathrm{H}_{2} 50 \mathrm{ppm}$ & 300 & 1.44 & - & $1760 \pm 260$ & - & [89] \\
\hline ZnO@ZIF-8 & formaldehyde 100 ppm & 300 & $\sim 13$ & $16 / 9$ & 307.4 & $5.6 \mathrm{ppm}$ & [80] \\
\hline $\begin{array}{l}\mathrm{ZnO@5nm} \\
\mathrm{ZIF-CoZn}\end{array}$ & acetone 10 ppm & 260 & 27 & $43.2 / 61.2$ & - & $0.0019 \mathrm{ppm}$ & {$[12]$} \\
\hline ZnO@ZIF-8 & $\mathrm{H}_{2} 50 \mathrm{ppm}$ & 250 & 3.28 & - & 4813 & - & [90] \\
\hline ZnO@ZIF-8 & $\mathrm{H}_{2} 10$ ppm & 125 & $\sim 5.2$ & $100 / 20$ & - & $\sim 1.9$ ppm & [91] \\
\hline $\begin{array}{l}\text { ZnO@ZIF-8 } \\
\text { ZnO@ZIF-71 }\end{array}$ & $\begin{array}{l}\text { ammonia, hydrogen, } \\
\text { ethanol, acetone and } \\
\text { benzene } 50 \mathrm{ppm}\end{array}$ & 250 & $\begin{array}{c}\sim 20 \sim 84 \sim 40 \\
\quad \sim 25 \sim 5 \\
\sim 25 \sim 85 \sim 325 \\
\sim 240 \sim 10\end{array}$ & - & $\begin{array}{l}\sim 295 \\
\sim 348\end{array}$ & - & [92] \\
\hline $\mathrm{SnO}_{2} @ \mathrm{ZIF}-67$ & $\mathrm{CO}_{2} 5000 \mathrm{ppm}$ & 205 & $16.5 \pm 2.1 \%$ & $18.4 \pm 3.5 / 25.5 \pm 4.5$ & 501 & - & [93] \\
\hline $\mathrm{In}_{2} \mathrm{O}_{3} / \mathrm{ZIF}-8$ & $\mathrm{NO}_{2} 1 \mathrm{ppm}$ & 140 & 16.4 & $80 / 133$ & 528.2 & $10 \mathrm{ppb}$ & [53] \\
\hline $\mathrm{ZIF}-8 / \mathrm{ZnO}$ & $\mathrm{H}_{2} \mathrm{~S} 1 \mathrm{ppm}$ & 25 & $18.70 \%$ & $420 / 642$ & 145.5 & $50 \mathrm{ppb}$ & [94] \\
\hline \multirow{2}{*}{ ZnO@ZIF-71 } & ethanol 10 ppm & 150 & $13.40 \%$ & $194.37 / 442.17$ & \multirow{2}{*}{$\sim 375$} & $21 \mathrm{ppb}$ & \multirow[t]{2}{*}{ [95] } \\
\hline & acetone 5 ppm & 150 & $38.90 \%$ & $195.9 / 535.5$ & & $3 \mathrm{ppb}$ & \\
\hline $\begin{array}{c}\text { Au-ZnO@ZIF } 5 \\
\text { nm-DMBIM }\end{array}$ & acetone $100 \mathrm{ppm}$ & 275 & 231 & $180 / 60$ & - & $0.0034 \mathrm{ppm}$ & [96] \\
\hline ZnO@ZIF-8 & $\mathrm{H}_{2}$ & 275 & $\sim 47.5 \%$ & $50 / 130$ & - & - & [87] \\
\hline WO $@ @ Z I F-71$ & $\mathrm{H}_{2} \mathrm{~S} 20 \mathrm{ppm}$ & 250 & 19.12 & $118 / 431$ & - & $0.697 \mathrm{ppm}$ & [88] \\
\hline ZnO@ZIF-71(Co) & acetone 50 ppm & 250 & 513 & $71 / 53$ & - & $50 \mathrm{ppb}$ & [97] \\
\hline
\end{tabular}

The first is the choice of MOF material, which requires an improvement of the selectivity of metal oxide-based gas sensors, a reduction of the cross-sensitivity to water vapor, and an increase in the stability of the MOF material. According to these criteria, the advantages of the ZIF family were found. Zeolite imidazolate skeletons (ZIFs) are MOF materials with a tetrahedral-type three-dimensional mesh structure, which are similar to zeolites that consist of tetrahedral $\mathrm{MN}_{4}(\mathrm{M}=$ metal cations, such as $\mathrm{Zn}(\mathrm{II})$ and $\mathrm{Co}(\mathrm{II}))$ and tetrahedral clusters that are connected by imidazolate ligands with ultra-high porosity and substantial internal surface area $[98,99]$. Moreover, it is found that due to the chemical tenability and structural flexibility, the metal cation can be replaced by another metal without changing its topology [100,101]. Additionally, after changing the metal ion or organic ligand, the ZIF pore size can be easily changed to adjust the gas sieving ability of ZIF, which provides an effective method to improve the controllable selectivity of the sensor [23,34,102]. In addition, ZIF was considered a hydrophobic material in some reports. [103]. In fact, the diffusion of water in ZIF materials cannot be completely inhibited. Only the absorption of water is 
negligible compared to the absorption of other gases [78]. This advantage of ZIF can be used to improve the resistance of SMOx to humidity.

From the table, it is known that ZIF-8 and ZIF-71 are the more used MOF materials, both of which have zinc metal ions, but the organic ligands are different, with 2-methylimidazole (mIm) for ZIF-8 and 4,5-dichloroimidazole (dcIm) for ZIF-71, and their structures are also different. Different organic ligands have different pore sizes, with a smaller pore size of $3.4 \AA$ for ZIF-8 and $4.8 \AA$ for ZIF-71 [100,104]. Therefore, for gas detection, ZIF-8 is usually used to detect smaller gas molecules (e.g., $\mathrm{H}_{2}$, formaldehyde, etc.) $[80,91]$, while ZIF-71 is used to detect larger gas molecules (e.g., ethanol, acetone, etc.) [95]. In addition, although ZIF-71 is slightly less insensitive to humidity than ZIF-8, it can still be used to reduce the cross-sensitivity of water vapor [80]. Apart from ZIF-8 and ZIF-71, ZIF-CoZn and ZIF-67 (metal ions are $\mathrm{Co}^{2+}$ ) have also been reported as MOF materials compounded with SMOx, ZIF-CoZn is isostructural with ZIF-8 and ZIF-67 and have different thermal stabilities. ZIF-8 has the highest thermal stability up to $330{ }^{\circ} \mathrm{C}$; ZIF-67 has relatively poor thermal stability and the structure cannot be maintained above $220^{\circ} \mathrm{C}$ and ZIF-CoZn ranges between $220^{\circ} \mathrm{C}$ and $330{ }^{\circ} \mathrm{C}$ [12].

Additionally, due to the adjustable molecular sieve effect, relatively good hydrophobicity, and thermal stability, the author deduces that another reason for choosing ZIF as MOF material may be due to its synthesis method, which is related to the choice of SMOx and will continue to be expressed below.

Next, comes the choice of oxides. As can be seen from the table, most of the oxides chosen are $\mathrm{ZnO}$ and a few are other SMOx. These works of literature show that many MOS and MOF composites are core-shell structures, and their preparation method is the oxide sacrificial template method. In brief, this method is to put MO into the solution of the linking group. SMOx, as a metal ion source, releases the metal cations needed for MOF synthesis through partial dissolution and reacts with organic ligands in solution under appropriate conditions to generate MOF materials. Therefore, we speculate that the use of $\mathrm{ZnO}$ as a metal oxide is more frequent due to the choice of MOF materials, and most of them are ZIF-8 and ZIF-71, both of which have Zn ions as metal ions. Additionally, the use of $\mathrm{ZnO}$ can be used as a substrate for the coating of MOF materials in addition to being a source of providing zinc ions, and it was found that the morphology and size of the coreshell heterostructures of MOFs can be directly controlled by the template $[80,90,105,106]$. For other metal compounds such as $\operatorname{In}_{2} \mathrm{O}_{3}$ and $\mathrm{WO}_{3}$, the researchers found that the MOF materials were also doped with $\mathrm{ZnO}$ inside the oxide or pretreated with $\mathrm{ZnO}$ on the surface before synthesizing the composites [53,88].

Although the synthesis method of $\mathrm{MOF} @ \mathrm{SMO}_{\mathrm{X}}$ is relatively simple at present, some reports can give us inspiration. Julien et al. [107] used a mechanical synthesis method to prepare MOF materials. They used water as a grinding liquid, and then mixed $\mathrm{ZnO}$ and $\mathrm{H}_{4}$ dhta, the precursor of the organic ligand, to obtain Zn-MOF-74 with low density. If this method of directly synthesizing MOF with metal oxides and a small number of solvents can be extended to MOF materials of metals other than zinc, it may provide some new ideas and directions for the preparation of MOF@SMOX.

For $\mathrm{MO}$ and MOF composites, there are more oxygen vacancies due to the presence of MOF material. In addition to the core-shell structure, the lattice mismatch between the core-shell leads to the appearance of more defects, which provides more active sites and thus leads to a higher response. Moreover, it has been shown that energy band bending occurs at the core-shell interface, which promotes spontaneous carrier transfer, so there is no need for higher temperatures to provide a large amount of energy. Its optimal operating temperature is greatly reduced compared to that of pure metal oxide-based gas sensors [91].

Having understood the choice of materials and their advantages, here is a look at how this composite material has evolved in recent years. 


\subsection{Development of SMOx@MOF Composites}

Summarizing from the limited literature, the development of SMOx@MOF composites is divided into four parts.

\subsubsection{Detection Using Molecular Sieve Only}

Earlier studies are ZnO@ZIF-8 materials, and detection of gases is limited to $\mathrm{H}_{2}$ and formaldehyde. In 2016, Martin Drobek et al. [89] reported encapsulating ZIF-8 on ZnO nanowires, to achieved improved selectivity for $\mathrm{H}_{2}$ relative to $\mathrm{C}_{7} \mathrm{H}_{8}$ and $\mathrm{C}_{6} \mathrm{H}_{6}$ at $300{ }^{\circ} \mathrm{C}$ using only the molecular sieving effect of ZIF-8. The response is reduced compared to the original $\mathrm{ZnO}$ sensor, which they attribute to the limitation of $\mathrm{H}_{2}$ diffusion through ZIF. By increasing the number of pure $\mathrm{ZnO}$ nanorods, Cui et al. [91] reduced the proportion of insulating ZIF in materials, thus improving the response to $\mathrm{H}_{2}$. The synthesized ZnO@ZIF-8 core-shell microrod gas sensor also reduced the optimal operating temperature for detecting $\mathrm{H}_{2}$ to $125^{\circ} \mathrm{C}$. Although the response is higher, the response-recovery rate remains lower than that of pure $\mathrm{ZnO}$ due to the limitation of $\mathrm{H}_{2}$ diffusion by ZIF-8.

From the above examples, it can be seen that there are two problems with the detection of gases using only the molecular sieve effect of MOF. The gas type is relatively limited to small molecules, and the response rate of the gas is slow due to the obstruction of diffusion.

\subsubsection{The Improvement of Response Rate}

The limitation of the target gas due to diffusion in ZIF is a problem to be solved. The team of $\mathrm{Wu}$ et al. found two successive solutions for the detection of $\mathrm{H}_{2}$, which are simply the thinning of the MOF layer or the reduction of the MOF loading. One approach is to obtain a thin shell of ZIF-8 with fine grains by tuning the reaction conditions. MOF membrane promotes the diffusion of $\mathrm{H}_{2}$, while the fine particles inhibit the flexibility of the framework of ZIF-8, thus weakening the molecular sieve effect and improving the selectivity for small molecules of $\mathrm{H}_{2}$ [90]. The other method they proposed was partial loading [94]. Instead of a core-shell structure formed by $\mathrm{ZnO}$ and ZIF-8, ZIF-8 is partially attached to the surface of $\mathrm{ZnO}$ nanorods in the form of particles. Thanks to ZIF-8, this provides a larger surface area and more active sites, and allows the target gas $\left(\mathrm{H}_{2} \mathrm{~S}\right)$ to reach the exposed $\mathrm{ZnO}$ surface. Therefore, compared to the sensor with a complete ZnO@ZIF-8 core-shell structure, the hindrance of diffusion of the target gas to the $\mathrm{ZnO}$ is significantly reduced. The morphologies of the resulting composites for both methods are shown in Figures 2 and 3. It can be seen from the figures that the former method obtained a thin shell layer wrapped around the oxide surface, while the second method obtains a partially loaded composite.
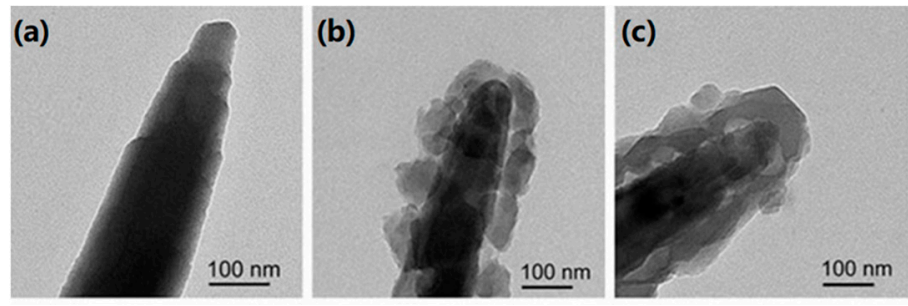

Figure 2. Cont. 

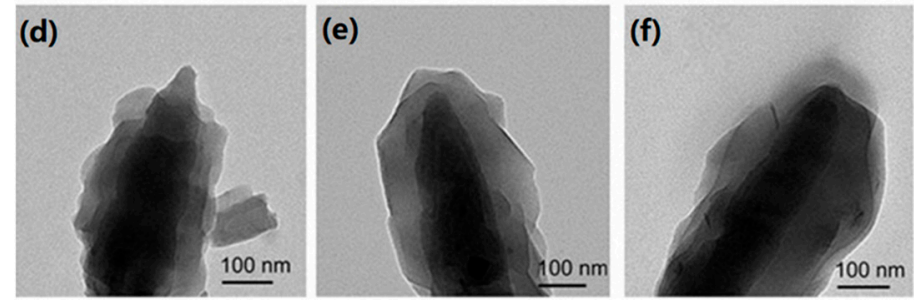

(g)

I Deposition of $\mathrm{ZnO}$ nanorods film

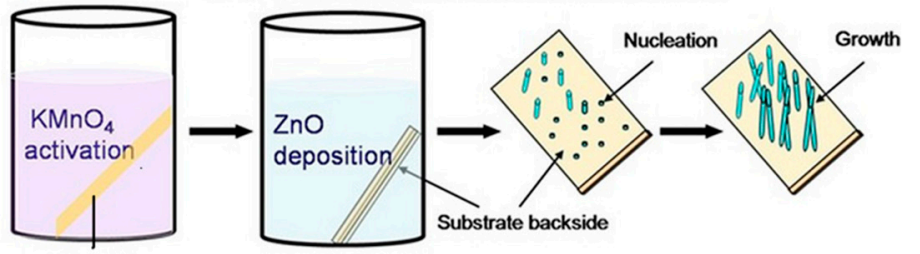

II Coating of ZIF-8 shell on $\mathrm{ZnO}$ nanorods surface

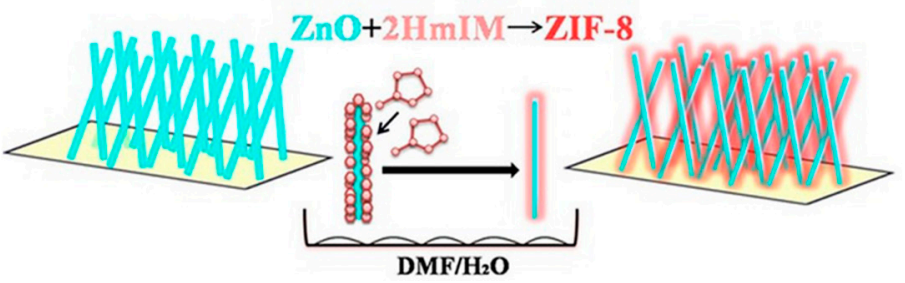

Figure 2. (a) TEM images of raw ZnO nanorods. (b-f) TEM images of the ZnO@ZIF-8 composite nanorods synthesized at reaction times of 2, 4, 10, 20, and $32 \mathrm{~h}$, respectively. (g) Formation process of ZnO@ZIF-8 core-shell nanorod films: (I) deposition of ZnO nanorods film and (II) coating of ZIF-8 shell on ZnO nanorods surface. (Reproduced with permission from [90], Copyright 2017 WILEY).

An essential factor affecting the gas sensing performance of the composites of $\mathrm{MO}$ and MOF is the thickness of the MOF shell layer (core-shell structure) or the loading of MOF (non-core-shell structure). An appropriate shell layer thickness can exhibit better sensing performance without increasing the diffusion path of the gas while increasing the specific surface area, as has been demonstrated in some recent studies. The thickness of the MOF shell layer is affected by many factors, which can be broadly classified into four types: (i) temperature, (ii) reaction time, (iii) concentration of organic ligands, and (iv) $\mathrm{H}_{2} \mathrm{O} / \mathrm{N}, \mathrm{N}$-Dimethylformamide (DMF) ratio (concentration of metal ions) [12]. For example, Tian et al. [80] obtained three ZnO@ZIF-8 nanorods using the hydrothermal method at different hydrothermal times. The $12 \mathrm{~h}$ reaction time was too short and did not form a complete MOF shell layer; the ZIF-8 shell layer obtained at $36 \mathrm{~h}$ was too thick and would hinder the diffusion of the gas; and the shell layer obtained at $24 \mathrm{~h}$ was uniformly continuous and thin. The related structure and selectivity to gases are shown in Figure 4 . We can see that the gas-sensitive performance of the sensor prepared from $24 \mathrm{~h}$ material is the best of the three. When the concentration of organic ligands is too low, the number of nucleation sites of ZIF is limited, and the size of the formed ZIF is large and not uniformly deposited on the oxide. With the increase of the concentration of organic ligands, the size of MOF crystals decreases, and a uniform shell layer is formed [78]. Changing the ratio of $\mathrm{H}_{2} \mathrm{O} / \mathrm{DMF}$ is to change the concentration of metal ions because the dissolution rate of $\mathrm{ZnO}$ is fast in the water and slower in DMF. When the ratio of water is high, the crystallization rate of $\mathrm{ZIF}$ is slower than the dissolution rate of $\mathrm{ZnO}$, which will lead to uneven deposition of ZIF-8. If too much ZNO dissolved too fast it will affect the conductivity of the material. When DMF is higher, it will make the ZIF-8 crystallization rate lower, so the suitable volume ratio is beneficial to the formation of the MOF shell layer [78]. 

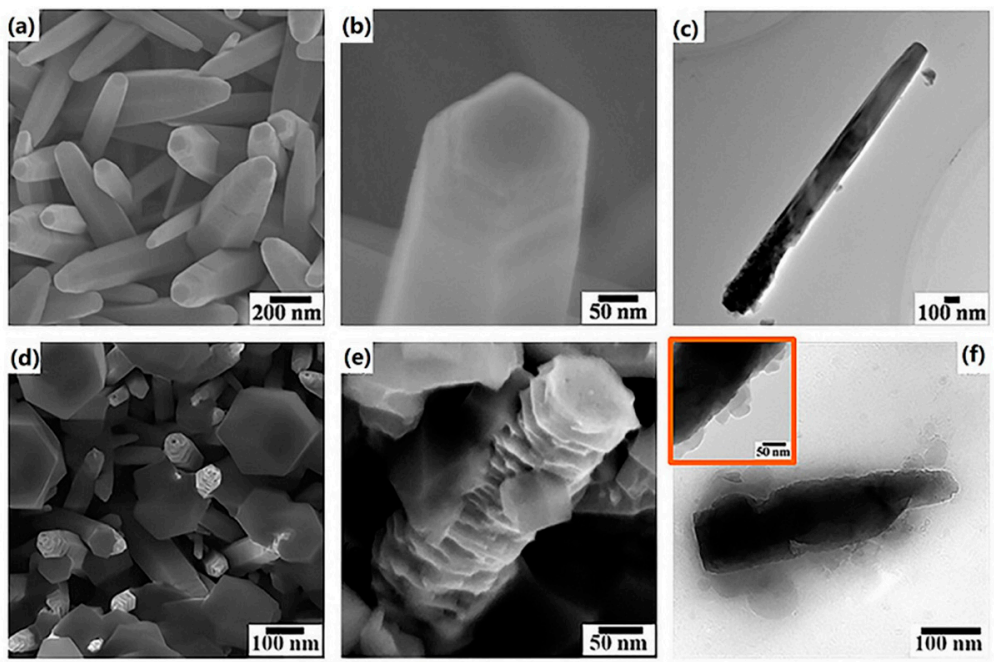

(g)
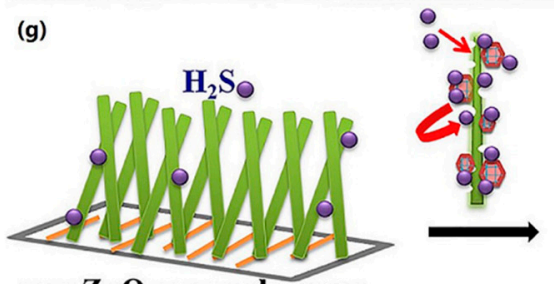

raw ZnO nanorod sensor

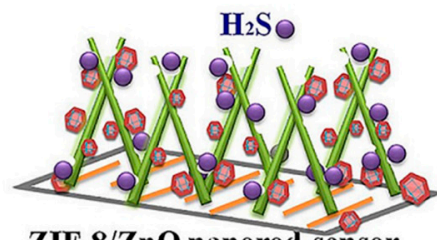

ZIF-8/ZnO nanorod sensor

\section{$\mathrm{ZnO} \quad \mathrm{H}_{2} \mathrm{~S} \quad \mathrm{ZIF}-8$}

Figure 3. (a,b) SEM images of $\mathrm{ZnO}$ nanorods. (c) TEM images of $\mathrm{ZnO}$ nanorods. (d,e) SEM images of ZIF-8/ZnO nanorods. (f) TEM images of ZIF-8/ZnO nanorods. (g) Schematic of raw ZnO and ZIF-8/ZnO nanorod sensors. (Reproduced with permission from [94], Copyright 2019 ELSEVIER).
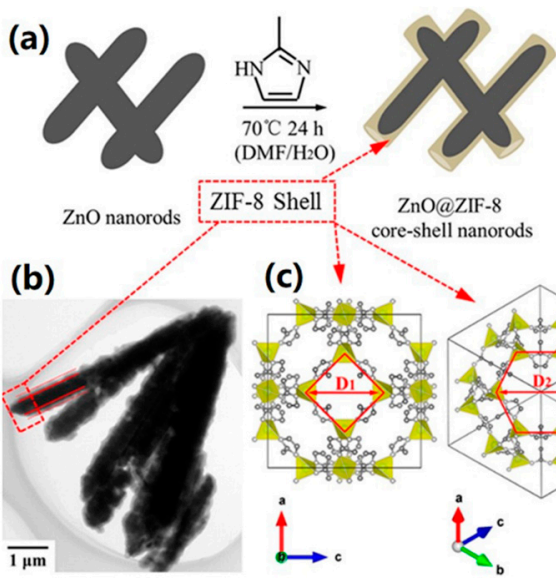

$\mathrm{ZnO} @ \mathrm{ZIF}-8$ core-shell nanorod

\section{(c)}

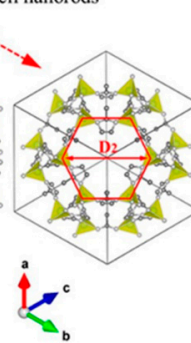

(d)

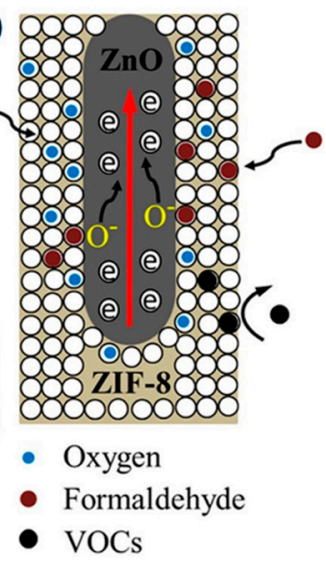

Figure 4. (a) ZnO @ ZIF-8 nanorods obtained by reaction at $70{ }^{\circ} \mathrm{C}$ for $24 \mathrm{~h}$. (b) TEM images of the ZnO @ ZIF-8 core-shell structure. (c) Two pore sizes of the ZIF-8 structure. (d) Selectivity of ZnO @ ZIF-8 nanorods sensor for different gas molecules. (Reproduced with permission from [80], Copyright 2015 American Chemical Society).

\subsubsection{Exploration of the Types of Detection Gases}

SMOx and MOF composites sometimes rely not only on the pore size of the MOF to sieve the gas-so as to improve the selectivity-but also can improve the selectivity due to the interaction with the target gas. The $\mathrm{ZIF}-8 / \mathrm{ZnO}$ nanorod sensor synthesized by Wu et al. [94] showed excellent selectivity in sensitivity to $\mathrm{H}_{2} \mathrm{~S}$, which they hypothesized was due to the reaction between $\mathrm{H}_{2} \mathrm{~S}$ and $\mathrm{ZnO}$ to generate the intermediate product $\mathrm{ZnS}$, which allowed electrons to enter $\mathrm{ZnO}$ leading to a further increase in conductivity. 
Although the presence of $\mathrm{ZnS}$ was not proved directly, the results of $\mathrm{N}_{2}$ comparison experiments presented evidence. Ying Zhou et al. [88] successfully synthesized the flowerlike $\mathrm{WO}_{3} @ Z I F-71$, and the sensors demonstrated improved performance in selectivity and response to $\mathrm{H}_{2} \mathrm{~S}$. Apart from the limitation of ZIF-71 pore size, they suggested that the improved sensing performance could be caused by the interaction between $\mathrm{H}_{2} \mathrm{~S}$ and ZIF-71, i.e., the five-membered C-N heterocycle of the organic ligand in ZIF-71 would enhance the adsorption of $\mathrm{H}_{2} \mathrm{~S}$ by the MOF. Gas permeation through the MOF consists of three steps: (1) adsorption of the gas in the MOF, (2) diffusion of the gas within the MOF, and (3) desorption [108]. The enhancement of gas adsorption may also contribute to the gassensitive performance, as evidenced by the study of Zhou et al. [95]. They synthesized ZnO@ZIF-71 nanorod arrays, and found that compared with pure $\mathrm{ZnO}$, it has better selectivity for ethanol and acetone, and its response is also improved. The in situ diffuse reflectance infrared Fourier transform (DRIFT) experiments showed that ZnO@ZIF-71 has better adsorption and desorption performance than $\mathrm{ZnO}$ for both ethanol and acetone. Further calculations of density functional theory (DFT), as shown in Figure 5, revealed that the active adsorption sites of ZIF-71 for both gases are $\mathrm{Zn}^{2+}$. Due to the strong interaction affinity between the target gas molecules and $\mathrm{Zn}^{2+}$, it can lead to physisorption of gas molecules, thus improving the gas-sensitive performance $[109,110]$. Furthermore, it can be seen that the adsorption energy for ethanol is greater than that for acetone, which explains why the response of ZnO@ZIF-71 nanorod array sensor to ethanol is higher than that of acetone. Looking for the gases that can interact with ZIF may also be one direction for future research.

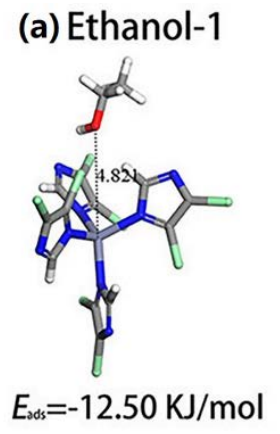

(d)Acetone-1

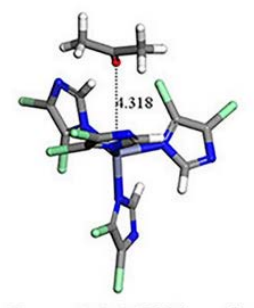

(b) Ethanol-2

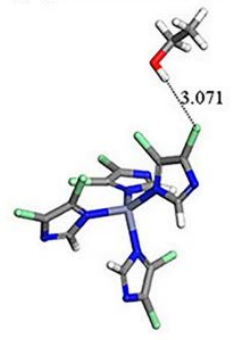

$E_{a s}=5.39 \mathrm{KJ} / \mathrm{mol}$

(e) Acetone-2

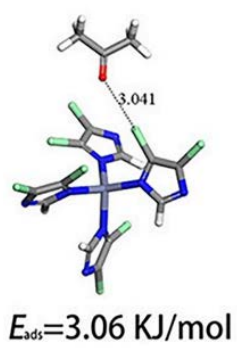

(c) Ethanol-3

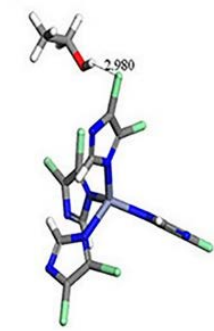

$E_{s s \mathrm{~s}}=93.48 \mathrm{KJ} / \mathrm{mol}$

(f) Acetone-3

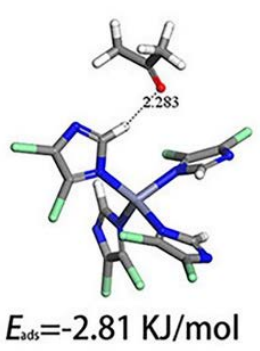

Figure 5. The possible adsorption sites of ZIF-71 for ( $\mathbf{a}-\mathbf{c})$ ethanol and (d-f) acetone, respectively, and the corresponding Eads values. (Reproduced with permission from [95], Copyright 2019 American Chemical Society).

\subsubsection{Addition of Other Substances}

It is not enough to synthesize only SMOx and MOF composites in terms of gassensitive performance improvement, so other methods need to be found. Starting from the improvement methods of SMOx and the nature of MOF, we found three current improvement methods. However, there are few corresponding studies, so these examples are only given to provide some ideas for the doping of complexes in the future. The first method is ion doping, and the commonly used metal ions in the ZIF family are known to 
be $\mathrm{Zn}(\mathrm{II})$ cations and $\mathrm{Co}(\mathrm{II})$ ions. It is known from the ZIF properties above that changing the metal ions does not change its topology $[101,111]$. Moreover, because the ionic radius of the $\mathrm{Co}^{2+}$ ion $(0.72 \AA)$ is similar to that of the $\mathrm{Zn}^{2+}$ ion $(0.74 \AA)$, another ion can be doped when ZIF is formed [112]. Yao et al. [12] added exogenous $\mathrm{Co}^{2+}$ ions to the synthesis to generate ZnO@ZIF-CoZn with higher selectivity for the target gas (acetone) and preserved resistance to humidity compared to ZnO@ZIF-8. Moreover, they found that the cobalt ions in ZnO@ZIF-CoZn have excellent catalytic properties at $200-300{ }^{\circ} \mathrm{C}$, which contribute to the generation of reactive oxygen species, and thus accelerate the response-recovery behavior, but the related mechanism is still incomplete [12]. Zhou et al. [97], on the other hand, proposed a specific catalytic mechanism for Co doping. They found that the Co site plays two catalytic roles, both in the oxidation of oxygen and acetone decomposition to intermediate products. The intermediates of acetone decomposition could be more effortlessly adsorbed on $\mathrm{ZnO}$, which led to the improved sensing performance of the synthesized ZnO@ZIF-71(Co) for gases due to the synergistic effect of these three catalytic activities. However, after further exploring the effects of different Co doping amounts, they found that this catalytic performance can only occur at a specific temperature with a specific Co doping amount. Co ions are randomly occupying $\mathrm{Zn}$ ion sites. Their catalytic ability is improved with increasing Co doping amounts, but due to pure Co ions and dcIM organic ligands, stable MOF structure cannot be formed. Therefore, the Co doping amount should not be too high. From the above two examples, it can be seen that the introduction of Co ions mainly utilizes its catalytic effect, which also provides an idea for future research.

The second method is to change the organic ligand, Yao et al. [96] synthesized AuZnO@ZIF-DMBIM nanowires by partially replacing the 2-MIM ligand of about $3.6 \AA$ length in ZIF-8 a DMBIM of $6.0 \AA$ length. The relevant gas-sensitive properties of the sensors prepared from the synthesized composites are shown in Figure 6. After the exchange of ligands, the material crystal structure did not change, but only the pore size was obviously reduced. The absorption of macromolecules (benzene series) was further inhibited by molecular sieve effect, and the moisture resistance was improved. Additionally, its adsorption of water was reduced.
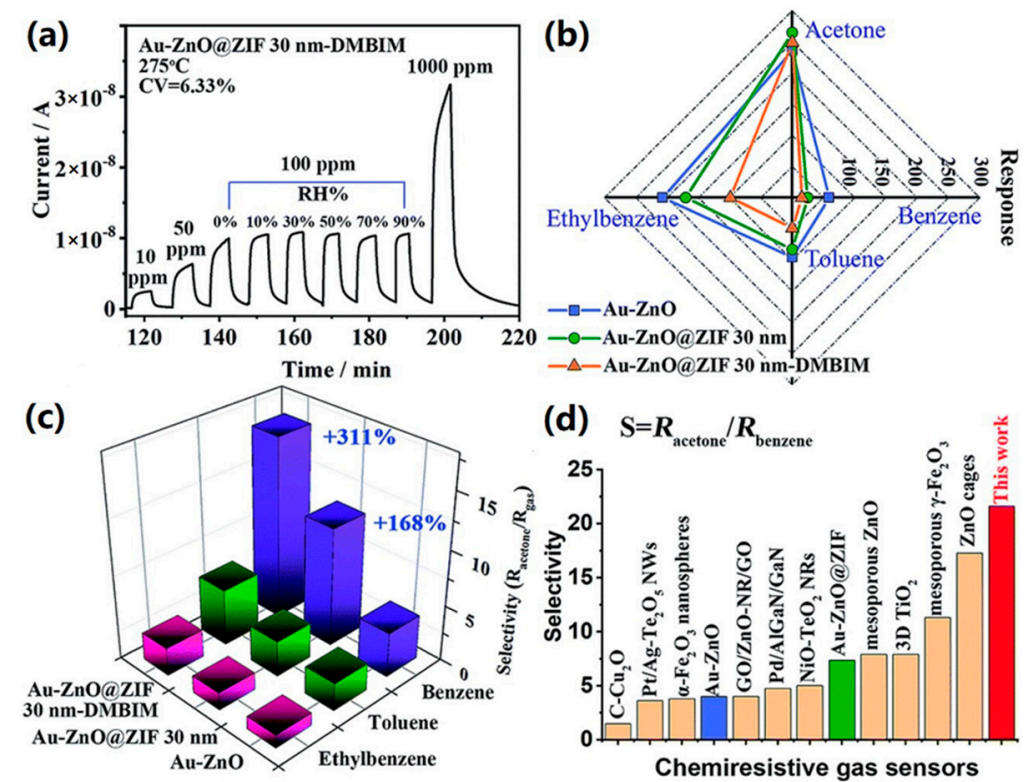

Figure 6. (a) Response-recovery curves for different concentrations of Au-ZnO @ ZIF 30 nm-DMBIM in acetone with relative humidity up to $100 \mathrm{ppm}$ and in dry air. (b) Comparison of sensor response to different gases. (c) Comparison of acetone selectivity for three benzenes. (d) Comparison of selectivity with different sensing materials. (Reproduced with permission from [96], Copyright 2019 ROYAL SOCIETY OF CHEMISTRY). 
The third method is to incorporate noble metals. Wang et al. [113] coated ZnO on the surface of Au nanorods to form Au@ZnO core-shell structure and then used sacrificial template method to generate ZIF-8 crystals on the surface of ZnO. The Janus Au@ZnO@ZIF8 material was generated by a reaction time of $40 \mathrm{~min}$. Under the irradiation of visible light, the sensor made of this material showed good recovery characteristics for $\mathrm{HCHO}$ in the concentration range of $0.25 \sim 100 \mathrm{ppm}$. The response was not affected by water vapor and toluene. A better feature was that it could be detected at room temperature. These advantages are mainly attributed to the synergistic effect of the three materials. $\mathrm{ZnO}$ ensures the conductivity of the composite and is an active sensing material, and the selectivity for HCHO is improved by ZIF-8 due to molecular sieving and hydrophobicity. The room temperature sensing performance is attributed to the plasmonic resonance of $\mathrm{Au}$ nanorods, where $\mathrm{Au}$ NRs contribute to carrier generation on the $\mathrm{ZnO}$ surface under visible light irradiation, thus reducing the required energy and improving the response.

\subsection{MOF-Derived SMOx for Gas Sensors}

Apart from the combination of $\mathrm{MOF}$ and $\mathrm{SMO}_{X}$, we also find that many studies use MOF as precursor, and SMOx can be prepared by calcining MOF. Let us give some examples to see the application of this MOF-derived SMOx in gas sensing.

Bai et al. [114] synthesized $\mathrm{Sn} / \mathrm{Ni}$ based MOFs by hydrothermal method, and then calcined it to obtain $\mathrm{SnO}_{2} / \mathrm{NiO}$. Their experiments not only determined the optimal calcination temperature of $\mathrm{MOF}\left(550^{\circ} \mathrm{C}\right)$, but also found the best content ratio of two oxides (molar ratio 9:1) through comparative experiments. Compared with the pristine SMOx, the sensing performance of the product prepared under optimal conditions has been greatly improved. It not only reduces the temperature of the sensor sharply, but also has higher response and selectivity. The highest response to $10 \mathrm{ppm}$ of triethylamine (TEA) at $70{ }^{\circ} \mathrm{C}$ was up to 14.03. The $\mathrm{SnO}_{2} / \mathrm{NiO}$ composite forms a heterogeneous structure compared to pristine $\mathrm{SnO}_{2}$ and pristine $\mathrm{NiO}$, thus improving the response by increasing the resistance of the material in air and decreasing the resistance in the reaction gas. Moreover, the improvement of its sensing performance is also attributed to its morphology and structure, as shown in Figure 7. When metal oxides are prepared by using MOF as a precursor, metal ions are highly dispersed by the organic ligands in MOF, thus avoiding the aggregation of oxides. The product also retains the porosity of porous structure, resulting in a significant increase in specific surface area. Therefore, MOF-derived metal oxides have potential for development as sensing materials.

In fact, besides being the precursor of SMOx, the limited pore size of MOF can also be used for loading. According to the resistive sensing mechanism of SMOx, in order to improve the gas sensing performance, apart from increasing the specific surface area, the use of catalysts can also be considered by promoting the occurrence of surface reactions. However, at present, it is still a challenge to functionalize catalysts on the SMOx by a simple synthesis [115]. In addition, the sensing performance of catalysts is often degraded by aggregation, so the dispersion of noble metals on the sensing materials is also an obstacle [116]. Koo et al. [117] first synthesized Pd@ZIF-67 structures by dispersing and loading nanoscale Pd onto ZIF-67, and then calcined to obtain $\mathrm{PdO}-\mathrm{Co}_{3} \mathrm{O}_{4}$ composite. As a catalyst, PdO can significantly improve the surface reaction of the oxide, thereby improving the sensing performance. They also tried to find the ideal conditions with the best performance by changing the calcination temperature. The experimental results found that calcination at $400{ }^{\circ} \mathrm{C}$ has the best effect. The smallest grain size is obtained at $400{ }^{\circ} \mathrm{C}$, when the specific surface area is the largest. Additionally, as the temperature increases, internal voids were generated. When the temperature exceeds a certain level, the hollow structure will collapse. It was found that $\mathrm{PdO}-\mathrm{CO}_{3} \mathrm{O}_{4}$ with $\mathrm{Pd}$ loading of $1.67 \mathrm{wt} \%$ prepared by ZIF-67 had the highest response to acetone at $350{ }^{\circ} \mathrm{C}$. As shown in Figure 8, this sensor has good selectivity for acetone and the sensor is more stable. However, the existence of water vapor still reduces the sensing response to some extent, and its sensing ability is not outstanding compared with other sensors [117]. As such, the response needs to be further 
improved. By combining the above two methods, using heterojunction and catalysts, they can further improve the gas-sensitive properties of the material. They prepared PdO@ZnO$\mathrm{SnO}_{2}$ through electrostatic spinning and subsequent calcination. The sensors made of this material not only has higher response to acetone, but also can ensure stability and shorter response and recovery time [118]. Experiments show that this method can also be used in combination with other SMOx.
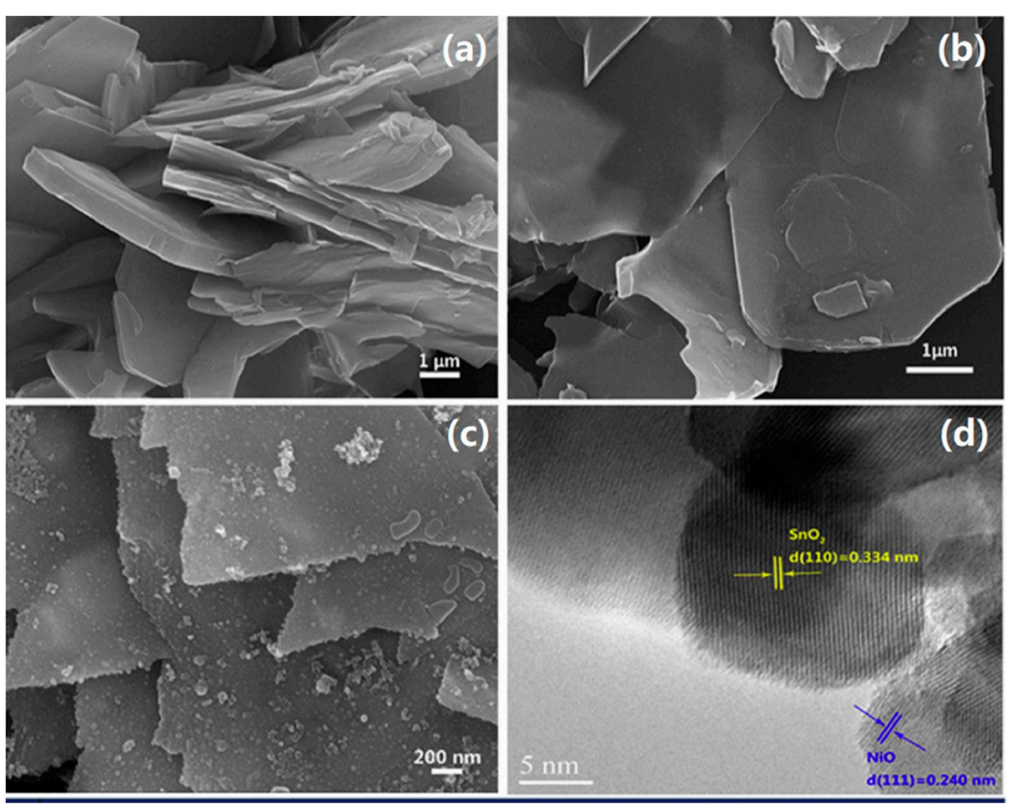

Figure 7. (a,b) FESEM images of pure MOF; (c) FESEM and (d) HRTEM images of 9Sn1Ni composite. (Reproduced with permission from [114], Copyright 2018 ELSEVIER).
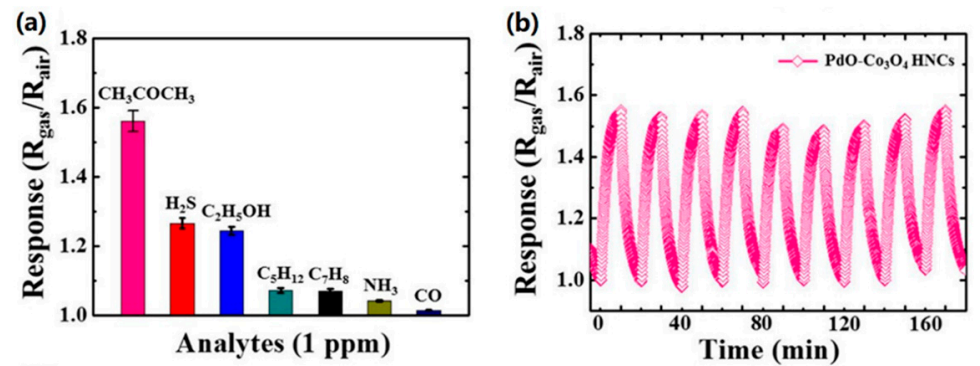

Figure 8. (a) Response of PdO- $\mathrm{Co}_{3} \mathrm{O}_{4} \mathrm{HNCS}$ to 1 ppm of various gases; (b) cyclic stability of PdO$\mathrm{Co}_{3} \mathrm{O}_{4} \mathrm{HNCS}$ to $1 \mathrm{ppm}$ acetone. (Reproduced with permission from [117], Copyright 2017 American Chemical Society).

Koo et al. [119] used ZIF-8 derived $\mathrm{ZnO}$ nanocubes loaded with $\mathrm{Pd}$ as composite catalysts and then combined the catalyst with $\mathrm{WO}_{3}$ via heterojunctions; the structure is shown in Figure 9. Sensors prepared from the synthesized materials showed a significant improvement in selectivity and response to toluene. In addition, they studied the influence of composite catalyst loading and found that the sensor made of $\mathrm{Pd} @ \mathrm{ZnO}-\mathrm{WO}_{3} \mathrm{NFs}$ with Pd@ZnO content of 0.136 wt. $\%$ had the highest response at $350{ }^{\circ} \mathrm{C}$. Compared with the pristine $\mathrm{WO}_{3}$ under higher humidity the response to $1 \mathrm{ppm}$ toluene is still 19.2 times higher and the response is faster. 


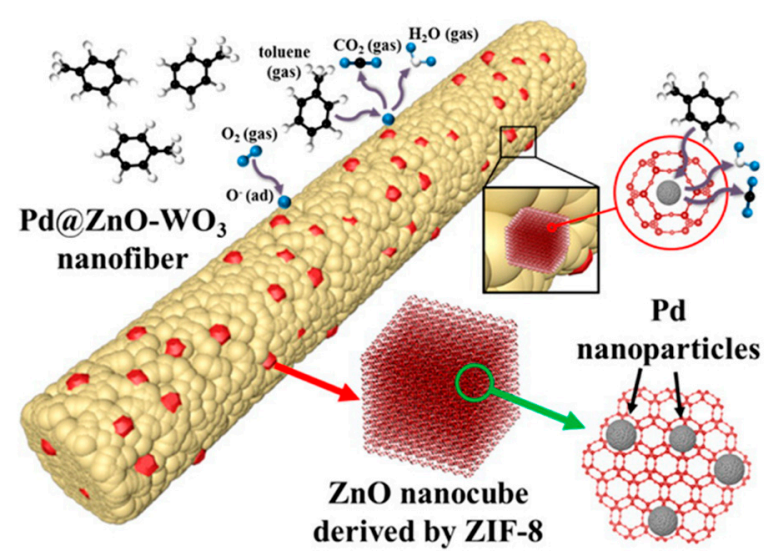

Figure 9. The structure of $\mathrm{Pd} @ \mathrm{ZnO}-\mathrm{WO}_{3} \mathrm{NFs}$ and the reaction in certain gas. (Reproduced with permission from [119], Copyright 2016 American Chemical Society).

According to these reports, the porosity of the SMOx can be improved by using MOF as a precursor, and this attempt can broaden the types of metal oxides, thereby increasing the types of detection gases. Therefore, this provides a new direction for the development of SMOx composites.

\subsection{Problems to Be Solved}

By reading the literature on $\mathrm{MO}$ and $\mathrm{MOF}$ composite gas-sensitive sensors, we found that there are still several problems.

(1) When the MOF only acts as a molecular sieve according to the pore size and does not interact with the detection gas, the adjustment of the pore size of MOF determines the selectivity of the sensor. However, when the molecular size of the interfering gas is smaller than or close to the target molecule, how to realize the selectivity of the target gas is an urgent problem.

(2) At present, the MOF materials compounded with SMOx are limited, so its pore size is limited, thus the size of gas molecules that can be detected at present is also limited; therefore, it is important to learn whether other MOF materials can be used instead of ZIF.

(3) Based on the existing MOF materials, the choice of SMOx is dominated by $\mathrm{ZnO}$ due to the limitation of the synthesis method. Liu et al. [53] improved the sensing performance for $\mathrm{NO}_{2}$ by adding $\mathrm{ZnO}$ to $\mathrm{In}_{2} \mathrm{O}_{3}$ and it is known that $\mathrm{ZnO}$ can be compounded with a variety of SMOx to form a heterogeneous structure. Thus, can the synthesis of MOF on these materials be successful and can the synthesis improve the sensing performance for specific gases?

\section{MOFs-Carbon Composites}

\subsection{Advantages and Disadvantages of a Single Material}

Carbon-based materials (e.g., graphite, carbon fiber, carbon nanotubes, carbon quantum dots, fullerene) have applications in many research fields due to their lightweight, good chemical and thermal stability, high mechanical strength and elastic strength, and excellent electronic and optical properties [120-123]. Among various carbon-based materials, graphene is a promising material for making chemical sensors because of its high specific surface area, tunable surface chemistry, and better electrical properties [124]. However, its chemistry is simple, and the van der Waals bonds between layers are weak. Graphene sheets are often stacked, which reduces the specific surface area, lowers the carrier mobility, and prevents gas molecules from diffusing in them. This will result in a decrease in the sensitivity of the sensor. Furthermore, the adsorption of gas molecules on the pristine graphene surface is very weak, and the selectivity of graphene sheets to gas is not high $[125,126]$. Carbon nanotubes are chemically inert, and due to their unique physicochemical properties, their application to gas-sensitive sensors is not only more sensitive but can also operate at room temperature. They also have low power consumption and high compatibility 
with microelectronic processes, but the selectivity of carbon nanotubes interacting with analytes is very limited $[127,128]$. In addition to the above-mentioned inherent problems of carbon nanotubes and graphene, it was found that they also have low adsorption capacity for gases, and it is difficult to separate the adsorbent after the reaction [129]. Therefore, researchers have been looking for other materials to replace them. As shown above, MOF materials have a larger specific surface area, more pores and better adsorption performance. In addition, the selectivity of specific gases can be enhanced by the action of molecular sieves. However, since many MOF materials are insulating materials, it is difficult to prepare individual MOFs directly into chemical sensors, and their stability is poor. Therefore, it can be speculated that these drawbacks can be solved by utilizing the synergistic interaction between the two to construct composite materials.

\subsection{The Choice of Carbon-Based Materials and MOF Materials}

According to various experiments, MOF materials can be composited with a variety of carbon-based materials, and the integration of MOF and carbon-based materials can improve the stability, electrical conductivity, template effect, etc. [130]. We have summarized the sensing performance of some sensors formed by the carbon-based materials and MOF composites, as shown in Table 2. Currently, most of the carbon-based materials reported in the literature that can be used for gas sensing and gas adsorption are concentrated in carbon nanotubes and graphene-based materials. Notably, the graphene-based materials used in the complexes include graphene, graphene oxide, reduced graphene oxide (rGO), aminated graphene oxide, etc. There are fewer pristine graphene flakes used at present. This is because pristine graphene flakes contain fewer oxygen groups, and thus they are less capable of promoting MOF crystal nucleation than GO. In addition, pristine graphene flakes may also serve as a physical barrier between MOF seeds during MOF formation [30]. Therefore, there are many researches on the composite materials of MOF and GO or rGO. This review focuses on the two composite materials, MOF/GO and MOF/CNT.

Table 2. A summary of the gas-sensitive properties of gas sensors prepared from composites of MOF and the carbonbased materials.

\begin{tabular}{|c|c|c|c|c|c|c|c|}
\hline Material & $\begin{array}{c}\text { Target Gas, } \\
\text { Concentration (ppm) }\end{array}$ & $\begin{array}{l}\text { Topt } \\
\left({ }^{\circ} \mathrm{C}\right)\end{array}$ & Response & $\begin{array}{c}\text { Response/Recovery } \\
\text { Time (s) }\end{array}$ & BET $\left(\mathrm{m}^{2} / \mathrm{g}\right)$ & $\begin{array}{l}\text { Detection } \\
\text { Limit }\end{array}$ & Ref. \\
\hline Cu-BTC/GO (25) & $\mathrm{NH}_{3} 500$ ppm & - & $7 \%$ & - & 916 & - & [131] \\
\hline Cu-BTC/PPy-rGO & $\begin{array}{c}\mathrm{NH}_{3} \\
50 \mathrm{ppm}\end{array}$ & 25 & $12.4 \%$ & $13 / 22$ & 1861 & 2 ppm & [132] \\
\hline $\begin{array}{c}\mathrm{SiO}_{2} \mathrm{CuOF}- \\
\text { graphene-PAni }\end{array}$ & $\begin{array}{c}\mathrm{NH}_{3} \\
40 \mathrm{ppm}\end{array}$ & - & - & $30 / 180$ & 756 & $0.6 \mathrm{ppm}$ & [133] \\
\hline $\begin{array}{c}\text { ZIF-8/ } \\
\text { MWCNTs/AgNPs }\end{array}$ & $\begin{array}{c}\text { methanol, ethanol, } \\
\text { acetone, acetonitrile, } \\
\text { n-hexane } 1 \%\end{array}$ & RT & $\begin{array}{c}8.0 \% 12.16 \% \\
2.28 \% 2.02 \% \\
\quad-0.81 \%\end{array}$ & - & 1176.24 & $\begin{array}{l}1.847 \% \\
0.399 \% \\
4.996 \% \\
4.431 \% \\
5.203 \%\end{array}$ & [134] \\
\hline $\begin{array}{c}\text { Co-Zn-Ni } \\
\text { MOF@CNT }\end{array}$ & $\mathrm{H}_{2} \mathrm{~S} 100 \mathrm{ppm}$ & 325 & $\sim 166$ & $126 / 23$ & 363 & - & [135] \\
\hline $\begin{array}{c}\mathrm{Ni}_{3} \mathrm{BTC}_{2} / \mathrm{OH}- \\
\text { SWNTs }\end{array}$ & $\begin{array}{c}\mathrm{SO}_{2} \\
15 \mathrm{ppm}\end{array}$ & 25 & - & $4.59 / 11.04$ & - & 4 ppm & [136] \\
\hline $\begin{array}{c}\mathrm{TiO}_{2}-\mathrm{SnO}_{2} / \\
\mathrm{MWCNTs} @ \mathrm{Cu}- \\
\text { BTC }\end{array}$ & $\begin{array}{c}\mathrm{NH}_{3} \\
-\end{array}$ & RT & $\begin{array}{l}\sim 0.58(10 \mathrm{ppm}) \\
\sim 0.64(20 \mathrm{ppm}) \\
\sim 0.70(30 \mathrm{ppm}) \\
\sim 0.83(40 \mathrm{ppm})\end{array}$ & $80 / 15$ & - & $0.77 \mathrm{ppm}$ & [137] \\
\hline $\begin{array}{l}\text { Ni-MOF/-OH- } \\
\text { SWNTs }\end{array}$ & $\mathrm{SO}_{2} 1 \mathrm{ppm}$ & RT & - & $10 / 30$ & - & $0.5 \mathrm{ppm}$ & [128] \\
\hline
\end{tabular}

Regarding the selection of MOF materials, the related research on gas adsorption and sensing mainly focusses on some common MOFs, including copperebenzene-1,3,5tricarboxylate (Cu-BTC), MOF-5, ZIF-8, etc. [138-140]. In fact, not all MOFs can be com- 
pounded with GO to form composites with high adsorption properties. As shown in Figure 10, MOF crystals must have a specific geometry (e.g., cubic Cu-BTC) and must not be spherical or have their metal centers too close to each other. Otherwise, GO will become disordered, which will prevent the growth of MOF crystals, resulting in poor crystallinity, porosity, and adsorption capacity [30]. $\mathrm{Cu}_{3}(\mathrm{BTC})_{2}\left(\mathrm{H}_{2} \mathrm{O}\right)_{3}(\mathrm{BTC}=1,3,5-$ benzenetricarboxylate), also known as HKUST-1, is an MOF material that has been studied by many theories and experiments [141]. It has a low preparation cost, relatively simple preparation, permanent pores, good thermal stability (about $300^{\circ} \mathrm{C}$ ), high adsorption energy, high adsorption capacity, and reversible adsorption-desorption performance [138,142]. At present, $\mathrm{Cu}_{3}(\mathrm{BTC})_{2}$ is widely used in gas adsorption, especially $\mathrm{CO}_{2}$ and $\mathrm{NH}_{3}$ adsorption. The adsorption of $\mathrm{CO}_{2}$ in $\mathrm{Cu}_{3}(\mathrm{BTC})_{2}$ belongs to physical adsorption. It is found that $\mathrm{Cu}_{3}(\mathrm{BTC})_{2}$ can adsorb $\mathrm{CO}_{2}$ preferentially by coordinating with the metal center in the terminal $\mathrm{O}=\mathrm{C}=\mathrm{O} \cdot \mathrm{C}$ u structure [143]. Alkaline ammonia molecules can be adsorbed by strong hydrogen bonding to the $\mathrm{Cu}-\mathrm{BTC}$ organic linker and strong interaction with the open Lewis acidic divalent copper ion metal sites in $\mathrm{Cu}_{3}(\mathrm{BTC})_{2}[132,133]$. However, some studies have shown that this interaction with the unsaturated $\mathrm{Cu}$ sites will break the $\mathrm{Cu}-\mathrm{O}$ bond, and $\mathrm{NH}_{3}$ will also react with the BTC ligand, which will lead to the collapse of the MOF structure. In particular, in the presence of water vapor, the combination of the two will lead to the slow decomposition of $\mathrm{Cu}$-BTC to form $\mathrm{Cu}(\mathrm{OH})_{2}$ and $\left(\mathrm{NH}_{4}\right)_{3} \mathrm{BTC}$, thus reducing the adsorption/sensing performance [144-148]. Moreover, $\mathrm{Cu}_{3}(\mathrm{BTC})_{2}$ also shows adsorption capacity for other small molecules [143]. Although Cu-BTC adsorption technology has been widely used, it has the potential to be developed as a gas sensor, but its hydrophilicity is a big obstacle, and the organic bridges in the structure will be replaced by water molecules, which will lead to the collapse of the MOF structure. The instability of the MOF structure will lead to a shortening of its lifetime, which is a problem in gas sensing [138]. It is found that $\mathrm{Cu}$ ions in Cu-BTC can react with carboxyl, hydroxyl, and sulfonic groups on carbon-based materials, which can reduce the influence of water to some extent and improve the selectivity of some gases (such as $\mathrm{NH}_{3}$ ) [131,149]. Of course, some methods have been adopted in the experiment to improve the hydrophobicity further, mainly introducing hydrophobic groups or hydrophobic substances [150-154]. For example, Nasim et al. used hydrophobic ZIF-8 to compound MWCNTs and silver nanoparticles. The influence of water vapor can be avoided, and some volatile organic gas molecules can be detected at room temperature [134]. Moreover, a layer of silicon dioxide can be coated on the surface of MOF. Due to the inherent porosity of silica, it can not only improve the water stability of the composite material, but also does not hinder the adsorption of gas $[133,155]$.

\begin{tabular}{|c|c|c|}
\hline $\begin{array}{l}\text { (a) MOF-5/Graphite oxide } \\
\text { composite }\end{array}$ & $\begin{array}{l}\text { (b) HKUST-1/Graphite oxide } \\
\text { composite }\end{array}$ & $\begin{array}{l}\text { (c)MIL-101/Graphite oxide } \\
\text { composite }\end{array}$ \\
\hline 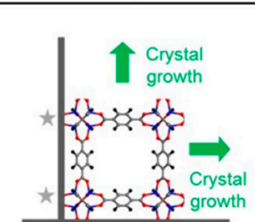 & 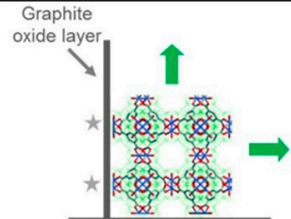 & \\
\hline$\star \star \star$ & $\begin{array}{l}\text { Coordination } \\
\text { GO/MOF }\end{array}$ & $\begin{array}{c}\star \star \star \\
\text { Crystal growth } \\
\text { prevented }\end{array}$ \\
\hline$\Rightarrow$ & $\rightarrow$ & \\
\hline$\star$ & $\star$ & \\
\hline
\end{tabular}

Figure 10. Schematic diagram of three composite materials: (a) MOF-5/GO composite; (b) HKUST1/GO composite; and (c) MIL-101/GO composite. (Reproduced with permission from [156], Copyright 2011 WILEY). 
MOF and graphene-based materials are combined and interact with each other. The following advantages are summarized: (1) GO has many oxygen-containing functional groups that can coordinate with the metal center of MOF and become nucleation sites of MOF crystals; other atoms (e.g., N) can also play this role [157,158]. For example, copper sites in $\mathrm{Cu}_{3}(\mathrm{BTC})_{2}$ can react with epoxy, hydroxyl, sulfonic acid, and carboxyl functional groups of GO. Due to the octahedral geometry of copper complex, the oxygen functional group of graphene phase can replace BTC ligand or water molecule [131]. Other atoms (such as N) can also be used as nucleation sites and can enhance the structural/chemical heterogeneity of composites. This heterogeneity determines the excellent performance of composite materials as reactive adsorbents of $\mathrm{NH}_{3}, \mathrm{H}_{2} \mathrm{~S}$, and $\mathrm{NO}_{2}$ and physical adsorbents of $\mathrm{CO}_{2}$ [30]. (2) The dispersion of MOF can be improved by GO. Oxygen-containing functional groups exist on the surface of GO, which may interact with metal sites in MOF to prevent the aggregation of MOF [159]. The functional groups on the surface of GO also promote the dispersion of MOF due to electrostatic repulsion, thereby enhancing the gas adsorption performance $[140,160,161]$. (3) The combination of the two materials increases the defects, and forms new pores at the interface between them, resulting in an increase in the pore space, the specific surface area, and the surface-active adsorption sites, which further improves the adsorption of gas molecules [162-164]. (4) Reduced graphene oxide (rGO) has high conductivity and high surface area. Developing MOF composites containing RGO can improve the conductivity of MOF-based composites [165]. The addition of GO and its chemical bond with MOF is also expected to enhance the conductivity of materials, which is very important for the sensing of chemically resistive gases [166-168]. (5) In addition, due to the addition of modified graphene-based materials into the MOF phase, the microstructure of the parent MOF changed, which led to the enhancement of molecular adsorption. (6) The introduction of GO enhances the water-resistance of the composites - which is mainly due to the fact that GO can adsorb water molecules-thus preventing water molecules from entering those hydrophilic MOFs (e.g., $\left.\mathrm{Cu}_{3}(\mathrm{BTC})_{2}\right)$ and reducing the effect of humidity in the composites when adsorbing gas molecules. Aminated graphene oxide/RGO also has good hydrophobicity [169]. (7) Adding a small amount of GO will lead to the deformation of MOF structure, which is beneficial to gas adsorption, but excessive GO will lead to excessive deformation, thus reducing the specific surface area and gas adsorption capacity. [170]. (8) The existence of GO/RGO is beneficial to the service life of MOF. RGO/Cu-BTC and GO/Cu-BTC prepared by Sun et al. could keep the adsorption capacity of n-hexane above $65 \%$ after 50 cycles, indicating that the service life is longer [138]. (9) With the addition of GO, the thermal stability of the material is improved [171,172].

However, at the same time, there are some problems that need attention. For example, the content of GO should not be too high. Otherwise, the MOF structure will be excessively deformed, resulting in a decrease of gas adsorption capacity [140,146]. Additionally, humid conditions will limit the application of some MOF/graphene-based materials in gas adsorption/sense, but there are exceptions. For example, MOF/GO composites prefer $\mathrm{H}_{2} \mathrm{~S}$ adsorption under wet conditions and $\mathrm{NO}_{2}$ adsorption under dry conditions [173].

Carbon nanotubes (CNTs) are one of the most suitable materials for synthesizing MOF composites, which can control the shape and size of MOF by increasing the dispersion force in MOF and inhibiting its aggregation [135]. In addition, after compounding MOF and CNTs it is found that new pores are formed on the interface between them, which increases the specific surface area of the composite material and is beneficial to improving the gas adsorption capacity and gas selectivity. Another advantage of carbon nanotubes is that they have adjustable surface chemical properties and certain chemical stability and their outer surfaces are hydrophobic [30]. For example, Yang and his colleagues synthesized an MOF-5/carbon nanotube (CNT) composite [139], which has higher moisture resistance than the original MOF-5. Moreover, carbon nanotubes (SWNTs) are also an excellent framework and conductive surface of some MOFs, which can form electron transmission channels in MOF to improve the conductivity. The functional groups at the outer side and 
tip of SWNTs provide active channels for chemical reactions, thus improving the sensitivity and repeatability of composite materials for gas molecule detection $[134,136,174]$.

\subsection{Preparation Method of MOF/Carbon-Based Composite Materials}

Different from SMOx and MOF composite materials, there are many preparation methods of carbon-based materials and MOF composite materials. At present, the research mainly focuses on graphene-based materials and carbon nanotubes, so we mainly look at the preparation of their composite materials with MOF materials.

Let us look at the preparation of MOF/graphene-based materials. Zheng et al. [173] summarized some preparation methods commonly used in gas adsorption and chemical sensors, including the Pickering emulsion interface growth method, the self-assembly method, the water/solvothermal method, and the layer-by-layer assembly method. According to a summary of the literature, it is found that solvothermal methods are widely used for their simplicity and low cost. This method is very simple and its sensing performance is very reliable [132]. Additionally, Pickering emulsion interfacial growth method is also a classical method. Pickering emulsion is a system composed of two immiscible liquids and stabilized by solid particles $[175,176]$. It has the advantages of low cost, easy separation, recyclability, etc., so it has wide applications. [175]. There are many kinds of stable Pickering emulsion solid particles, including MOF and GO [177-180]. The reason is that both GO and MOF are amphiphilic materials, so both MOF and GO solid particles can be used as stabilizers, which can be adsorbed to the liquid-liquid interface to form a Pickering emulsion. In addition, because the oxygen-containing functional groups (hydroxyl, carboxyl, epoxy, and ketone) of GO can coordinate with the metal center of MOF, an MOF crystal can grow on GO films $[157,158]$. Compared with other reported MOF/GO composites with huge integral or closely packed layered block morphology, the MOF/GO synthesized by the Pickering emulsion method can make GO pieces highly dispersed, thus giving full play to the advantages of GO [181,182]. Zhang et al. [175] used Zr-BDC-NO and GO to synthesize a Pickering emulsion, and then freeze-dried it in liquid nitrogen to remove the liquid, thus obtaining the $\mathrm{Zr}-\mathrm{BDC}-\mathrm{NO}_{2} / \mathrm{GO}$ complex with a simple method. Through an FT-IR test, it is found that GO interacts with MOF through hydrogen bonding, and through XRD test and analysis it is found that the original MOF crystal structure was retained, the composite structure has a honeycomb structure, and its porosity can be changed by adjusting the concentration of GO and MOF. Therefore, it is reasonable to speculate that the MOF/GO composite material synthesized by this method may have application potential in gas adsorption or sensing.

Bian et al. [169] prepared $\mathrm{Cu}_{3}$ (BTC) $2 / \mathrm{GO}$ composites by the Pickering emulsion growth method. The synthesis process is shown in Figure 11. Here, GO has three functions. Initially, it plays the role of stabilizing the Pickering emulsion and providing a large interface area for MOF crystal growth. As shown in Figure 11, in the Pickering emulsion stabilized by amphiphilic GO tablets, the presence of the concentration gradient can drive the diffusion of $\mathrm{H}_{3}$ BTC to the surface of GO. $\mathrm{Cu}^{2+}$ ions are adsorbed on the surface of graphene oxide through electrostatic action and coordination with oxygen-containing functional groups, thus forming $\mathrm{Cu}_{3}(\mathrm{BTC})_{2} / \mathrm{GO}$ material. Furthermore, the morphology and surface porosity of MOF can be significantly changed. Finally, the water adsorption of $\mathrm{Cu}_{2}$ (BTC) $)_{2}$ is reduced through the hydrophilicity of the highly dispersed GO sheets, and thus the adsorption capacity of $\mathrm{CO}_{2}$ is enhanced by reducing the competition of water molecules. 


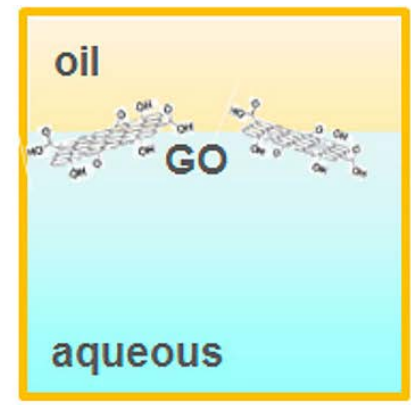

\section{emulsification}

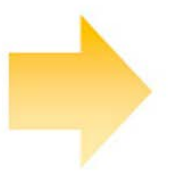

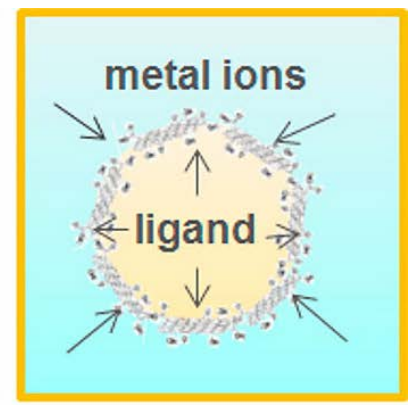

Interfacial growth
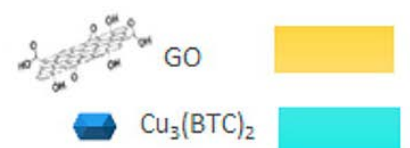

Octanol solution of ligand (BTC)

Aqueous solution of metal ions $\left(\mathrm{Cu}^{2+}\right)$
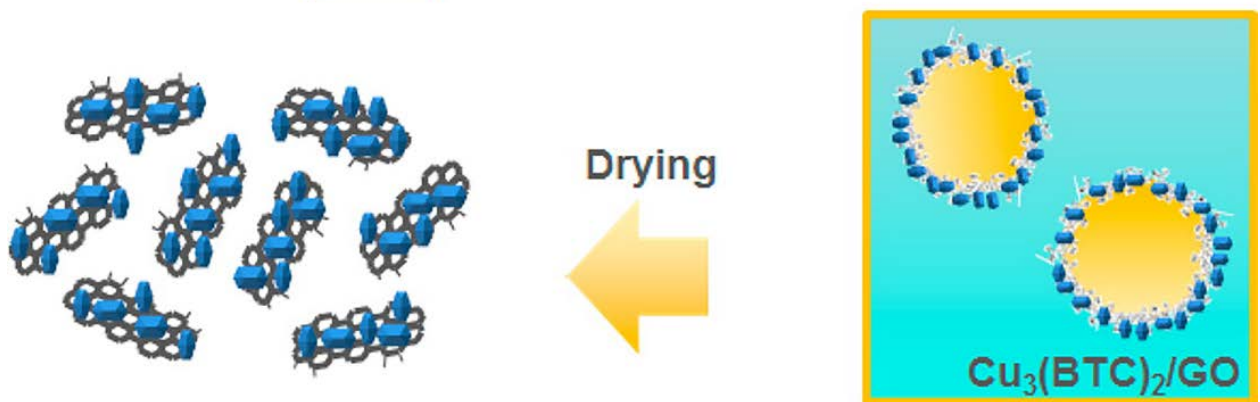

Figure 11. Schematic Illustration of the synthesis approach for $\mathrm{Cu}_{3}(\mathrm{BTC})_{2} / \mathrm{GO}$. (Reproduced with permission from [169], Copyright 2015 American Chemical Society).

The gas adsorption properties of composites prepared by different preparation methods are different. The properties of MOF-graphene-based composite materials depend on MOF and graphene-based materials. As mentioned above, MOF crystals must have a certain crystal structure, otherwise MOF crystals are difficult to grow. Moreover, graphenebased materials themselves will also have an impact on the properties of materials. Firstly, the oxidation level of graphene will directly affect the nucleation of MOF. XRD patterns and some studies show that GO can be used as the nucleation sites of MOF crystals, and oxygen-containing groups (such as carboxyl or epoxy groups) on GO can act in the nucleation of MOF, thus generating bonds with MOF. These bonds will increase the porosity of the composite, that is, new pores will be generated at the interface between them, while the porosity and gas adsorption capacity of graphene sheets with almost no functional groups are not as high as those of GO [30,183]. Moreover, the active sites/defects at the edge of graphene layer are related to its oxidation degree, which is the key feature of the interaction between GO component and MOF unit [184]. Secondly, the types and numbers of surface functional groups, especially oxygen-containing groups, will also affect the selective adsorption of graphene-based adsorbents for different polar gases. Taking RGO and GO as examples-although RGO will reduce the specific surface area of composite materials due to agglomeration-RGO is nonpolar compared with GO, so $\mathrm{RGO} / \mathrm{MOF}$ is the first choice for nonpolar gases. The specific adsorption capacity is closely related to the reduction degree of RGO. Additionally, RGO is hydrophobic. For polar gases, the adsorption capacity of GO/MOF is higher [138]. The porosity of GO with different oxygen-containing groups is also different, which affects the adsorption performance. It is found that the composites synthesized by GO with hydroxyl groups show the highest porosity [30]. Thirdly, the content of GO will also affect the porosity. With the increase of GO content, the carboxyl group at the edge of graphene sheet will interact with MOF, which will lead to the increase of porosity of the composite. However, the content of GO should not be too high, because the interaction between GO and MOF will lead to the distortion 
of the MOF structure. Furthermore, when carboxyl groups are not the main groups on the surface of GO, epoxy, phenol, and carbonyl groups can also become the main reactive groups with metal sites [184]. Fourth, different sizes of GO sheets will also have an impact. The ideal composite structure should be composed of graphene sheets and MOF alternately. It is found that with a decrease of GO sheets, the porosity of the composite increased and the carboxyl groups in GO also increased. The carboxyl groups of GO can interact with the metal sites of MOF and play the role of nucleation sites. Therefore, it can be estimated that GO chips close to or smaller than MOF size are the best $[30,184]$.

Let us take a look at the preparation method of MOFs/carbon nanotube materials. The synthesis of MOFs/CNTs composite materials is mainly based on solvothermal/hydrothermal method, which is a crystallization process in an organic solvent under high temperature and high pressure in a closed container $[139,185]$. It is generally divided into three steps, and the process is shown in Figure 12. To start with, a metal salt and ligand molecule are added into a solvent to prepare the MOF precursor. Additionally, the carbon nanotubes are uniformly dispersed in the solvent. The second step is to mix the two, carry out ultrasonic treatment, and stir for a certain time. Then, the hydrothermal reaction takes place at a specific temperature. Finally, washing the product obtained in the second step with a solvent to remove unreacted substances, and drying in an oven to obtain the final compound [129]. Note that other experimental conditions should also be considered in this preparation method, such as solvent type, reagent concentration and ratio, temperature and time, etc. In order to prevent the decomposition of MOF structure, the hydrothermal temperature should be close to the synthesis temperature of original MOF.

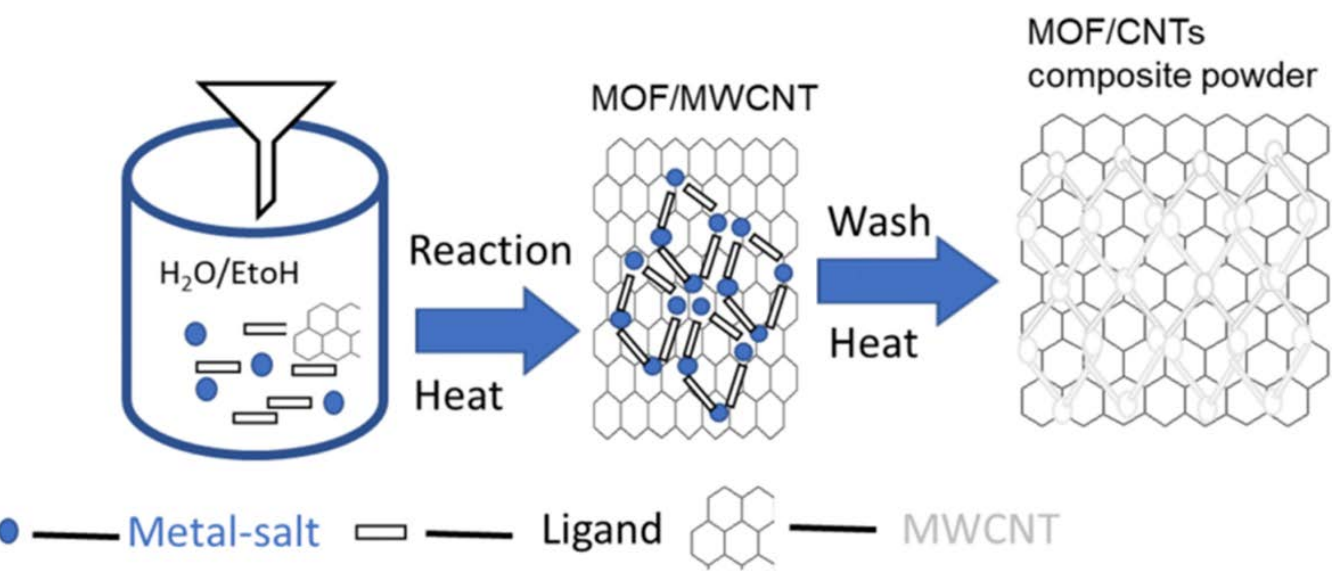

Figure 12. Schematic representation of an MOFs/CNT composite. (Reproduced with permission from [129], Copyright 2020 Springer Nature).

Another method to synthesize MOFs/CNTs composites is spin-coating technique. Chappanda et al. [186] reported the synthesis of carbon nanotubes/HKUST-1 composites using this method. Briefly, the base solution of MOF is synthesized first, then the carbon nanotubes are added into the MOF solution for sonication, the treated solution is spincoated on the electrode of QCM at a certain speed for a certain time, and then the solvent is evaporated, thus forming the CNT-MOF composite film. It is found that the existence of dispersed carbon nanotubes increased the number of nucleation sites and the effective surface area for MOF growth, which may be the reason for the decrease of MOF crystal size and the increase of MOF crystal number. Although this approach is easy and convenient to use and the generated films are stable and reliable, not many MOFs/CNTs composites have been prepared using this method. 


\subsection{Current Development of Research in Gas Sensing and Gas Adsorption}

3.4.1. MOF-Carbon Nanotube/Graphene-Based Composites for Gas-Sensitive Sensing Applications

Tran et al. [187] used pristine graphene ( $\mathrm{pG}$ ) compounded with three MOF materials, Cu-BTC, zirconium 1,4-dicarboxybenzene (UiO-66), and ZIF-8. Then, the sensing performance of the sensors prepared from these three materials for several volatile organic compounds (VOCs) was tested. It was found that all three gas sensors could detect chloroform vapors at ppm level at room temperature. pG-Cu-BTC sensors showed the highest response to chloroform, as well as the highest sensitivity and selectivity to chloroform and methanol. There are several reasons for this. Firstly, $\mathrm{Cu}-\mathrm{BTC}$ has the largest specific surface area among the three MOFs. Secondly, as shown in Figure 13, ZIF-8 and UiO-66 are randomly distributed on the surface of graphene due to the aggregation phenomenon, while Cu-BTC is uniformly distributed on the graphene carrier and inserted between the graphene sheets, increasing the specific surface area and the number of active sites. Finally, the interaction of chloroform molecules with Cu-BTC leads to increased selectivity, while for methanol molecules, which possess higher polarity and can form coordination bonds with $\mathrm{Cu}$ ions in $\mathrm{Cu}-\mathrm{BTC}$, their response is higher.
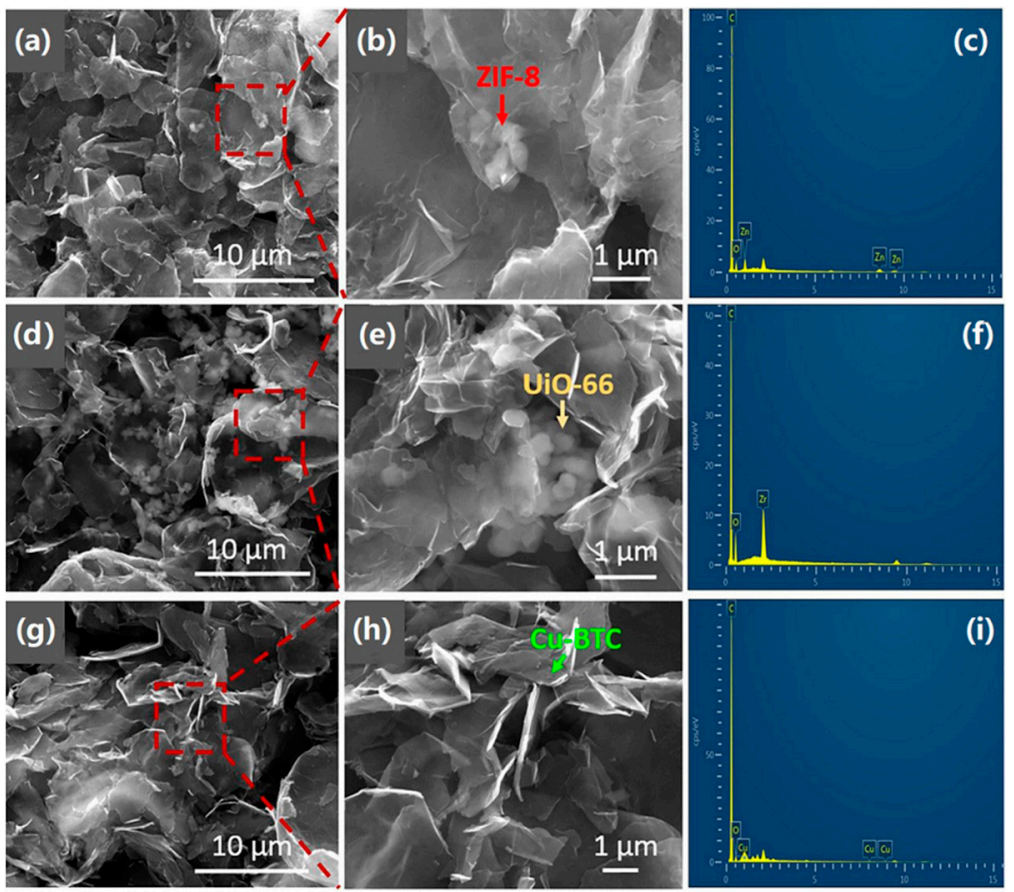

Figure 13. SEM images of (a-c) pG-ZIP-8, (d-f) pG-UiO-66, and (g-i) pG-Cu-BTC. (Reproduced with permission from [187], Copyright 2020 ELSEVIER).

Tan et al. [135] first synthesized a p-type Zn-Co-Ni MOF@CNT composite with a hollow core-shell structure in a leaf-like bilayer by hydrothermal method. The synthesis scheme and the microstructure of the obtained composites are shown in Figure 14. The pores of the material are mainly mesoporous, and this structure has a large specific surface area, which facilitates the diffusion of gas molecules and the transfer of electrons, thus improving the gas sensing performance. Carbon nanotubes here can be modified by carboxyl groups in addition to inhibiting MOF aggregation, thus facilitating the uniform growth of MOF. Compared with the monolayer Zn-Co MOF@CNT composite, the sensor prepared from this bilayer trimetallic MOF composite exhibited higher $\mathrm{H}_{2} \mathrm{~S}$ sensing performance at $325^{\circ} \mathrm{C}$, with a response of up to 166 for $100 \mathrm{ppm} \mathrm{H}_{2} \mathrm{~S}$ and response recovery times of $126 \mathrm{~s}$ and $23 \mathrm{~s}$, respectively. After adding Ni ions and annealing, the surface of the material becomes rougher and many pores are formed due to the production of more nanoparticles. The mesoporous nanostructure promotes the transport and diffusion of 
gas molecules, which results in the improvement of gas-sensitive performance. In addition, the selectivity of the sensors prepared by this complex is also good for $\mathrm{H}_{2} \mathrm{~S}$ compared to $\mathrm{NO}_{2}$, $\mathrm{C}_{3} \mathrm{H}_{6}, \mathrm{NH}_{3}$, and $\mathrm{CO}$. This report suggests that polymetallic MOF materials compounded with carbon nanotubes should be used to improve gas sensing properties. This also provides a new direction for the selection of MOF materials in MOF-carbon-based materials.

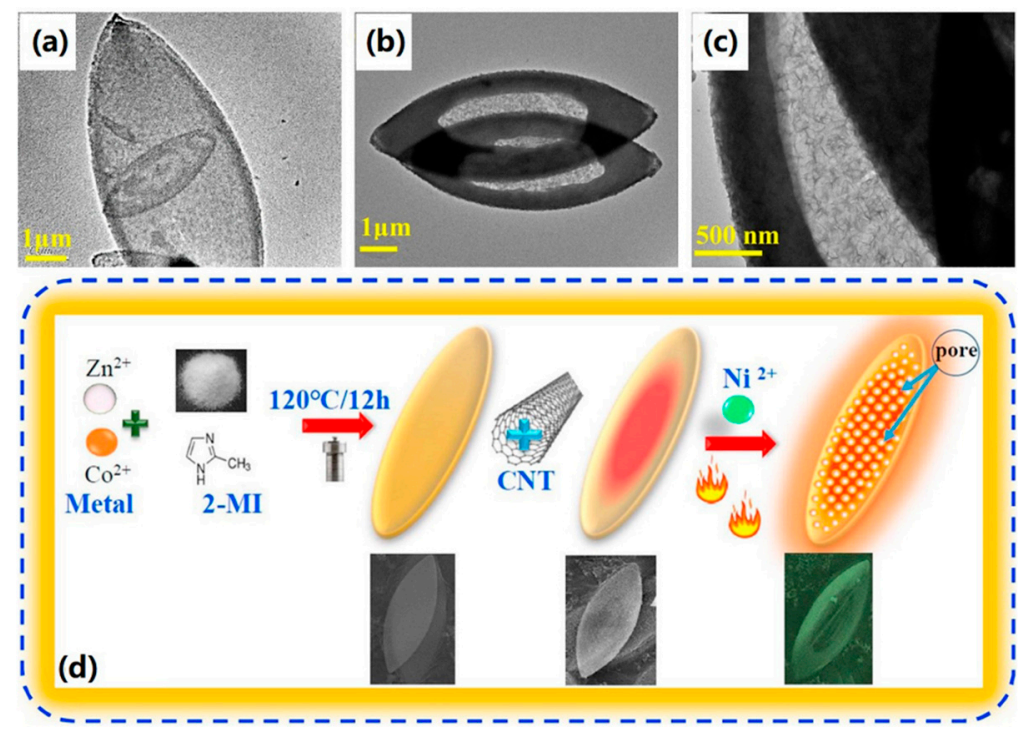

Figure 14. (a-c) TEM images of Zn-Co-Ni MOF@CNT composite. (d) Schematic illustration of the ZnCo-Ni MOF@CNT composite. (Reproduced with permission from [135], Copyright 2020 ELSEVIER).

It has been reported that single-walled carbon nanotubes can serve as a robust backbone for the uniform growth of Ni-MOF and provide excellent electrical conductivity using a solvothermal method [174]. Ingle et al. [136] combined Nickel Benzene Carboxylic $\left(\mathrm{Ni}_{3} \mathrm{BTC}_{2}\right)$ with OH-Functionalized Single-Walled Carbon Nanotubes (OH-SWNTs), and the complexes showed the p-type. The addition of OH-SWNTs resulted in the formation of a micro-network in the MOF that facilitates charge transfer, thus enhancing the conductivity and sensing performance. The sensor made of this composite can reversibly detect $\mathrm{SO}_{2}$ down to $4 \mathrm{ppm}$ at room temperature with good reproducibility and shows fast response recovery for different concentrations of $\mathrm{SO}_{2}$ gas, with response recovery times of $4.59 \mathrm{~s}$ and $11.04 \mathrm{~s}$ at a $\mathrm{SO}_{2}$ concentration of $15 \mathrm{ppm}$, respectively. In addition, its selectivity is also good, as shown in Figure 15, for five gases at 5 ppm detection, with the highest sensitivity for $\mathrm{SO}_{2}$. This report is the first to use $\mathrm{Ni}_{3} \mathrm{BTC}_{2} / \mathrm{OH}-\mathrm{SWNTs}$ composites for reversible sensing of $\mathrm{SO}_{2}$ in chemical field-effect transistors.

Ingle et al. [80] used a solvothermal method to compound single-walled carbon nanotubes and multi-walled carbon nanotubes functionalized with nitric acid with $\mathrm{Ni}$ $\mathrm{MOF}$ and prepared gas sensors to detect $\mathrm{SO}_{2}, \mathrm{NO}_{2}, \mathrm{NH}_{3}$, and $\mathrm{CO}$ at room temperature, respectively. As shown in Figure $16 \mathrm{a}-\mathrm{c}$, the gas-sensitive performance of the sensors prepared by the complexes was better than that of the single material because the carbon nanotubes established a connection network between the agglomerated MOFs, which facilitated the electron transfer. In addition, as shown in Figure 16e,f, the sensors prepared from Ni-MOF/-OH-SWNTs had higher sensitivity due to the larger average roughness (Ra) than the value of Ni-MOF/-OH-MWNTs. Because Ni-MOF/-OH-MWNTs have honeycomb structured pores and thus retain gas molecules for a long time, the recovery time required for the sensors prepared from Ni-MOF/-OH-MWNTs is longer. As shown in Figure $16 \mathrm{~g}-\mathrm{j}$, the sensing results of the gas sensor under dry conditions show that the $\mathrm{Ni}$ MOF/-OH-SWNTs sensor has higher selectivity for $\mathrm{SO}_{2}$ and shorter response recovery time of $10 \mathrm{~s}-30 \mathrm{~s}$. The repeatability of this sensor at room temperature is also excellent. This material has excellent gas-sensitive performance due to its easy preparation, low cost, and workability at room temperature. 


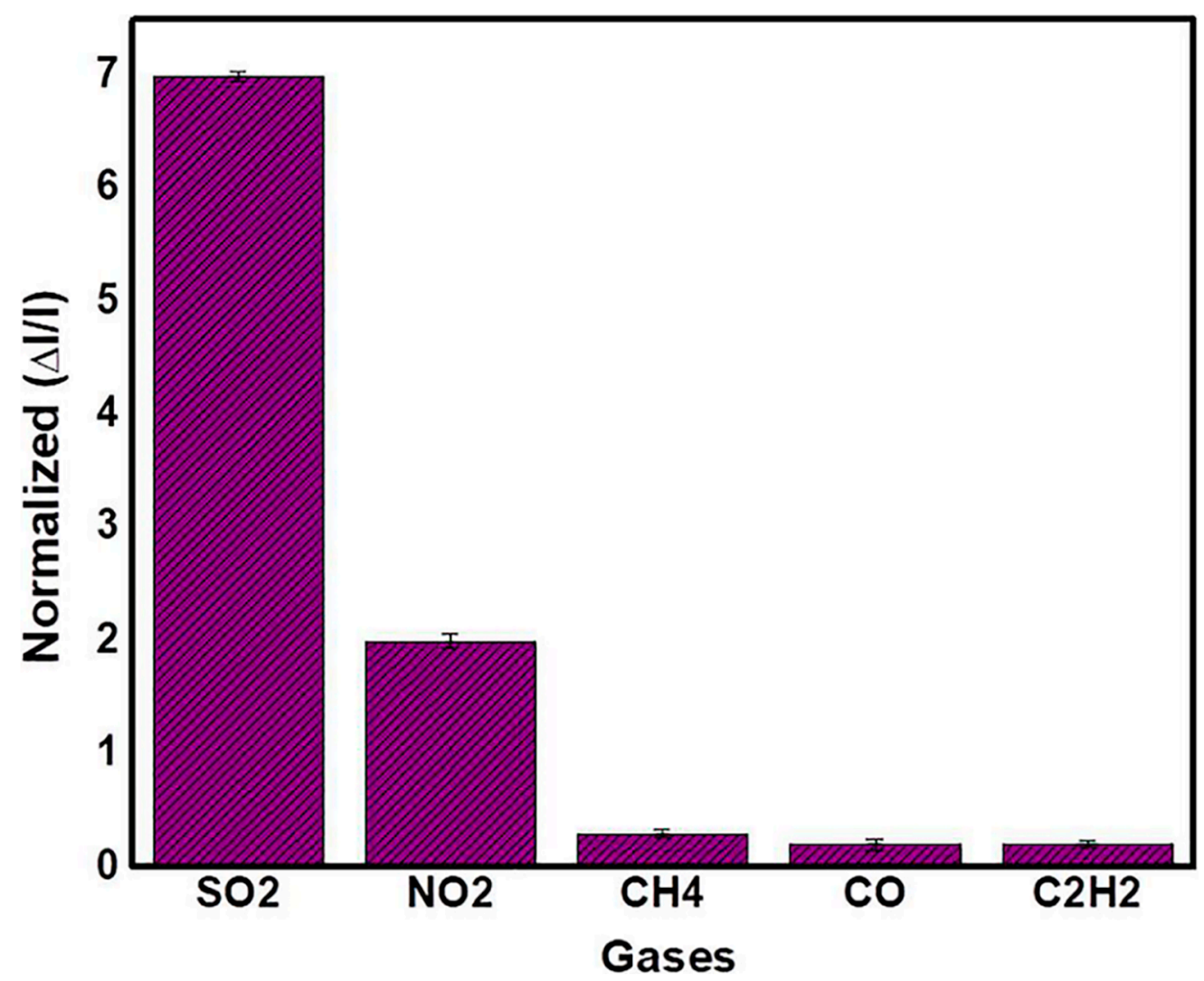

Figure 15. Selectivity of the $\mathrm{Ni}_{3} \mathrm{BTC}_{2} / \mathrm{OH}-\mathrm{SWNT}$ composite sensor toward 5 ppm of $\mathrm{SO}_{2}, \mathrm{NO}_{2}$, $\mathrm{CH}_{4}, \mathrm{CO}$, and $\mathrm{C}_{2} \mathrm{H}_{2}$. (Reproduced with permission from [136], Copyright 2020 FRONTIERS).

Travlou et al. [131] found that although exposure of $\mathrm{Cu}_{3}(\mathrm{BTC})_{2}-\mathrm{GO}$ to $\mathrm{NH}_{3}$ causes the reaction of $\mathrm{NH}_{3}$ with the $\mathrm{Cu}$ sites in $\mathrm{MOF}$, leading to the disruption of the $\mathrm{Cu}-\mathrm{O}$ bond and the destruction of the MOF structure, which results in a significant reduction in the specific surface area of the material. Irreversible signals can be generated by the interaction between the amorphous phase obtained after the collapse of the structure and $\mathrm{NH}_{3}$ and the interaction between $\mathrm{NH}_{3}$ and GO. The weaker interaction between $\mathrm{NH}_{3}$ and BTC in GO again leads to a change in the reversible signal. Even though the MOF structure collapses, the absorption of low concentration of $\mathrm{NH}_{3}$ by this material can still be used for sensing applications. Although they did not solve the problem of humidity, their study provides hope for sensing of MOF-carbon-based materials.

Selectivity and stability are two major problems to be solved for MOF materials used in gas sensing [148]. Many studies have found that some MOFs will undergo structural decomposition when exposed to $\mathrm{H}_{2} \mathrm{O}$ or toxic gases (such as $\mathrm{H}_{2} \mathrm{~S}, \mathrm{NH}_{3}$, etc.). So, how can we improve the selectivity of gas and solve the problem of poor water stability of MOF?

The use of hydrophobic MOF materials can be a solution to the moisture problem. As mentioned above, ZIF- 8 materials are inherently hydrophobic so that they can be laminated with carbon-based materials. Ellis et al. [188] grew ZIF-8 on the surface of SWCNTs to form p-type semiconductor nanowires. They discussed the influence of the preparation conditions of the composites. According to the literature, the factors affecting the size and morphology of ZIF-8 include the source of zinc precursors, zinc concentration, temperature, and the ratio of zinc to $2 \mathrm{mIM}[189,190]$. At the same time, the addition of oxidized monolayer graphene (ox-SWCNTs) was found that changing the order of precursor addition also changed the final MOF size and the properties of the last complex, so the effect of the order of addition of zinc ions and 2mIM was also discussed. The comparison of the two routes is shown in Figure 17. If zinc ions are added first, it leads to the agglomeration of ox-SWCNTs, when the size of the resulting MOF crystals is larger, and the interface 
between the two in the complex is greatly reduced. In contrast, adding $2 \mathrm{mIM}$ first can prevent the material from agglomeration and a solvation layer ( $2 \mathrm{mIM})$ can be formed around the ox-SWCNTs. The nucleation and growth of ZIF-8 crystals on the sidewalls of ox-SWCNTs were promoted, and the generated ZIF-8 crystals grew along the axial direction and were not large. They used pathway 2 to prepare composites. Then, they synthesized the ethanol gas sensor by using the porosity of ZIF-8, the conductivity of singlewalled carbon nanotubes, the large specific surface area of nanowires, and sensitivity to the change of nanowire spacing. This sensor showed an increase in relative response change to saturated ethanol from $1.5 \%$ to $13.7 \%$ compared to the sensor of SWCNTs. One possible reason for the increase in sensitivity is that with the addition of ethanol, it combines with the pores of the MOF and ZIF- 8 adsorbs the ethanol and expands in volume, so the interface distance between the nanotubes increases, which increases the electron tunneling distance. This report provides a new idea that the morphology of the composite can be changed by changing the experimental conditions, thus affecting its properties.
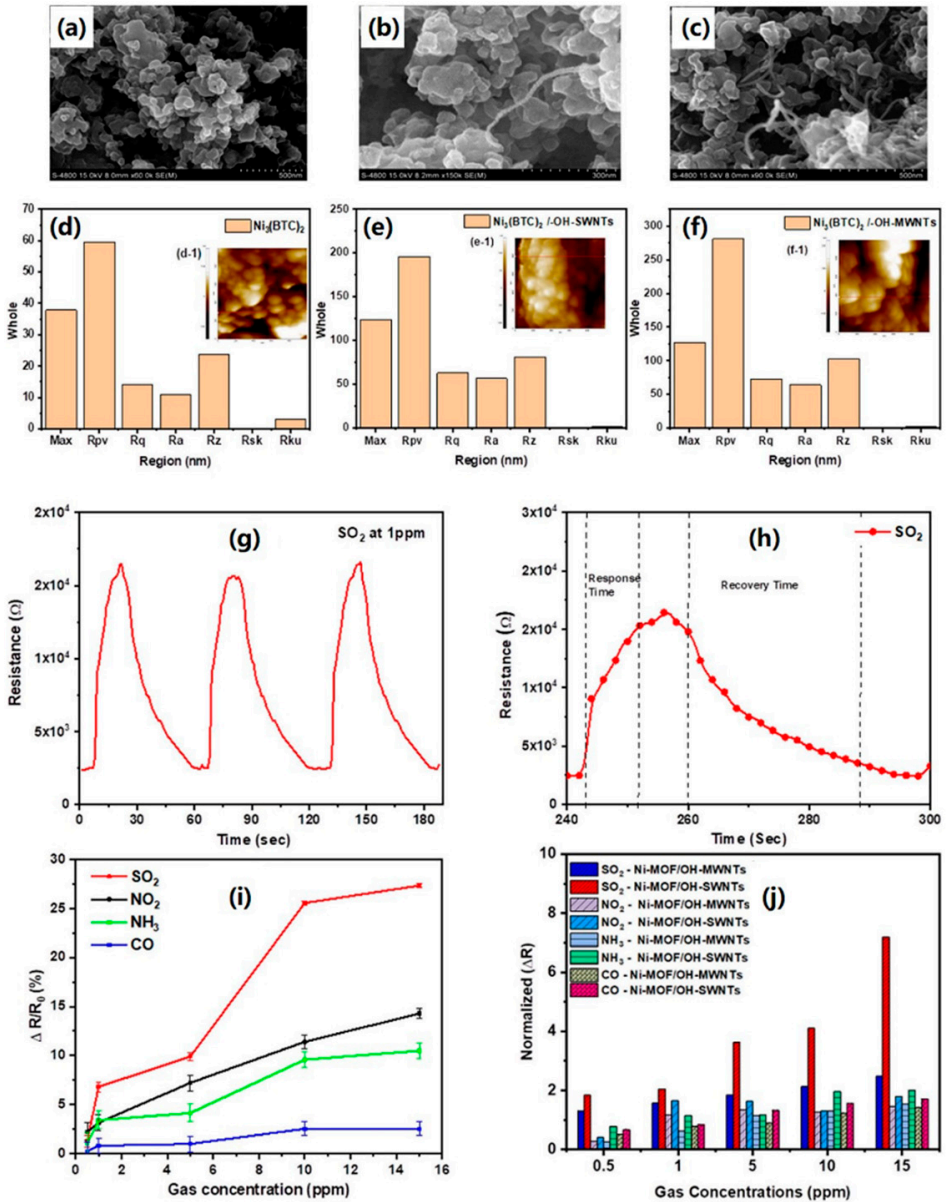

Figure 16. FESEM images and AFM images of $(\mathbf{a}, \mathbf{d})$ pristine Ni-MOF, $(\mathbf{b}, \mathbf{e}) \mathrm{Ni}-\mathrm{MOF} /-\mathrm{OH}-\mathrm{SWNT}$, and $(\mathbf{c}, \mathbf{f}) \mathrm{Ni}-\mathrm{MOF} /-\mathrm{OH}-\mathrm{MWNT}$ materials, respectively. Ni-MOF/-OH-SWNTs sensors: (g) reproducibility performance for $\mathrm{SO}_{2}$ gas at $1 \mathrm{ppm}$; (h) response and recovery time for $\mathrm{SO}_{2}$ analytes; (i) standard error for various gases; (j) comparison with Ni-MOF/-OH-MWNTs sensors for the selectivity of $\mathrm{SO}_{2}, \mathrm{NO}_{2}, \mathrm{NH}_{3}$, and $\mathrm{CO}$. (Reproduced with permission from [128], Copyright 2021 Springer Nature). 


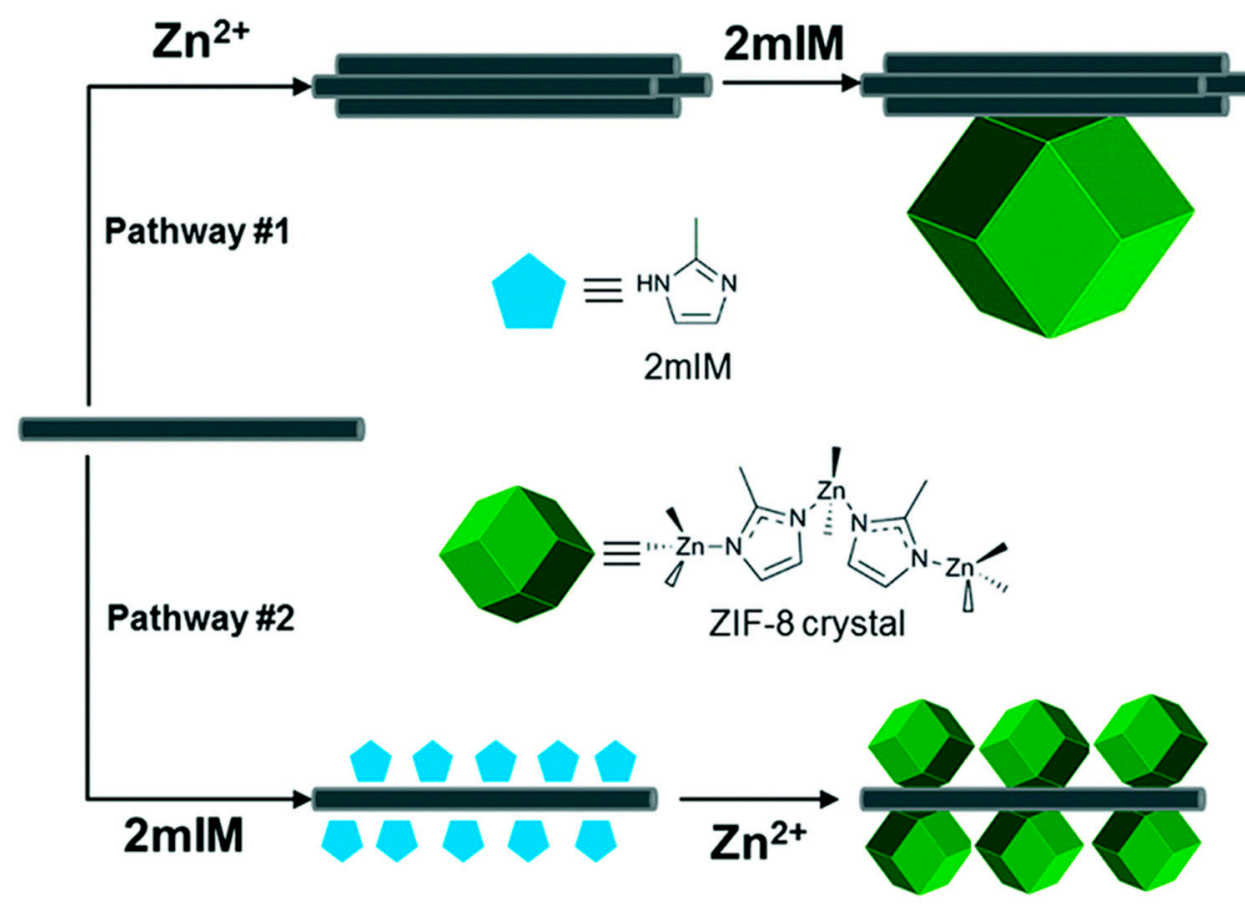

Figure 17. Pathway \#1: Zinc ions are added first. Pathway \#2: $2 \mathrm{mIM}$ is added first. (Reproduced with permission from [188], Copyright 2019 ROYAL SOCIETY OF CHEMISTRY).

The problem can also be solved by introducing a hydrophobic layer. Bhardwaj et al. [133] synthesized a three-phase composite by compounding $\mathrm{Cu}$-BTC coated with $\mathrm{SiO}_{2}$ with graphene and PANI. Cu-BTC plays the role of enlarging the specific surface area and adsorption of $\mathrm{NH}_{3}$. The silica coating on the surface is permeable to gases, thus improving the water stability of the material [191]. Graphene plays the role of ensuring thermal stability and high electrical conductivity. Polyaniline can improve the semiconductor properties of the composites. Its addition to this complex can also avoid the restacking of graphene sheets [192]. The sensor prepared by $\mathrm{SiO}_{2} \mathrm{CuOF}$-graphene-PAni can be repeatedly used many times at room temperature. The detection limit is as low as $0.6 \mathrm{ppm}$. $\mathrm{NH}_{3}$ can be detected rapidly and effectively in the range of 1-100 ppm. Although the recovery time depends on the concentration of $\mathrm{NH}_{3}$, its average response recovery time is between $30 \mathrm{~s}$ and $180 \mathrm{~s}$, which remains relatively fast.

Danny et al. [137] loaded $\mathrm{TiO}_{2}-\mathrm{SnO}_{2} / \mathrm{MWCNT}$ into $\mathrm{Cu}-\mathrm{BTC}$, which formed a hydrophobic layer to improve the humidity stability and improved the stability of the framework, as shown in Figure 18. The composite of MOF with carbon-based materials can increase the specific surface area of the material and improve the selectivity for $\mathrm{NH}_{3}$. As mentioned above, besides this, SMOx added here has the following effects: (i) The oxygen functional groups can replace the water molecules or BTC in octahedral Cu-BTC, thus improving the hydrothermal stability of MOF. (ii) Functionalizing metal oxide nanoparticles onto MWCNTs can improve the porosity and the diffusion rate of gas molecules [193]. (iii) N-P heterojunctions formed by N-type semiconductor $\mathrm{SnO}_{2}$ and p-type semiconductor MWCNTs can provide more charge transfer, so as to improve the sensitivity of the sensor. (iv) The co-existence of $\mathrm{TiO}_{2}$ and $\mathrm{SnO}_{2}$ can reduce the energy barrier of charge transfer and shorten the response time. Therefore, the sensor prepared by this material has better sensing performance for $\mathrm{NH}_{3}$, with improved selectivity for $\mathrm{NH}_{3}$ at room temperature, a shortened response recovery time, and the detection limit can be as low as $0.77 \mathrm{ppm}$. 


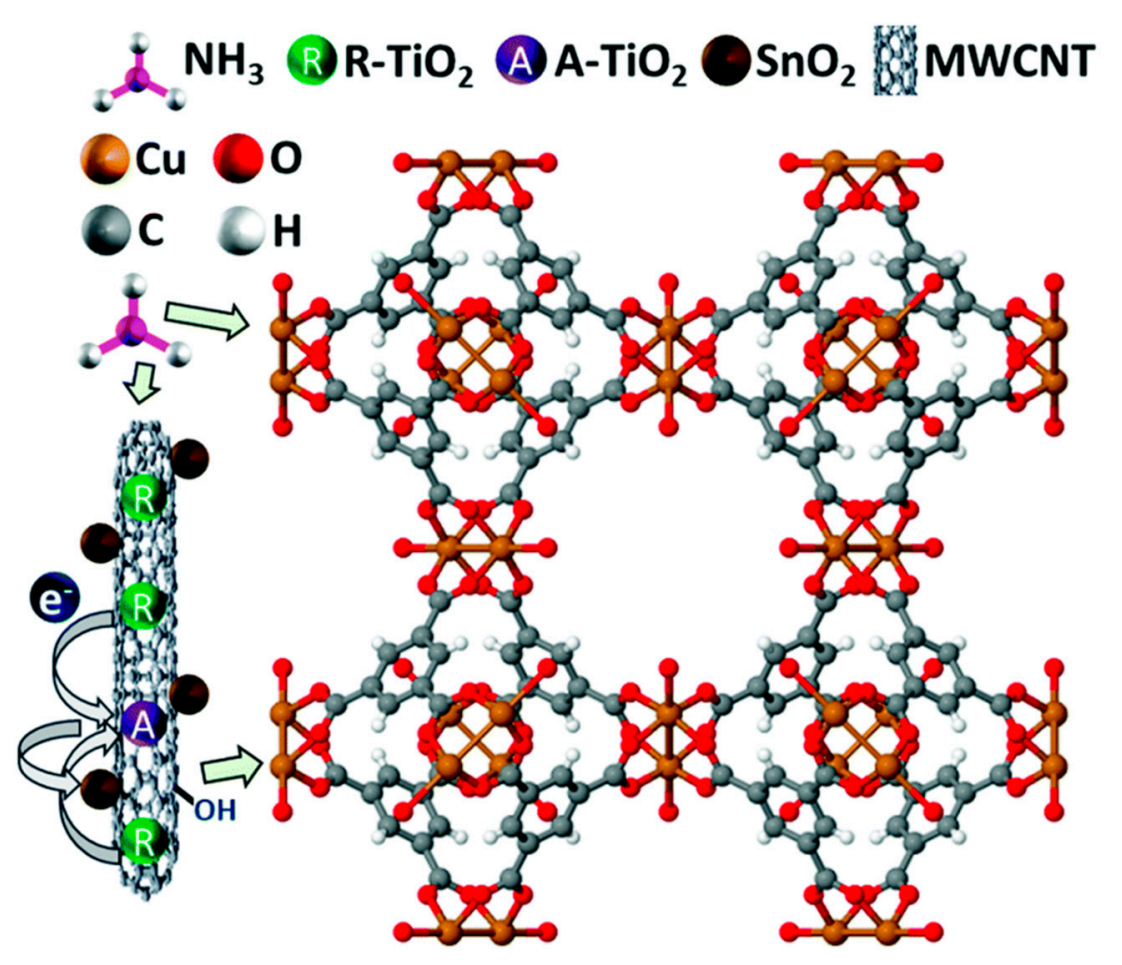

Figure 18. Schematic diagram of $\mathrm{TiO}_{2}-\mathrm{SnO}_{2} / \mathrm{MWCNT}$ doping on $\mathrm{Cu}-\mathrm{BTC}$. (Reproduced with permission from [137], Copyright 2020 ROYAL SOCIETY OF CHEMISTRY).

The stability can also be improved by introducing some substances to suppress the collapse of the structure. Huang et al. [140] found that the addition of GO resulted in the distortion of the MOF-5 structure in MOF/GO composites, and the exposure of MOF to $\mathrm{H}_{2} \mathrm{~S}$ also leads to a partial collapse of the MOF- 5 structure due to the reaction. However, the addition of glucose hinders the deformation effect of GO. This is due to the good matching between GO and glucose, which makes an MOF-5-like porous crystal structure, thus the highest adsorption capacity for $\mathrm{H}_{2} \mathrm{~S}$ can be obtained. The reaction mechanism of the composite material with $\mathrm{H}_{2} \mathrm{~S}$ is shown in Figure $19 . \mathrm{H}_{2} \mathrm{~S}$ can not only react with the $\mathrm{Zn}$ site to form $\mathrm{ZnS}$ but also change the coordination of $\mathrm{Zn}$ with $\mathrm{O}$ in BDC.

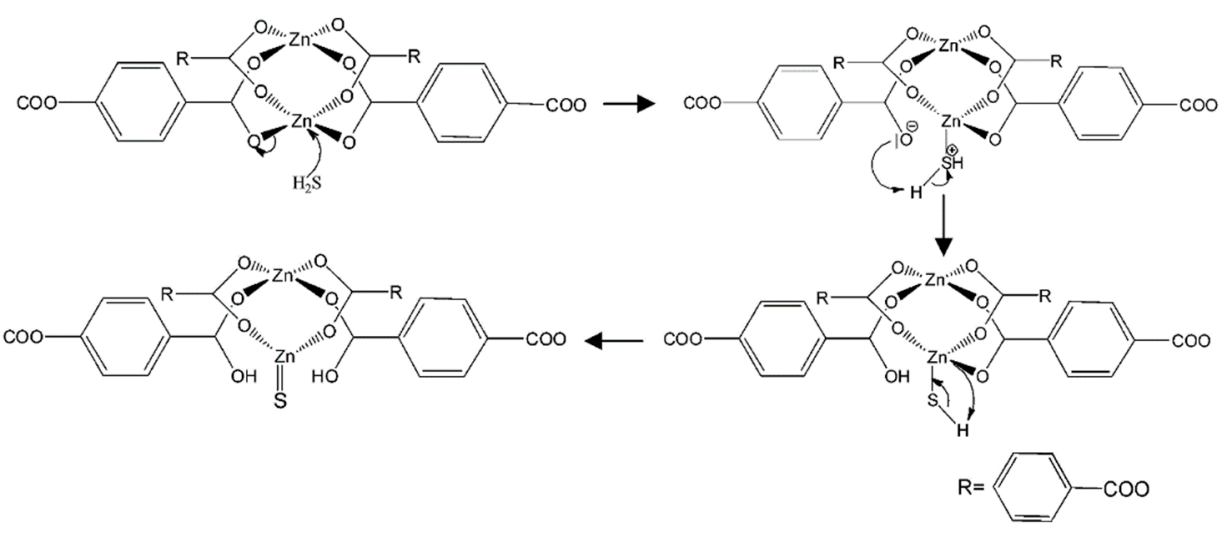

Figure 19. Mechanism of the desulfurization process of MOF-5/GO composites. (Reproduced with permission from [140], Copyright 2012 American Chemical Society).

Yin et al. [132] prepared Cu-BTC/PPy-rGO nanocomposites using hydrothermal and in situ polymerization methods, where PPy-rGO served to improve the electrical conductivity and induce the formation of $\mathrm{Cu}$-BTC particles. $\mathrm{Cu}-\mathrm{BTC}$ is the main $\mathrm{NH}_{3}$ trapping material due to its high accessibility to $\mathrm{NH}_{3}$ and specific surface area. After adding non-porous PPy-rGO, the specific surface area is larger than pure $\mathrm{Cu}-\mathrm{BTC}$, which is 
attributed to the good dispersion of $\mathrm{Cu}-\mathrm{BTC}$ and the formation of pores at the interface between PPy-rGO and MOF. The sensors prepared from this composite showed good detection performance for $\mathrm{NH}_{3}$ at room temperature with a minimum detection limit of $2 \mathrm{ppm}$, a response of $12.4 \%$ for $50 \mathrm{ppm} \mathrm{NH}_{3}$, and response recovery times of $13 \mathrm{~s}$ and $22 \mathrm{~s}$, respectively. Compared with PPy and PPy-rGO sensors, the sensitivity and response speed were improved. Moreover, the sensors made of this composite were not seriously affected by the relative humidity compared to the pure MOF. The authors also investigated the effects of $\mathrm{rGO}$ and PPy-rGO contents on the $\mathrm{NH}_{3}$ response. As shown in Figure 20, both rGO and PPy-rGO contents should not be too high. Otherwise, the response may be degraded due to the lower adsorption energy of gas molecules or the poor decorative properties of MOF. In addition, it can be seen above that $\mathrm{Cu}$-BTC may collapse the structure after exposure to $\mathrm{NH}_{3}$, but after adding PPy-rGO it is found that the $\mathrm{Cu}$-BTC structure maintains the stability, as shown by an XRD test. This composite has potential applications for sensitive detection of $\mathrm{NH}_{3}$ gas due to the practicality of low temperature and the simplicity of preparation.
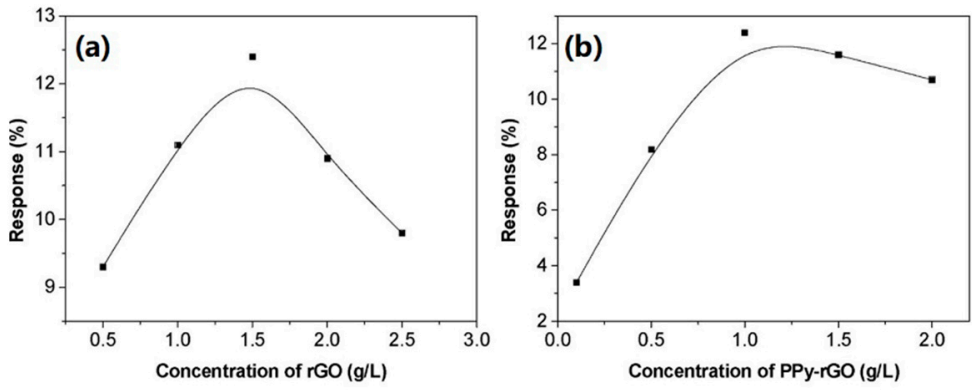

Figure 20. Sensors based on Cu-BTC/PPy-rGO-nanocomposites: (a) $\mathrm{NH}_{3}$ response versus rGO concentration and (b) $\mathrm{NH}_{3}$ response versus PPy-rGO concentration. (Reproduced with permission from [132], Copyright 2018 ELSEVIER).

\subsubsection{Gas Adsorption of MOF-GO Composites}

MOF is a porous material, thus it can be used for gas adsorption. Different MOF materials can adsorb other materials. For example, it was found that materials such as Mg-MOF-74 and MIL-101 (Cr) can adsorb $\mathrm{H}_{2} \mathrm{~S}$ [194]. Various MOF materials such as $\mathrm{Cu}-$ BTC, MOF-5, and Mg-MOF-74 can adsorb $\mathrm{CO}_{2}$, etc. [195-197]. However, due to the weak interaction between MOF walls and the small size of gas molecules, their ample void space has not been fully utilized by gas adsorption [158]. One way to modify MOF to have the best performance in the adsorption process is the synthesis of MOF-containing nanocomposites.

In previous studies, composites combining MOF and graphene oxide or aminated graphene oxide with synergistic effects of porosity and chemical properties have been reported, and these composite treatments have significantly improved the adsorption performance of some small molecules such as $\mathrm{NH}_{3}, \mathrm{H}_{2} \mathrm{~S}, \mathrm{NO}_{2}, \mathrm{H}_{2}$, and $\mathrm{CO}_{2}$ [63,131,198-200].

Dastbaz et al. [172] synthesized Cu-BDC-NH $\mathrm{N}_{2} @ G O$ composites using an acousticchemical synthesis method with the synthesis procedure shown in Figure 21. Using this synthesis method has the following advantages: compared to the conventional solvothermal method, the reaction time and energy consumption are significantly reduced, smaller sized and uniformly distributed MOF crystals can be produced, and the yield is improved. Through a series of experiments as well as analysis, it was found that the adsorption capacity of pure MOF for $\mathrm{H}_{2}$ at a low temperature of $77 \mathrm{k}$ and a pressure of 40 bar is $54 \%$ lower than that of $\mathrm{Cu}-\mathrm{BDC}-\mathrm{NH}_{2} @ \mathrm{GO}$, and the reasons for this may be considered as follows. Firstly, an increase in copper ions was found by EDX analysis in the composites, which indicates an increase in the adsorption sites. Secondly, the GO added to the MOF can introduce functional groups and thus replace the main ligands in the MOF, which can lead to defects in the composite framework. These defects can increase the accessibil- 
ity of the active sites to $\mathrm{H}_{2}$, thus allowing the adsorption capacity of $\mathrm{H}_{2}$ to be increased. Moreover, the water stability of the MOF material is improved by adding GO due to the increased binding strength of the metal-linked bonds. They explored the effect of changing the composite obtained from the experimental conditions on the composite yield. The main variables included the content of GO, the power of sonication, and sonication time. It was found that the optimum content of GO was $0.7 \mathrm{mg} / \mathrm{mL}$. When the optimum value is exceeded, the yield of the composite material decreases because most of the ultrasonic energy is absorbed by the multilayer GO and the energy absorbed by the GO nanosheets as a modifier is not enough to peel off. The optimum ultrasonic power was $600 \mathrm{~W}$, which directly affected the synthesis temperature. When the optimum synthesis temperature is exceeded, the yield decreases due to the increase of metal content in solution. The optimal sonication time is $150 \mathrm{~min}$, after which it will lead to the aggregation of GO nanosheets because of the high energy and also increase the oxidation of metal ions in the solution. The highest yield of this composite was $84 \%$ when all the above three conditions were met optimally.

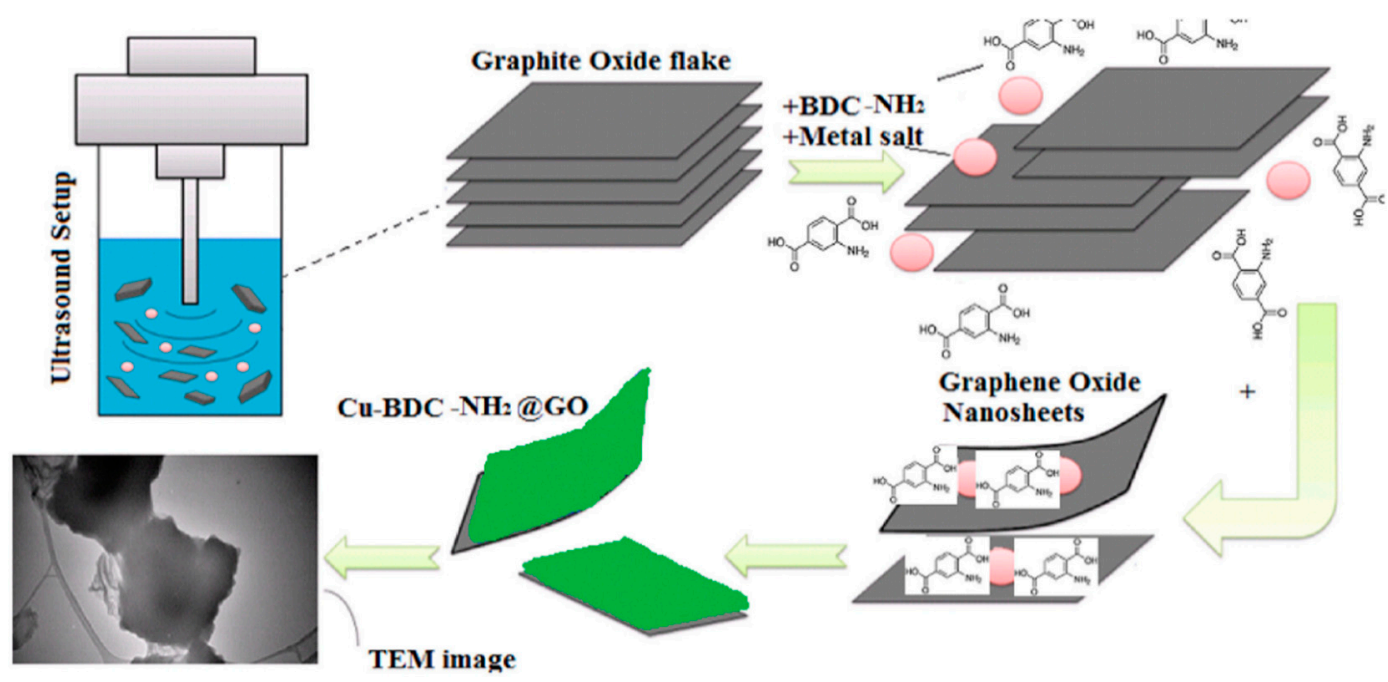

Figure 21. The Synthesis procedure of Cu-BDC-NH ${ }_{2} @ G O$. (Reproduced with permission from [172], Copyright 2019 ELSEVIER).

Ning et al. [201] synthesized a super-crosslinked polyimide-UiO-graphene composite (PI-UiO/GO) by chemical in situ braiding and condensation reaction. As shown in Figure 22, the carbonyl, $\mathrm{N}$ atom, oxygen atom, and - $\mathrm{NH}$ - (primary amine) in the polyimide are the adsorption sites for $\mathrm{CO}_{2}$. The amino group on $\mathrm{UiO}-66-\mathrm{NH}_{2}$ generated by condensation and nucleophilic substitution of $\mathrm{GO}$ is also the adsorption site for $\mathrm{CO}_{2}$. The addition of PI and GO also extends the molecular diffusion/transport channels to the material. The addition of PI and GO also extends the molecular diffusion/transport channels to the micropores of the material, which makes the adsorption capacity of this composite material for $\mathrm{CO}_{2}$ significantly improved. Moreover, the negatively charged $\mathrm{N}$ and $\mathrm{O}$ atoms in PI have strong interactions with the positively charged $\mathrm{C}$ in $\mathrm{CO}_{2}$, thus improving the $\mathrm{CO}_{2} / \mathrm{N}_{2}$ selectivity. They tested this composite material under water-containing conditions as well as acidic and alkaline conditions, and found that it could maintain the morphology of MOF, which indicates that this material has good chemical stability. The heating analysis found that its thermal stability is sufficient to withstand the average flue gas temperature used for $\mathrm{CO}_{2}$ separation. This material also has good recycling ability, which indicates that it is promising to apply this material for selective adsorption of $\mathrm{CO}_{2}$ in flue gas. 


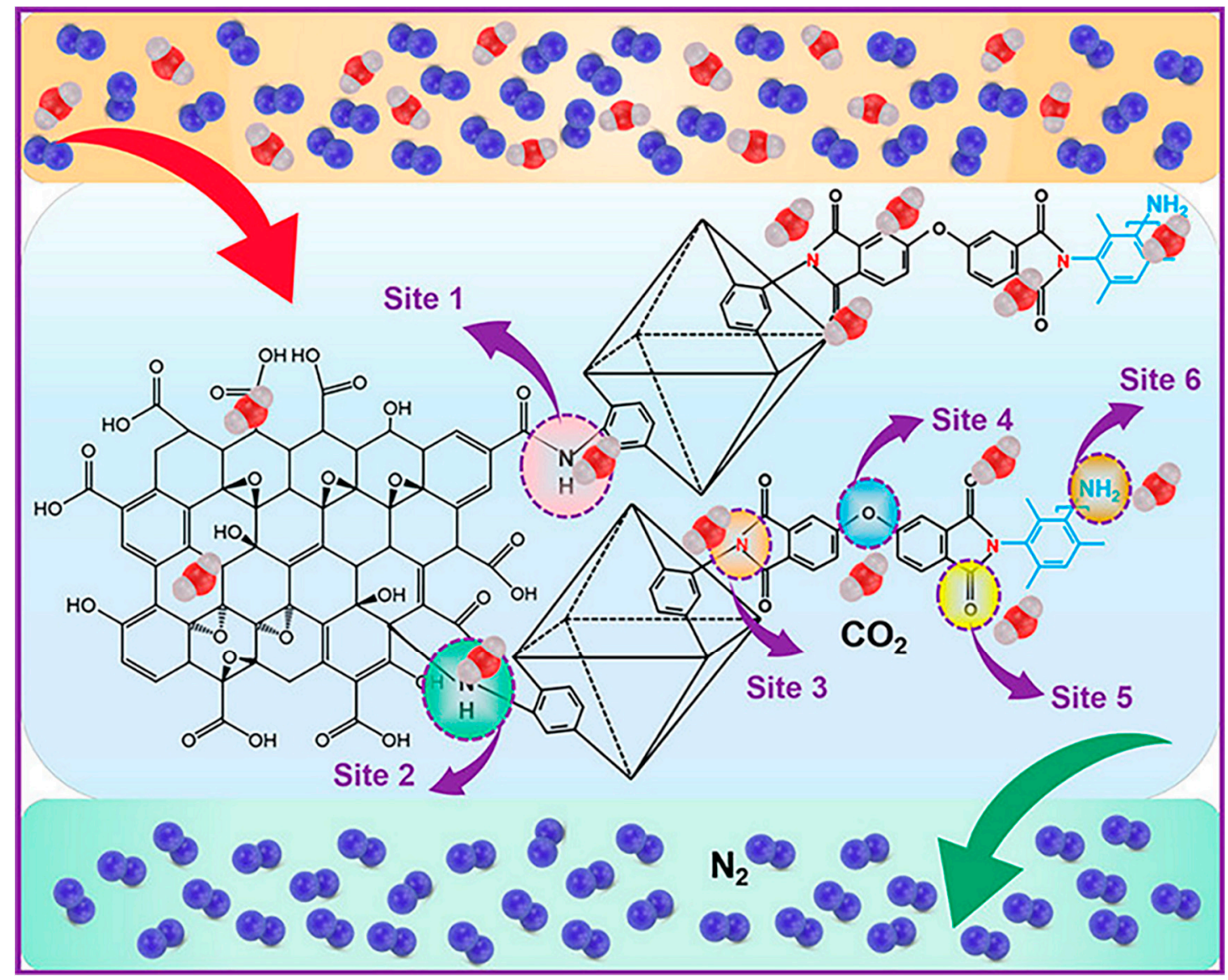

Figure 22. Adsorption sites for $\mathrm{CO}_{2}$ on the structure of PI-UiO/GOs. (Reproduced with permission from [201], Copyright 2021 American Chemical Society).

Some studies have used urea modified GO to obtain aminated graphene oxide and aminated GO. Nitrogen-containing groups, as well as oxygen groups, can be considered as nucleation sites for the growth of MOF. In addition, BTC ligand can interact with the amines existing on the surface of the GO layer [30]. The combination of Cu-BTC with this aminated graphene oxide leads to an improved adsorption performance on $\mathrm{CO}_{2}$, which is summarized in the literature for the following reasons: in the first place, the obtained graphene oxide contains amino groups, which not only provide sites for reaction with BTC in MOF but also chemically interact with acidic gases, thus improving the adsorption performance and selectivity on $\mathrm{CO}_{2}$ [200]. Next, the amino group introduced in GO, as well as residual oxygen groups, lead to a change in the chemical environment of the $\mathrm{Cu}$ sites, resulting in an increase in porosity and defects in the MOF crystals, thus exposing more unsaturated $\mathrm{Cu}$ sites than in the parent MOF. In addition, under dry conditions, $\mathrm{CO}_{2}$ is mainly adsorbed on the composite materials through physical adsorption, and the main adsorption sites is the open $\mathrm{Cu}$ centers, so the increase in $\mathrm{Cu}$ sites is beneficial to $\mathrm{CO}_{2}$ adsorption [202]. The schematic diagram of the adsorption sites of $\mathrm{CO}_{2}$ by the composite is shown in Figure 23. [30]. Lastly, the compounding of the two resulted in the creation of new pores at the interface, thus increasing the porosity, which improved the physical adsorption capacity for $\mathrm{CO}_{2}$. During the synthesis process, with the increase of urea content, the adsorption capacity of $\mathrm{CO}_{2}$ increased [200]. Moreover, it was found that the adsorption process of $\mathrm{CO}_{2}$ by MOF/aminated graphene oxide composites is completely reversible, and its $\mathrm{CO}_{2}$ adsorption capacity can be recovered without heat treatment, indicating that this material can be recycled [203,204]. Reading through the literature we found that most of the current studies on MOF/aminated graphene oxide composites have focused on improving $\mathrm{CO}_{2}$ adsorption and there are very few relevant reports in 
recent years. Nevertheless, we speculate that it is a promising material, which can improve the adsorption and selectivity for acid gases.

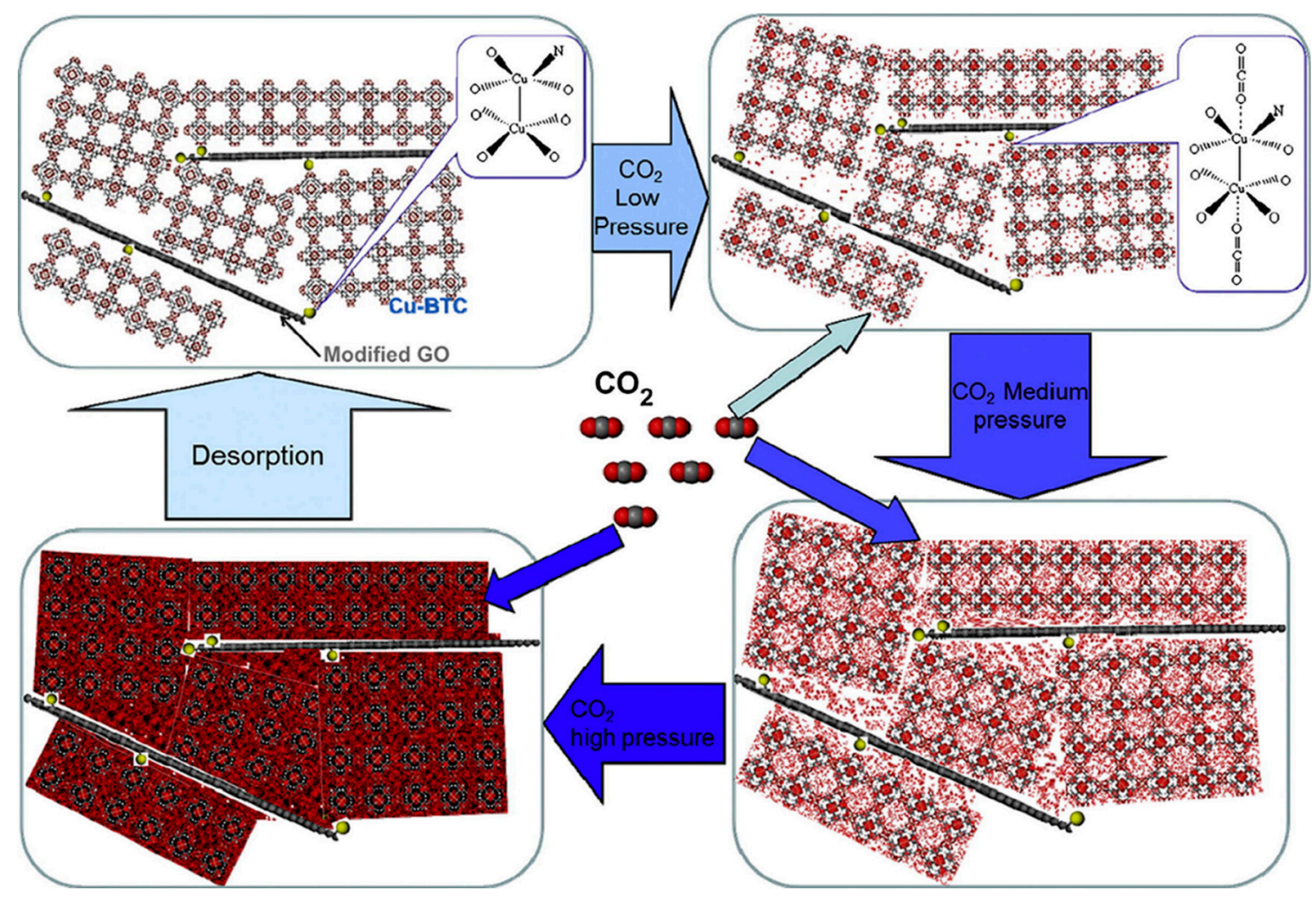

Figure 23. Schematic representation of $\mathrm{CO}_{2}$ adsorption sites on the heterogeneous MOF/aminated GO composites. (Reproduced with permission from [30], Copyright 2015 ELSEVIER).

Levasseur et al. [181] combined GO with HKUST-1 to form composites and investigated their adsorption capacity of $\mathrm{NO}_{2}$ gas under dry and humid conditions. It is found that when compared with pure MOF, the adsorption capacity of composite materials for $\mathrm{NO}_{2}$ under dry conditions is mainly improved by physical adsorption, which is due to the formation of extra pores between MOF and GO. As shown in Figure 24, the change in the composite structure before and after exposure to $\mathrm{NO}_{2}$ under dry conditions indicates that the MOF units are enclosed between the GO layers. After $\mathrm{NO}_{2}$ adsorption, the $\mathrm{MOF}$ undergoes accumulation, thus leading to an increase in the densities. The micropores of the material decrease, but mesopores are generated, while the number of mesopores of pure MOF only increases slightly. In the presence of water vapor, although the stability of the material is significantly improved, the adsorption capacity of $\mathrm{NO}_{2}$ decreases and the corresponding adsorption mechanism is analyzed. Firstly, the adsorption of $\mathrm{NO}_{2}$ by this composite material is divided into physical adsorption and chemisorption. Physical adsorption mainly uses the micropores of MOF and new pores of MOF/GO interface to adsorb $\mathrm{NO}_{2}$, which is not affected by water. The reactive adsorption mainly refers to the adsorption of $\mathrm{NO}_{2}$ by $\mathrm{Cu}$ sites. The adsorption of $\mathrm{NO}_{2}$ will produce a disproportionate reaction, resulting in $\mathrm{NO}$ and nitrate, which will lead to partial destruction of the MOF structure, thereby reducing the porosity. This adsorption is reduced by water, which reacts with the $\mathrm{Cu}$ sites to form complexes, thus resulting in lower chemisorption of $\mathrm{NO}_{2}$ and lower the release of $\mathrm{NO}$, but also in higher stability. In the study, it is proposed to increase the densities of particle and allow the formation of micropores, thus improving the physical adsorption of $\mathrm{NO}_{2}$. 

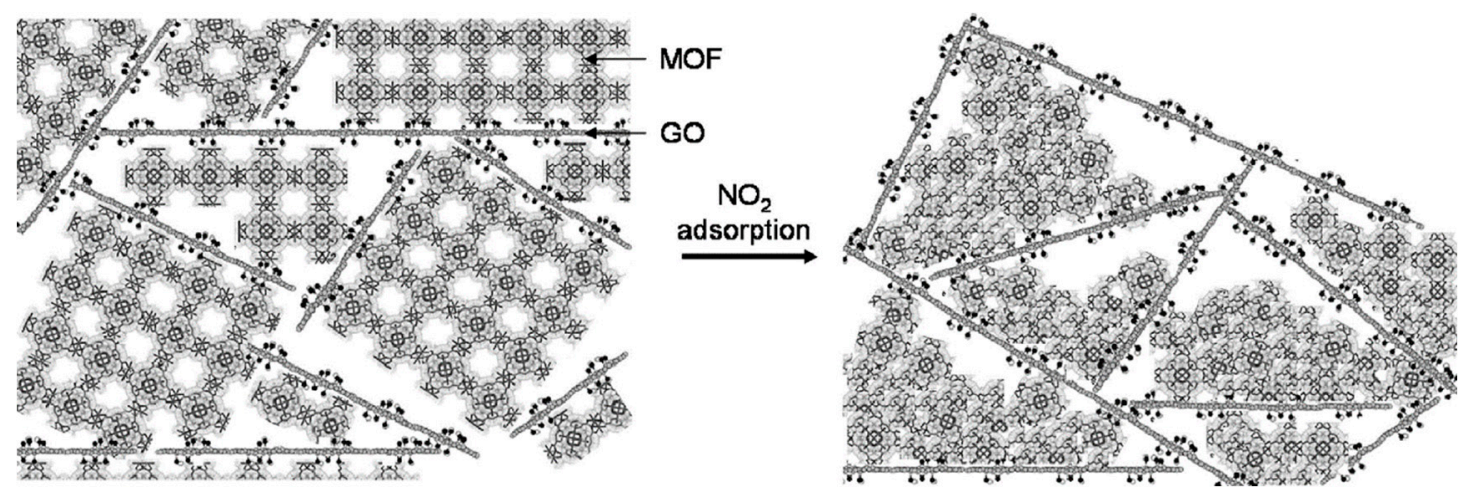

Figure 24. Changes in the texture of the composite materials after exposure to $\mathrm{NO}_{2}$. (Reproduced with permission from [181], Copyright 2010 American Chemical Society).

UiO-66 has relatively good mechanical, thermal, and chemical stability and is, therefore, a suitable MOF material for practical applications [205]. Daraee et al. [206] combined UiO-66 with $\mathrm{GO}$ by hydrothermal method to adsorb $\mathrm{H}_{2} \mathrm{~S}$ gas. XRD results showed that GO had been successfully doped into the MOF material, and the crystal structure of the MOF material can be prevented from being destroyed. However, the amount of GO addition should not be too high. Otherwise, the microcrystals will still be deformed and the high content of GO may cause agglomeration, which is unfavorable for gas adsorption. The thermal stability of UiO-66 can be further enhanced by the addition of GO, which can also improve the adsorption activity of $\mathrm{H}_{2} \mathrm{~S}$ by introducing oxygen-containing functional groups. The specific surface area and pore volume measurements revealed that the surface properties of the complexes containing $3 \mathrm{wt} . \% \mathrm{GO}$ are better than the original MOF as well as the other $\mathrm{GO}$ content of $\mathrm{ZMCO}$, which facilitates the adsorption of $\mathrm{H}_{2} \mathrm{~S}$. The reasons are summarized as follows. First, the new pores are generated due to the partial filling of the mesopores at the interface between the two materials and then porous MOF is grown on the surface of mesopores. In addition, microporous channels can be embedded in the mesoporous channels of composite materials and the number of micropores is reduced, resulting in new mesopores. The best adsorption capacity of ZMCO-3 for $\mathrm{H}_{2} \mathrm{~S}$ was found to be $8.7 \mathrm{mmol} \mathrm{S} / \mathrm{g}$ at $30^{\circ} \mathrm{C}$. The decrease in adsorption capacity after warming up to $50{ }^{\circ} \mathrm{C}$ indicates that physical adsorption may be the main form of adsorption. However, compared with pure uio-66, the decrease of adsorption capacity was slowed down due to the improvement of chemisorption. Figure 25 explains the mechanism of $\mathrm{H}_{2} \mathrm{~S}$ adsorption on ZMCO-3. Subsequently, the regeneration experiments were carried out, and it was found that this composite material was very renewable, which showed its effectiveness as an adsorbent.

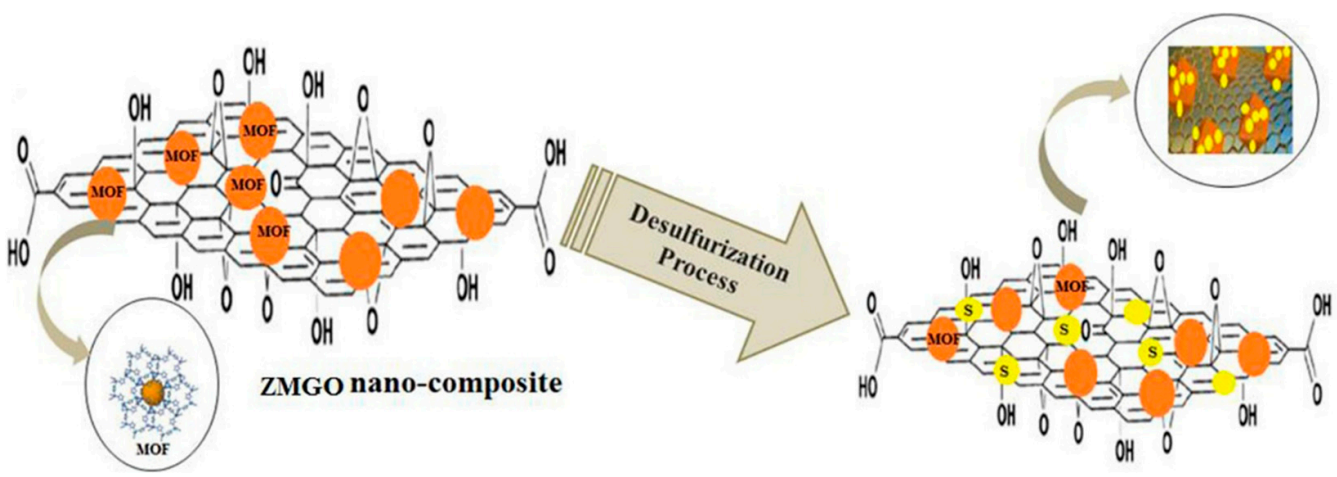

Figure 25. Possible adsorption mechanism of $\mathrm{H}_{2} \mathrm{~S}$ by ZMGO-3 nanocomposites. (Reproduced with permission from [206], Copyright 2020 ELSEVIER). 
At present, there are very many studies on gas adsorption using MOF-carbon-based materials, especially MOF-GO composites. There have been reviews for systematic summaries $[63,173,199]$. Here, we give some examples for analysis. How these adsorbable gases such as $\mathrm{H}_{2} \mathrm{~S}, \mathrm{SO}_{2}, \mathrm{H}_{2}, \mathrm{CO}_{2}$, and $\mathrm{NO}_{2}$ can be detected is a possible future research direction. The research on the adsorption of these gases can provide some insight and ideas for their application in gas sensing.

\subsubsection{Future Developments}

In summary, some MOF/carbon-based materials have been investigated for gas sensing/adsorption, and their applications are still progressing and evolving. However, there are still some issues that need to be addressed. As mentioned above, this limits the types of MOFs since they must have a specific geometry to grow properly on GO. We believe that other MOFs may also produce composite materials with tremendous potential, which is a promising research direction. In addition, although there are more studies on gas adsorption using $\mathrm{MOF} /$ carbon-based materials, there are fewer reports on gas sensing. For those physical adsorptions, we can consider how to improve the reversible adsorption of gases. For those chemisorbed gases, we can consider using Raman spectroscopy to detect the presence of gases by detecting the formation of chemical bonds. In conclusion, the research of MOF/carbon-based materials in gas sensing is still developing.

\section{MOFs-Polymer Composites}

\subsection{Advantages and Disadvantages of Polymers as Gas Sensing Materials}

A survey of the literature shows that besides SMOx and carbon-based materials, polymers can also be used as a material for preparing gas sensors. [18]. Conductive polymers are a kind of attractive sensing material due to good electrical conductivity, magnetic properties, and optical properties. Meanwhile, the mechanical properties and processing advantages of the polymer itself are not affected [207]. The main advantage of conducting polymer-based sensors over metal oxide-based sensors is that they can operate at room temperature, which implies the low energy consumption and safety of such devices [208]. Additionally, conducting polymers have a fully reversible doping/de-doping process, a feature that when combined with room temperature conductivity can be used in highly selective and reproducible gas sensors. Organic conducting polymers can be used as coatings or encapsulants on electrode surfaces to fabricate gas sensors. Commonly used conducting polymers include polypyrrole (PPy) [209-212], polythiophene (PTh) [213,214], poly (3,4-ethylenedioxythiophene) (PEDOT) [215-217], and polyaniline (PANI) [218,219]. Among them, PPy and polyaniline are more studied. Gas sensors based on conductive polymers have been prepared in previous studies and they have shown very encouraging results in gas response. According to the literature, $\mathrm{PPy}$ can be used for sensing $\mathrm{NH}_{3}, \mathrm{H}_{2}$, nitrogen dioxide, carbon monoxide, hydrogen chloride, methanol, and acetone, among which $\mathrm{NH}_{3}$ is the most studied [208]. PANI can detect $\mathrm{NH}_{3}$, carbon monoxide, nitrogen dioxide, $\mathrm{H}_{2}, \mathrm{H}_{2} \mathrm{~S}$, ethanol, xylene, and triethylamine. Additionally, $\mathrm{NH}_{3}$ is the most studied, although polyaniline sensors show significantly better sensing performance for carbon monoxide and nitrogen dioxide gases [208]. Polythiophene (PTh) can detect a variety of gases, including $\mathrm{NH}_{3}, \mathrm{NO}_{2}, \mathrm{H}_{2} \mathrm{~S}$, acetone, chloroform, and toluene [208]. PEDOT sensors can detect $\mathrm{NH}_{3}, \mathrm{NO}, \mathrm{NO}_{2}$, methanol, and ethanol, but the overall response is relatively lower than that of PPy, PANI, and PTh-based sensors. Only PEDOT nanowires at $80^{\circ} \mathrm{C}$ have a high response of 6.67 for nitric oxide (NO) gas, and not for other gases [208], which can be exploited to improve the selectivity of NO. In the case of non-conductive polymers, they can be used to immobilize specific receptor reagents on the sensor device [18]. Conductive polymers show promising applications for sensing gases with acid-base or oxidizing properties. Other polymers with reactive functional groups and SPEs (e.g., PVC, PMMA, etc.) can also be used to detect such gases [18]. However, the presence of rigid molecular chains with $\Pi$-conjugated structure in conducting polymers makes both chemically synthesized conducting polymer powders and electrochemically synthesized films 
have the disadvantages of poor mechanical ductility and difficult processing. In addition to the poor selectivity of the gas sensors prepared from these materials, there are various methods to improve the processability of conducting polymers, such as the preparation of soluble conducting polymer derivatives [220], the synthesis of polymer films by the selfassembly and template method [221], and the preparation of composite materials, in which inorganic phase and polymer are often compounded [222,223]. Relatively few reports have used specific data to illustrate the gas-sensitive properties of MOFs-polymer composites (Table 3). The processability of the material can be improved to a certain extent, and their sensitivity and selectivity can be changed by forming composite materials.

Table 3. Gas sensing properties of some gas sensors made of MOF and polymer composite materials.

\begin{tabular}{|c|c|c|c|c|c|c|c|}
\hline Material & $\begin{array}{c}\text { Target Gas, } \\
\text { Concentration (ppm) }\end{array}$ & $\begin{array}{l}\text { Topt } \\
\left({ }^{\circ} \mathrm{C}\right)\end{array}$ & Response & $\begin{array}{c}\text { Response/Recovery } \\
\text { Time (s) }\end{array}$ & BET $\left(\mathrm{m}^{2} / \mathrm{g}\right)$ & $\begin{array}{l}\text { Detection } \\
\text { Limit }\end{array}$ & Ref. \\
\hline $\begin{array}{l}\text { MIL-101(Cr) } \supset \\
\text { PEDOT }(45)\end{array}$ & $\begin{array}{c}\mathrm{SO}_{2} \\
200 \mathrm{ppb}\end{array}$ & RT & $0.9 \%$ & $<30 /-$ & 1038 & $60 \mathrm{ppb}$ & {$[61]$} \\
\hline $\begin{array}{l}\text { Cu-BTC/ } \\
\text { PPy-rGO }\end{array}$ & $\begin{array}{c}\mathrm{NH}_{3} \\
50 \mathrm{ppm}\end{array}$ & 25 & $12.4 \%$ & $13 / 22$ & 1861 & $2 \mathrm{ppm}$ & [132] \\
\hline $\begin{array}{c}\mathrm{SiO}_{2} \mathrm{CuOF}- \\
\text { graphene-PAni }\end{array}$ & $\begin{array}{c}\mathrm{NH}_{3} \\
40 \mathrm{ppm}\end{array}$ & - & - & $30 / 180$ & 756 & $0.6 \mathrm{ppm}$ & [133] \\
\hline $\begin{array}{c}{\left[\mathrm{Ni}(\mathrm{TPyP})\left(\mathrm{TiF}_{6}\right)\right] \mathrm{n}} \\
\text { MOF-A/ } \\
\text { PDVT-10 }\end{array}$ & $\begin{array}{c}\mathrm{NO}_{2} \\
25 \mathrm{ppb}\end{array}$ & 20 & $\sim 18 \%$ & $43 / 438$ & - & $8.25 \mathrm{ppb}$ & [224] \\
\hline $\begin{array}{c}\text { Matrimid- } \mathrm{NH}_{2-} \\
\text { MIL-53(Al) } \\
(20 \%)\end{array}$ & methanol 20,000 ppm & 28 & $\sim 8 \%$ & - & - & - & [225] \\
\hline
\end{tabular}

The polymerization of MOF with polymers can show many advantages. MOF has a large specific surface area. When it is added into polymer matrix, there is a very strong interface interaction between MOF and polymer, which leads to a great improvement in the performance of the polymer. When the polymer is used as a carrier, it can not only prevent agglomeration of MOF particles, but also control the size and distribution of the particles, and enhance/maintain the stability of MOF including chemical stability, thermal stability, and mechanical stability [226]. It is known that many MOFs have poor water stability and they break the coordination bonds between the metal and the ligand, which caused the framework to be decomposed. The addition of polymers can improve the water stability and one method is to introduce polymers into the MOF pores to strengthen the coordination bonds between the metal and the ligand $[227,228]$. Additionally, it is known that MOF-5 is a hydrophilic MOF and that water molecules break its coordination bonds [229]. Ding et al. [227] used in situ polymerization of aromatic acetylenes in the pores of MOF-5 and the polymer PN separated the micropores of MOF-5, resulting in the formation of ultra-micropores, as shown in Figure 26b. Additionally, $\mathrm{CO}_{2}$ on the surface and edges of PN can reduce water adsorption. As shown in Figure 26a, PN can effectively prevent a water attack on the coordination bonds, so the water stability and hydrophobic properties of PN@MOF-5 are significantly improved. Moreover, the aromatic ring contained in PN has enough exposed surface and edge and the pore size of MOF is reduced, which is beneficial to the adsorption of $\mathrm{CO}_{2}$, so the adsorption capacity of the complex for $\mathrm{CO}_{2}$ is also increased. 
(a)

(b)
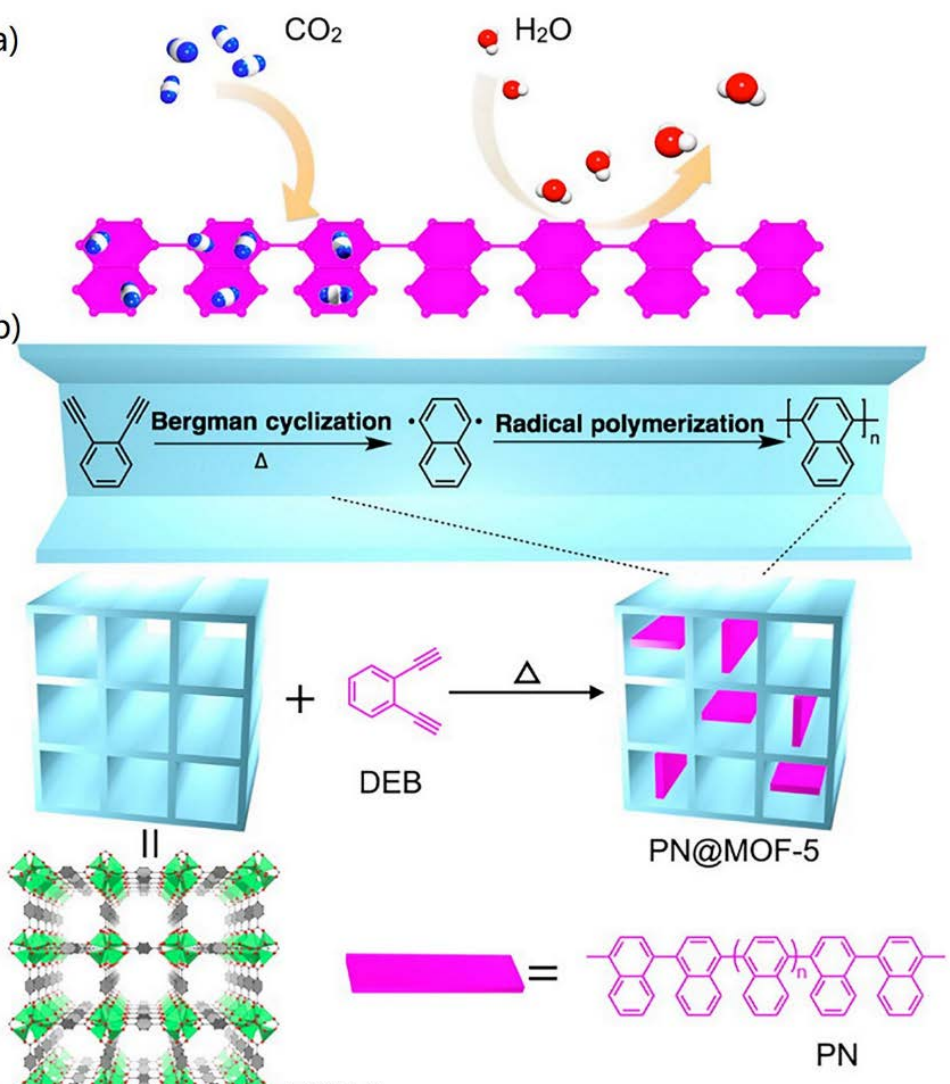

Figure 26. (a) Competitive adsorption of $\mathrm{CO}_{2}$ against $\mathrm{H}_{2} \mathrm{O}$ at the surface and edge of PN; (b) polymerization of DEB in MOFs. (Reproduced with permission from [227], Copyright 2016 American Chemical Society).

The second method is to encapsulate the hydrophilic MOF into a hydrophobic polymer so as to inhibit the diffusion of water into the MOF pores. As we have mentioned before, HKUST-1 is an MOF material that is very sensitive to water. It will undergo structural decomposition under the influence of water [230], but at the same time it can store $\mathrm{CH}_{4}$ well at room temperature [231]. Therefore, Carné-Sánchez et al. [232] synthesized HKUST-1 @ PS composite by the spray-drying (SD) synthesis method. The waterproof PS effectively encapsulates the MOF, so this composite material can reduce the attack of water on MOF material without reducing the adsorption capacity. In a word, the introduction of hydrophobic polymers on the inner and outer surfaces of MOF can enhance the water stability without significantly reducing the specific surface area and properties of the material. In addition, various studies have shown that direct insertion of polymers into the pores of MOF stabilizes the pores, thereby improving mechanical stability [233]. $\mathrm{XRD}$ analysis shows that the composite material retains the porous structure of the original MOF crystals after adding the polymer [234-236]. Factors affecting the thermal stability include the metal-ligand bond strength and the number of attachment sites at a given MOF node [226]. Yan et al. [237] found a slight increase in thermal stability after PEI incorporation into MOF compared to the pristine amine-MIL-101(Cr), which was attributed to the interaction between the amine group in PEI and the open metal sites in MOF. In addition, other studies have also shown that the addition of a polymer could maintain or improve thermal stability $[237,238]$.

There are other advantages of MOF-polymer composites for gas sensing, but they are not necessarily representative due to limited literature reports, and we will describe them accordingly based on specific examples. 


\subsection{Comparison of Synthesis Methods of MOF-Polymer Composites and Their Advantages} and Disadvantages

As shown in Figure 27, Yang et al. [226] summarized five commonly used methods for synthesizing MOF-polymer composites: (a) in situ polymerization reactions; (b) MOF construction using polymeric ligands MOF method; (c) post-synthetic covalent grafting of polymers onto reactive ligands, (d) the post-synthetic introduction of preformed polymers, and (e) MOF self-assembly around polymers.

At present, the most commonly used method in gas sensing applications is in situ polymerization. The method is mainly used for polymerization of polymer monomers in MOF pores. It has many advantages, including mild reaction conditions, a wide range of applicable frameworks, and ease of preparation of porous polymers at the expense of MOF derivatives [228,239,240]. Mashao et al. [241] combined polyaniline (PANI) with CoZIF by in situ oxidative polymerization to form PANI-CoZIF composites. SEM images of the complexes are shown in Figure 27e, where spherical CoZIF grafting on the polymer can be seen. The study investigated the sensing of $\mathrm{H}_{2}$ based on chrono-current analysis and found that the sensors prepared from the composite have a faster current response and good sensitivity to $\mathrm{H}_{2}$ when $\mathrm{H}_{2} \mathrm{SO}_{4}$ is present as the hydrogen source, proving that the material can be used for electrochemical hydrogen sensing. However, the current method has some shortcomings. Initially, it may lead to the heterogeneous nature of the resulting composite due to the inability to control the uniform diffusion of polymer monomers [242]. Furthermore, the polymerization reaction may occur on the MOF surface rather than inside the pores, which can lead to pore blockage. However, both problems can be solved, as Sun et al. [243] found that MOFs with catalytically active open metal sites, their metal sites can contribute to the homogeneous distribution of the polymer through catalytic polymerization. By improving the synthesis method, the polymerization of monomer on the surface of MOF can be inhibited. They proposed a two-solvent method with the scheme shown in Figure 28. This method effectively introduces PDA into the pores of MOF so as to polymerize in the pores, but the loading of PDA should not be too high. Otherwise, part of PDA may polymerize on the surface [244].

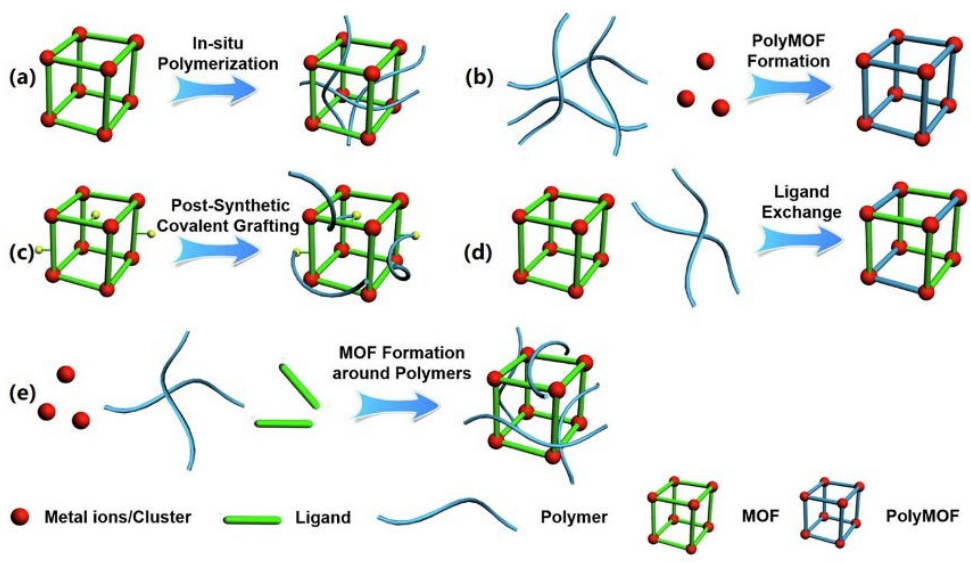

Figure 27. Schematic diagram of the five methods commonly used to prepare MOF composites. (Reproduced with permission from [226], Copyright 2021 ELSEVIER).

In addition to in situ polymerization, there are also studies on the use of prefabricated polymer ligands directly incorporated into the MOF framework during crystallization, which is referred to as "polyMOFs" [70]. This method is considered to be a unique and promising method for synthesizing MOF composites, which not only controls the shape, size, and colloidal stability of MOF by exploiting the chemical stability and processability, but also by controlling the loading, structure, and composition of supported polymer.

In addition, we have seen a method named "wet impregnation" in the literature related to $\mathrm{CO}_{2}$ adsorption, which is presumed to be a "Post-synthetic introduction of preformed polymers" method since the polymers are first synthesized and then introduced 
into the MOF. Compared with in situ polymerization, this method has the following advantages. The loading of the polymer can be controlled. Furthermore, the properties of the MOF-polymer composite can be more easily inferred because the properties of the polymer itself are known. For example, if the amine group in PEI is known to interact with $\mathrm{CO}_{2}$, then the $\mathrm{CO}_{2}$ adsorption of the composite can be improved by compounding PEI into MOF $[235,236]$. Of course, there are some problems with this method, such as that the addition of polymers may block the pores of MOF resulting in the decrease of specific surface area, which is not conducive to the adsorption of gas molecules, and it is difficult to ensure uniformity of polymer distribution. Moreover, some highly branched polymers may be challenging to enter the pores of MOF creating obstacles for the preparation of complexes [226].

\subsection{Development of MOF-Polymer Gas-Sensitive Sensing Materials}

\subsubsection{Blended Films Formed by MOF and Polymers}

Polymer membranes are widely used for gas separation because of their simple manufacture and low cost $[245,246]$. However, the permeability and selectivity of most polymer membranes are contradictory, so it is difficult to obtain these two properties at the same time $[247,248]$. In order to solve the problem of selectivity and permeability, mixing MOF with polymers for gas sensing has also been reported in recent years. For example, Yuvaraja et al. [224] coated a porous N-type porphyrin-based MOF film on an organic field-effect transistor device containing only a p-type PDVT-10 layer. PDVT-10 interacts with $\mathrm{NO}_{2}$ and provides electrons for $\mathrm{NO}_{2}$. The porphyrin-based MOF prepared in this experiment has a high affinity for $\mathrm{NO}_{2}$, so it has a high selectivity. The two form a heterogeneous structure. $\mathrm{NO}_{2}$ is an electrophile and absorbs electrons from the polymer, creating holes in the polymer. At the same time, the MOF material also attracts electrons in the polymer due to its high electron affinity, which increases the holes in PDVT-10, thus improving the sensitivity to $\mathrm{NO}_{2}$. The interaction between $\mathrm{NO}_{2}$ and the heterogeneous structure is shown in Figure 29. By mixing the two, the sensitivity to $\mathrm{NO}_{2}$ is improved by $700 \%$, the detection limit is as low as $8.25 \mathrm{ppb}$, and the water stability is better than that of the original device. This report innovatively puts forward the strategy of using MOF to form heterojunctions with polymers, which may be a new development direction.

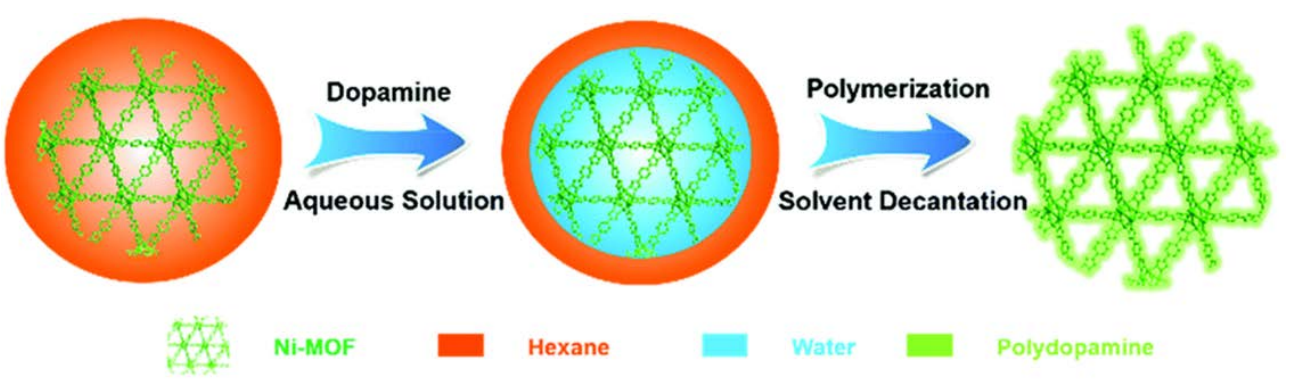

Figure 28. Synthesis process of Ni-MOF/PDA composite [244], (Copyright 2018 ROYAL SOCIETY OF CHEMISTRY).

However, it is clear from the literature that the preparation of mixed matrix membranes (MMMs) by dispersing MOFs in polymeric matrices is relatively more reported in sensing or adsorption studies [249-251]. Among the various porous fillers, metal-organic backbones (MOFs) are a better filler for fabricating MMMs because their crystal structure is highly porous. Compared with other fillers, the organic ligands provide more desired interactions with the surrounding polymer [252]. Moreover, the shape and size of the pores, as well as the chemical functionality, can be highly modulated by proper alteration of the metal node-organic ligand pairs [253]. Furthermore, due to their selectivity with enhanced gas permeability the problems of polymeric membranes can be overcome [254]. In addition, because of the flexibility and easy processability of polymers the problem of difficult preparation of MOF membranes and the limited processability can also be solved [52]. 
Zhang et al. [52] reported a fluorescent sensor that can detect $\mathrm{H}_{2} \mathrm{~S}$ in water, and they mixed different amounts of Al-MIL-53- $\mathrm{NO}_{2}$ into PVDF. The $-\mathrm{NO}_{2}$ groups in $\mathrm{MOF}$ can selectively detect $\mathrm{H}_{2} \mathrm{~S}$ by reducing it to amine groups, as shown in Figure 30a. It can be seen that the active detection material here is the MOF material. The polymer's role is mainly as a substrate to provide flexibility and processability. As MOF material can increase the adsorption sites, with the increase of MOF loading, the response of $\mathrm{H}_{2} \mathrm{~S}$ (expressed as fluorescence intensity) increases significantly, as shown in Figure 30b.

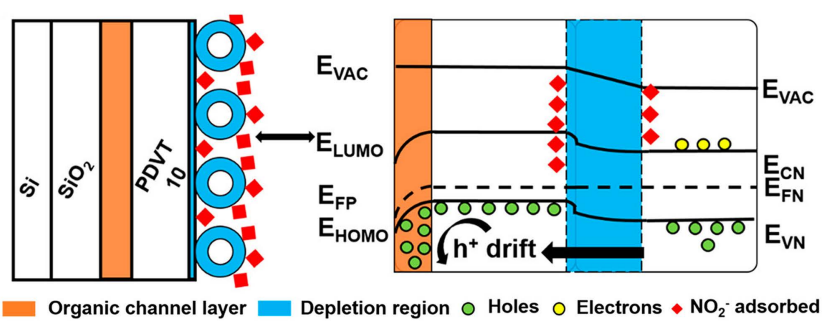

Figure 29. Interaction between $\mathrm{NO}_{2}$ and the MOF-A/PDVT-10 heterostructures. (Reproduced with permission from [224], Copyright 2020 American Chemical Society).

Although MMMs have many advantages, they also have some problems. The problems are that there may be non-selective voids at the interface between MOF and polymer, especially those MMMs that use micron-sized MOFs. These voids can lead to the transport of other interfering gases; thus, the membrane is less selective for the target gas. The reason for these interfacial defects is that the compatibility between MOF and polymer is general and produces a low interfacial adhesion [255-257]. For these problems of MMMs, the use of composite materials can be considered to solve them.

Regarding the application of MOF-polymer composites in gas sensing, in the limited literature available, the author divided it into two types according to the matrix and dopant. One is doping MOF in the polymer (including composite film) and the other is doping polymer in MOF (including polymerization in holes), and we look at the composites prepared in these two ways below.

\subsubsection{Application of Composites Prepared by Doping MOF in Polymers for Gas Sensing}

One strategy was the doping of MOF in polymers and Sachdeva et al. $[225,258]$ used Matrimid 5218 as a substrate to prepare thin films of nano $\mathrm{NH}_{2}-\mathrm{MIL}-53$ (Al) dispersed in polymers for use on capacitive sensor devices. Matrimid 5218 has high thermal and mechanical stability, while the selected MOF has good compatibility [259]. It reduces the detection limit of the capacitive gas sensor fabricated by the composite membrane for methanol gas because of $\mathrm{NH}_{2}-\mathrm{MIL}-53$ (Al) affinity for methanol [260]. Subsequently, a cross-sensitivity analysis was performed to expose the $20 \mathrm{wt}$.\% MOF-Matrimid film device to 20,000 ppm of water, methanol, ethanol, and 2-propanol. The results are shown in Figure 31a. It was found that the change in capacitive response after exposure to ethanol and 2-propanol was negligible, and the response of methanol was not affected due to the large molecular size and hindered diffusion, but when exposed to water and methanol, the capacitance changes faster. In order to investigate whether water has an effect on the methanol response and examine the impact of MOF loading on the sensing performance, they continued their experiments and found that the response of this sensor device to methanol is greatest when the polymer contains $40 \mathrm{wt} . \% \mathrm{NH}_{2}-\mathrm{MIL}-53$ (Al), as shown in Figure 31b. When the loading amount is less than $40 \mathrm{wt} . \%$, the sensitivity of methanol changes with the increase of MOF content, and the adsorption sites increases with the increase of MOF content, thus the response increases. When the load exceeds $40 \%$, the hardening of the polymer occurs at the MOF-polymer interface, which can lead to a brittle or even cracked coating, so its response decreases [261,262]. To explore the effect of water on methanol, the water concentration was kept at $5000 \mathrm{ppm}$ at $28^{\circ} \mathrm{C}$, and the concentration of methanol was varied to observe the capacitance change. It can 
be seen from Figure 31c,d that water has little interference with the detection of methanol response. Similarly, it is found that methanol has little effect on water, which indicates that the influence of the device on water and methanol is independent. This is the first reported $\mathrm{MOF}$-polymer composite that can be used for capacitive sensor applications at room temperature.
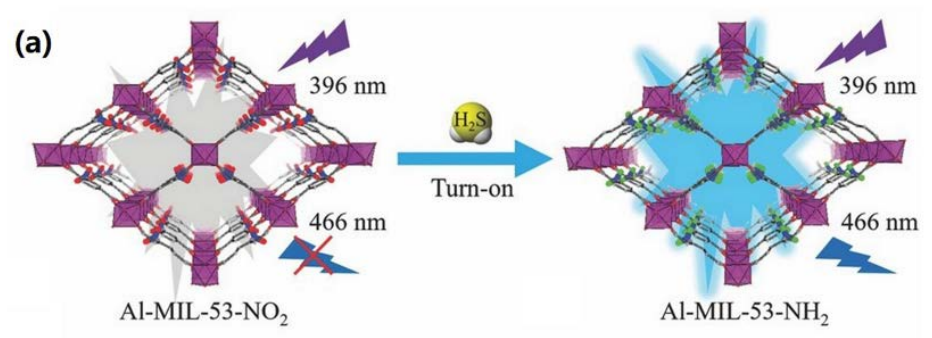

(b)

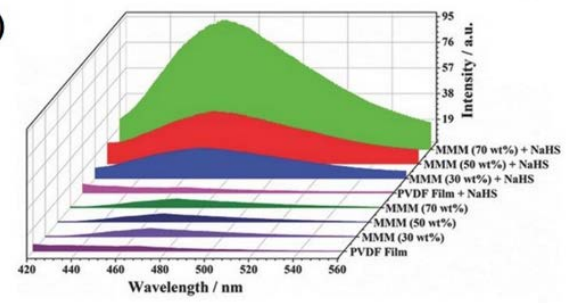

Figure 30. (a) Illustration of nitro $\left(-\mathrm{NO}_{2}\right)$-functionalized $\mathrm{MOF}$ as a fluorescence-based turn-on probe for $\mathrm{H}_{2} \mathrm{~S}$. (b) Emission spectra of PVDF membranes; Al-MIL-53-NO $\mathrm{NO}_{2}$ MMs with different MOF contents before and after treatment with NaHS. (Reproduced with permission from [52], Copyright 2016 WILEY).
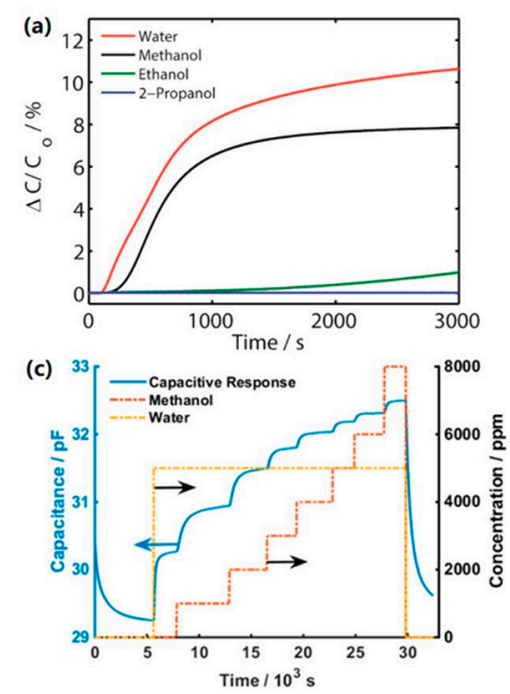

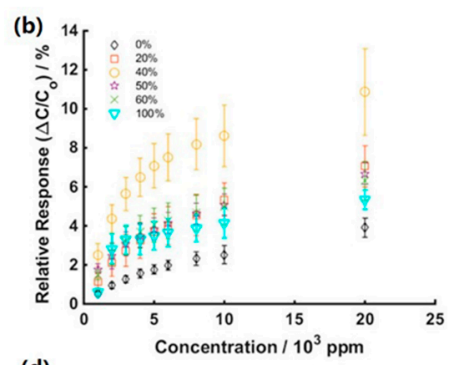

(d)

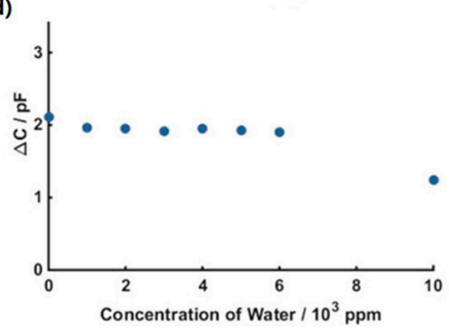

Figure 31. (a) Response of Matrimid-MOF (20\%) coated device toward 20,000 ppm of water, methanol, ethanol, and isopropanol at $28^{\circ} \mathrm{C}$. (Reproduced with permission from [225], Copyright 2016 American Chemical Society). (b) Comparison of the sensor response by devices with different ratios of $\mathrm{NH}_{2}$ MIL-53(Al) and Matrimid to the exposure of different concentrations of methanol. (c) Response of devices containing $40 \mathrm{wt}$ \% $\mathrm{NH}_{2}$-MIL-53(Al) in Matrimid to different concentrations of methanol in the presence of 5000 ppm water. (d) Capacitive response of devices containing $40 \mathrm{wt}$. $\% \mathrm{NH}_{2}-\mathrm{MIL}-53$ (Al) in Matrimid to $5000 \mathrm{ppm}$ methanol at $28^{\circ} \mathrm{C}$ and different water concentrations. (Reproduced with permission from [258], Copyright 2017 American Chemical Society).

Additionally, in 2020 Cao et al. [263] applied a ZIF-8/PDMS polymer coating on an optical fiber to prepare an optical fiber gas sensor to detect $\mathrm{CH}_{4}$ in $\mathrm{N}_{2}$ at concentrations 
as low as $1 \%$. Here, PDMS polymer provides hydrophobicity, good mechanical properties with good permeability to $\mathrm{CH}_{4}$ gas, and $\mathrm{MOF}$ to increase the free volume of the polymer and the diffusion of $\mathrm{CH}_{4}$ rate. At the same time, the addition of MOF can change the mechanical properties of the polymer matrix. Regarding the higher selectivity of $\mathrm{CH}_{4}$ relative to $\mathrm{N}_{2}$, the authors summarized three points: (1) $\mathrm{CH}_{4}$ has a higher adsorption potential than $\mathrm{N}_{2}$ in PDMS and ZIF-8. (2) The molecular size of $\mathrm{CH}_{4}$ is smaller, so it diffuses more quickly in the complexes. (3) $\mathrm{CH}_{4}$ interacts with the polymer preferentially to $\mathrm{N}_{2}$.

Besides loading MOF in polymers, we found some reports about loading polymers in MOF. Most commonly, the polymer monomers are polymerized in the pores of MOF to prepare a composite.

4.3.3. Application of Composites Obtained by Doping Polymers in MOF for Gas Sensing and Gas Adsorption

Here, we look at composites obtained by doping polymers in MOF. Le Ouay et al. [61] prepared MIL-101(Cr) $\supset$ ПPEDOT with different polymer contents by introducing uniformly dispersed EDOT monomers in MIL-101(Cr) by evaporating the solvent, followed by oxidative polymerization in the pores by iodine vapor to obtain PEDOT. It was found that PEDOT belongs to a P-type semiconductor and can be used for $\mathrm{NO}_{2}$ detection [264-268]. PEDOT mainly functions as an active and conductive material here. MOF can improve the sensitivity and increase the specific surface area by providing micropores, while composite material can also solve the drift problem of PEDOT sensors. As the PEDOT content increases, the BET specific surface area of the composites decreases, but the electrical conductivity increases. As shown in Figure 32, to achieve the best result between the electrical conductivity and accessibility of the composite to $\mathrm{NO}_{2}$, the researcher chose a mass fraction of PEDOT of $45 \%$. This gas sensor has many advantages, including operating at room temperature, high sensitivity, $\mathrm{LOD}$ to $\mathrm{NO}_{2}$ down to about $60 \mathrm{ppb}$, and its wide linear range. Therefore, preparing MOF/conductive polymer composites may be a promising method to obtain porous conductive materials.

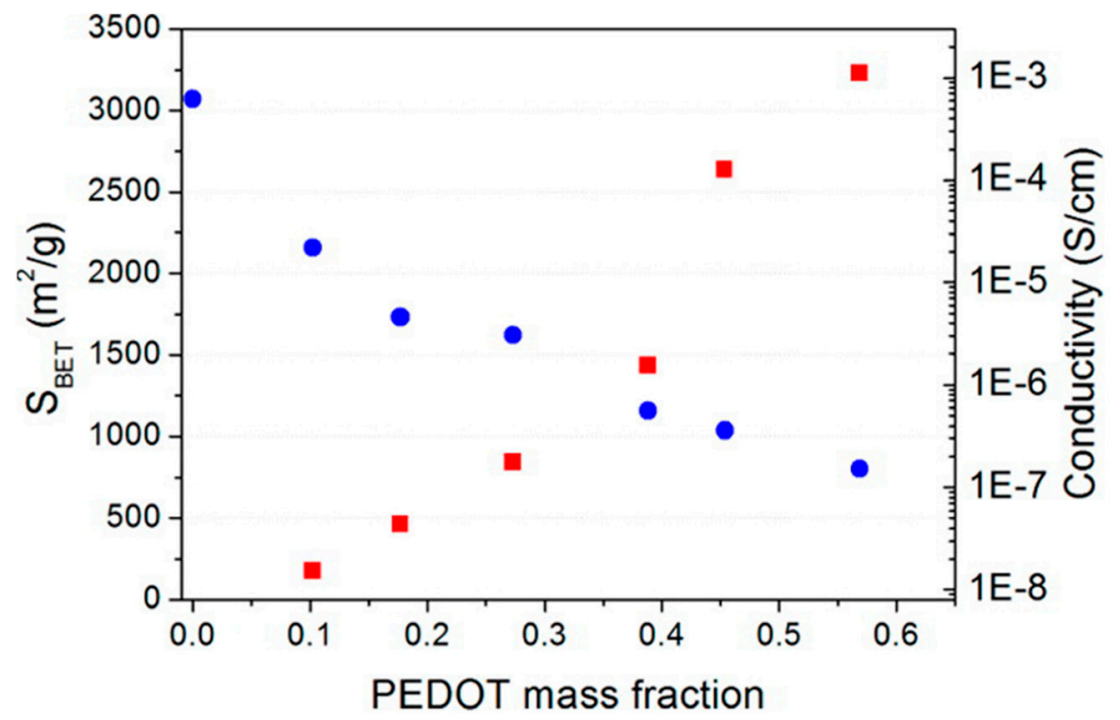

Figure 32. Changes in conductivity and specific surface area of $1 \supset \bigcap$ PEDOT with changes in PEDOT mass fraction (red squares represent conductivity, blue dots represent specific surface area [61], Copyright 2016 American Chemical Society).

In fact, besides MOF-polymer composites, other materials can be introduced to improve the sensing performance for gases, such as carbon-based materials (graphene, GO, etc.) and the corresponding studies we have given examples in the carbon-based materials section and will not repeat them here. 


\subsubsection{Application of MOF-Polymer Composites for Enhanced $\mathrm{CO}_{2}$ Adsorption}

It is well known that the first step in the sensing of gases is adsorption, so the study of gas adsorption can provide some ideas and directions for the research of gas sensing.

Global warming is a serious global environmental problem, which is caused by the increase of carbon dioxide in the atmosphere [269]. Fossil-fuel powerplants emit a relatively high proportion of $\mathrm{CO}_{2}$ in flue gases, accounting for about $40 \%$ of the total $\mathrm{CO}_{2}$ emissions [270]. The main components of flue gas include $\mathrm{N}_{2}$ (about $80 \%$ molar fraction), $\mathrm{CO}_{2}$ (about 3-15\% molar fraction), and $\mathrm{O}_{2}$ (about 5-15\% molar fraction). Additionally, the flue gas also contains water, $\mathrm{SO}_{2}, \mathrm{NO}_{\mathrm{x}}$, and carbon monoxide, as well as particles in suspension [271].

In order to alleviate global warming, people have started to consider reducing the carbon dioxide concentration in the atmosphere. In addition to using plants to absorb $\mathrm{CO}_{2}$ by photosynthesis, anthropogenic carbon capture and sequestration (CCS) techniques can be considered [272-275], and various studies have considered many materials that can be used for $\mathrm{CO}_{2}$ adsorption, such as zeolites [276,277], activated carbon [278,279], etc. MOF can also be used for $\mathrm{CO}_{2}$ adsorption due to its large specific surface area and high gas adsorption capacity $[280,281]$. However, MOF needs to be optimized to improve the adsorption capacity and selectivity of $\mathrm{CO}_{2}$ and avoid the interference of water. Previous studies have concluded that there are several methods to improve the adsorption capacity and selectivity of MOF for $\mathrm{CO}_{2}$. The first is to immobilize basic groups or add alkali metal cations including $\mathrm{Mg}^{2+}$ on MOF [244,282-284]. The second one is introducing open metal sites to induce the polarization of $\mathrm{CO}_{2}$ [285-289]. Additionally, the third one is to introduce highly polar functional groups to $\mathrm{MOF}$ (such as $-\mathrm{OH},-\mathrm{NO}_{2}$, pyridine, etc.), which can induce the polarization of $\mathrm{CO}_{2}$ and enhance the affinity of MOF with $\mathrm{CO}_{2}[227,250,290]$. The methods of introducing these functional groups include introducing groups directly into MOF and preparing MOF composites to introduce corresponding groups [285,291,292]. At the same time, polymers are a medium to introduce these groups [235-237]. Compared to zeolite or granular activated carbon, through these chemical modification methods, the material can show a larger adsorption capacity of $\mathrm{CO}_{2}$ [293].

We found that quite a few pieces of literature have reported the enhancement of $\mathrm{CO}_{2}$ adsorption by MOF-polymer, mainly by using the basic sites of the polymer. Yoo et al. [234] chose to polymerize aniline in MIL-101 (Cr) pores using the wet impregnation method to obtain the PANI@MOF complex. They found that although the specific surface area and pore volume of the composite decreased with the addition of PANI, the adsorption of $\mathrm{CO}_{2}$ was increased. The selectivity for $\mathrm{CO}_{2} / \mathrm{N}_{2}$ was also improved, indicating that the adsorption of $\mathrm{CO}_{2}$ on this material depends not only on the surface area but also on the interaction. To verify the existence of this interaction, the composite material was treated with acid and then the adsorption tests was carried out again. It was found that the adsorption of $\mathrm{CO}_{2}$ on the material after acid treatment was significantly lower than that before acid treatment, which indicates that the alkaline sites introduced by PANI may effectively promote the adsorption of $\mathrm{CO}_{2}$. Still, the adsorption of $\mathrm{CO}_{2}$ on the material after acid treatment was higher than that of pure MOF, which indicates that besides alkaline sites there are other substances present on the composites that contribute to $\mathrm{CO}_{2}$ adsorption. They further investigated the adsorption mechanism and found that according to XPS, there is a high concentration of amine $(-\mathrm{NH}-)$ and low concentration of imine $(=\mathrm{N}-)$ on PANI-MOF-as shown in Figure 33-so it can be presumed that it is the amine in PANI that effectively adsorbs $\mathrm{CO}_{2}$. After acid treatment, $-\mathrm{NH}$ - may become $-\mathrm{NH}_{2}{ }^{+}-$ while $=\mathrm{N}-$ may become $=\mathrm{NH}^{+}-$. They may have dipole-quadrupole interaction or weak electrostatic interaction with $\mathrm{CO}_{2}$. There is a dipole-quadrupole interaction or a weak electrostatic interaction between them so that the adsorption of $\mathrm{CO}_{2}$ is still increased even after treatment with acid. 


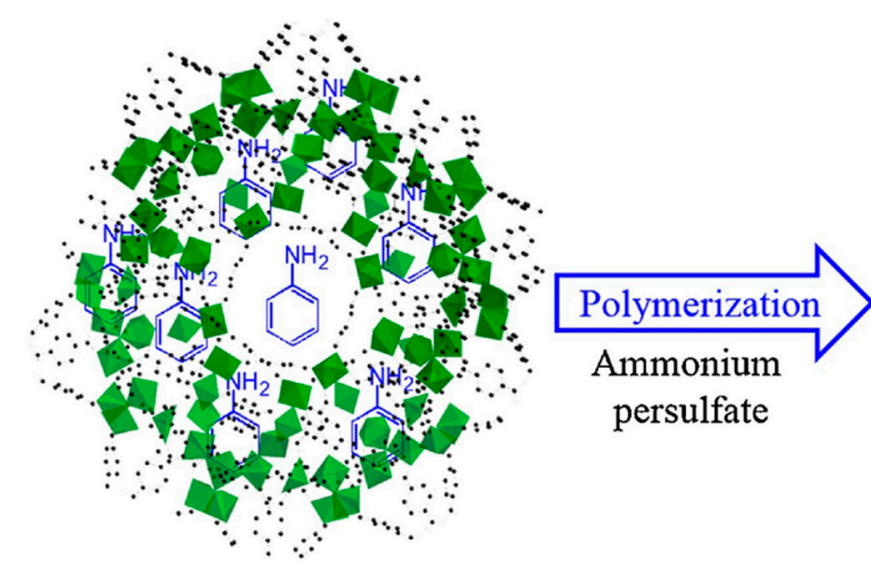

Aniline@MIL-101(Cr) MIL-101: $\mathrm{Cr}_{3} \mathrm{O}(\mathrm{F} / \mathrm{OH})\left(\mathrm{H}_{2} \mathrm{O}\right)_{2}\left[\mathrm{C}_{6} \mathrm{H}_{4}\left(\mathrm{CO}_{2}\right)_{2}\right]$

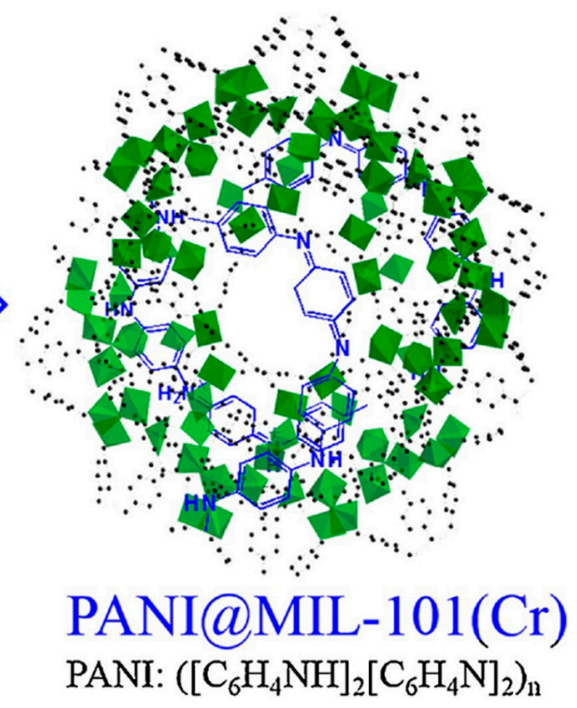

Figure 33. Production of PANI@MIL-101 (Cr) from aniline-loaded MIL-101 (Cr) and the amine groups present in the two structures. Green indicates Cr, black indicates C on MOF, and blue represents aniline or polyaniline [234], (Copyright 2018 ELSEVIER).

From the above examples, it can be seen that the introduction of some polymers can introduce basic sites to improve the adsorption capacity of $\mathrm{CO}_{2}$. Such polymers include PEI, etc. For example, Yan et al. [237] modified the amine group to MIL-101 (Cr) to obtain smaller amine-MIL-101 (Cr) particles with good water stability [294] and then used wet impregnation to dope PEI into the pores of amine-MIL-101 (Cr). This composite can improve the adsorption performance of $\mathrm{CO}_{2}$ at room temperature and low pressure and significantly improve the selectivity for $\mathrm{CO}_{2} / \mathrm{CH}_{4}$. However, one point that needs attention is the selection of MOF. First of all, the MOF material we choose must be alkali-resistant MOF. Other MOF materials such as Cu-BTC are not suitable for loading these polymers because the framework structure may be destroyed in alkali amine solution. Moreover, the presence of water is an important variable. Some MOF materials, such as MIL-101 (Cr) mentioned above, have good thermal and water stability and high adsorption capacity for $\mathrm{CO}_{2}[295,296]$. Still, the adsorption of $\mathrm{CO}_{2}$ in humid air decreases significantly due to the competition from water vapor because of the hydrophilic nature of the unsaturated metal center [297-301]. Therefore, it is also essential to develop composites with high $\mathrm{CO}_{2}$ capacity and better moisture resistance. With regard to improving the hydrophobicity of MOF by polymers, two methods have been introduced above, mainly through the water repellency by polymers on the inner and outer surfaces of MOF. However, we also found that some studies can use water vapor to improve the adsorption of $\mathrm{CO}_{2}$, which is undoubtedly a new development direction but this is limited to polymers containing specific groups.

Xian et al. [235,236] synthesized UiO-66 and ZIF-8 complexes modified with PEI by the wet impregnation method and investigated the adsorption properties of the complexes on the adsorption performance and humidity of $\mathrm{CO}_{2}$. Both UiO-66 and ZIF-8 are alkalistabilized MOF materials, and their binding sites to PEI are metal sites [302]. The $\mathrm{CO}_{2}$ adsorption experiments revealed that the adsorption was significantly improved by the addition of polymer, which is due to the fact that PEI is a polymer containing a high density of amine groups that can interact with $\mathrm{CO}_{2}$ to generate carbamates [303]. The reaction of the amine group on PEI with $\mathrm{CO}_{2}$ under the condition of no water vapor is shown in Figure $34 \mathrm{a}, \mathrm{b}$. The reaction equation is as follows [304].

$$
\begin{aligned}
& \mathrm{CO}_{2}+2 \mathrm{RNH}_{2} \rightarrow \mathrm{RNHCOO}^{-}+\mathrm{RNH}_{3}{ }^{+} \\
& \mathrm{CO}_{2}+2 \mathrm{R}_{2} \mathrm{NH} \rightarrow \mathrm{R}_{2} \mathrm{NCOO}^{-}+\mathrm{R}_{2} \mathrm{NH}_{2}{ }^{+}
\end{aligned}
$$




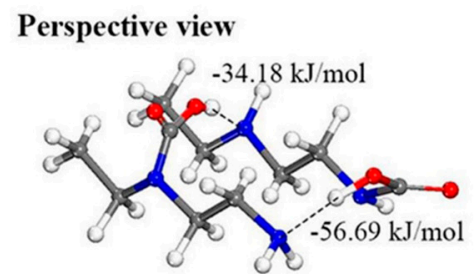

Top view

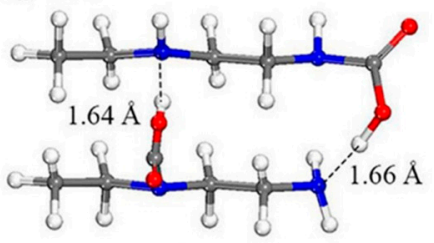

(a)
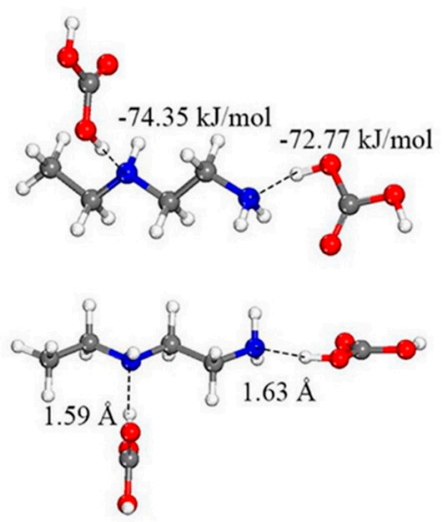

(b)

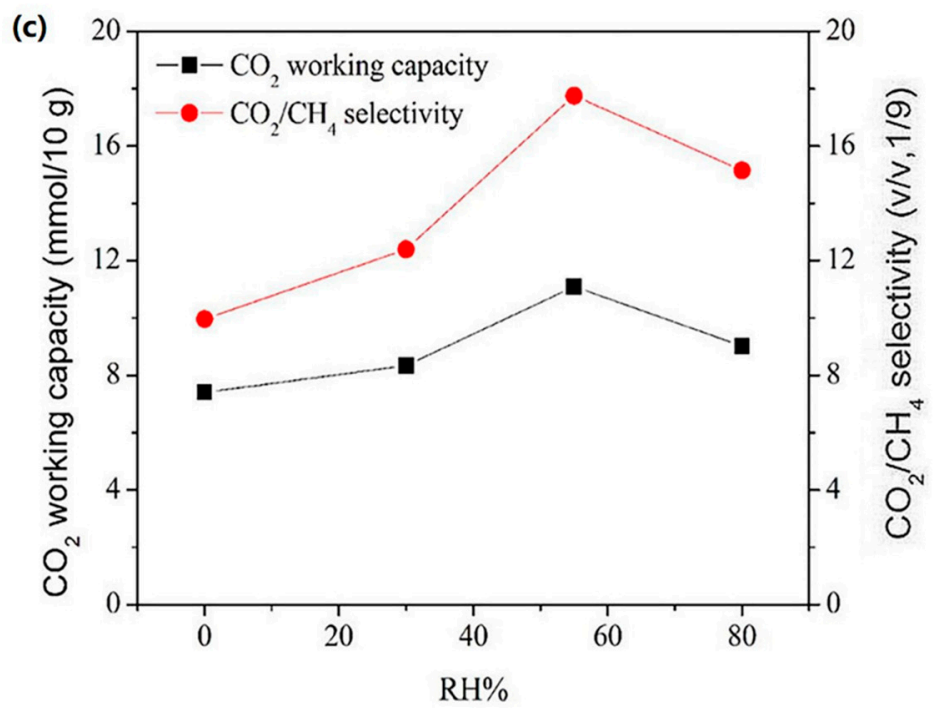

Figure 34. The best interaction configurations and adsorption energies for $\mathrm{CO}_{2}$ adsorption on tetraethylenepentamine under (a) dry conditions and (b) wet conditions, respectively (gray represents $\mathrm{C}$, red represents $\mathrm{O}$, blue represents $\mathrm{N}$, and white represents $\mathrm{H}$ ). (c) $\mathrm{CO}_{2}$ adsorption capacity and $\mathrm{CO}_{2} / \mathrm{CH}_{4}$ selectivity at $308 \mathrm{~K}$ for 30PEI @ UiO-66 at $0 \%, 30 \%, 55 \%$, and $80 \%$ relative humidity, respectively [235], (Copyright 2015 American Chemical Society).

It can be seen that under these experimental conditions, one $\mathrm{CO}_{2}$ molecule needs to consume two amine groups to generate stable carbamates. The adsorption capacity of $\mathrm{CO}_{2}$ varies by changing the PEI loading. For UiO-66, the maximum $\mathrm{CO}_{2}$ adsorption was achieved at a PEI loading of $30 \mathrm{wt}$ \%. In contrast, for ZIF-8, the maximum $\mathrm{CO}_{2}$ adsorption was achieved at a PEI loading of $45 \mathrm{wt} . \%$ at a temperature of $298 \mathrm{~K}$ and pressure between 0 and 0.8 bar and greater than 0.8 bar. The PEI loading of the maximum adsorption was observed at $30 \mathrm{wt} . \%$. This is because as the increase of PEI loading, the active site of the complex adsorption for $\mathrm{CO}_{2}$ increases, but at the same time, its specific surface area decreases, so there is a compromise between the two loadings, which leads to the maximum adsorption amount of $\mathrm{CO}_{2}$. Hence, when water vapor is added to the experimental conditions, will it affect the $\mathrm{CO}_{2}$ adsorption? They tested the $\mathrm{CO}_{2}$ adsorption capacity and $\mathrm{CO}_{2} / \mathrm{CH}_{4}$ selectivity at $308 \mathrm{~K}$ for 30PEI@UiO-66 at 0\%, 30\%, 55\%, and $80 \%$ relative humidity, respectively, and the results are shown in Figure 34c. It can be seen that both adsorption capacity and selectivity are improved in the presence of water vapor compared to water-free conditions, and the maximum value is reached at $55 \%$ relative humidity, which indicates that the presence of water molecules has a favorable impact on the adsorption of $\mathrm{CO}_{2}$. The result was also observed for 45PEI@ZIF-8. They suggest that this is because water molecules may have preferentially formed bicarbonate with 
$\mathrm{CO}_{2}$ molecules and then adsorbed on the amine group of the complex through hydrogen bonding, with the following reactions [305-307].

$$
\mathrm{CO}_{2}+\mathrm{H}_{2} \mathrm{O}+\mathrm{R}_{1} \mathrm{NHR}_{2} \longleftrightarrow \mathrm{R}_{1} \mathrm{R}_{2} \mathrm{NH}_{2}{ }^{+}+\mathrm{HCO}_{3}{ }^{-}
$$

$\mathrm{N}_{2}$ or $\mathrm{CH}_{4}$ do not react, so as PEI increases and the specific surface area decreases, the adsorption capacity decreases, and therefore the selectivity for $\mathrm{CO}_{2}$ improves significantly as the $\mathrm{CO}_{2}$ adsorption capacity increases. However, after the relative humidity (RH) exceeded $55 \%$, the adsorption amount, as well as the selectivity for $\mathrm{CO}_{2}$, decreased again, which could be attributed to the excess of water molecules that would compete with $\mathrm{CO}_{2}$.

To conclude, their study provides a new way to enhance the adsorption of $\mathrm{CO}_{2}$ in flue gas, which can be enhanced by the synergistic interaction of water molecules with amine groups on the polymer.

The addition of adsorption provides an improved direction for the development of sense, and for those chemically reactive adsorptions, chemical bond detection by Raman spectroscopy can also be considered for gas detection purposes.

\subsubsection{Current Problems}

The current development of MOF-polymer for gas sensing faces several problems: (i) The pores of MOF have a certain pore size, so the polymer may hinder the transport of some gas molecules if it is polymerized pore. If it is polymerized and inserted into the pore, it may be difficult to enter the pore because of the pore size and lead to difficulties in preparing the complexes. (ii) When loading polymers in MOF, various synthetic methods need to be improved and explored to control the loading amount, while maintaining the high porosity of MOF and the accessibility of the target to the active site. (iii) The homogeneous dispersion of polymers in MOFs still needs to be explored. They are influenced by several factors, which also affect the sensing and adsorption properties of the composites for gases. (iv) At present, from the evidence in the literature, there are few applications of MOF-polymer in gas sensing and the corresponding selection of MOF materials and polymers is also small; therefore, many laws cannot be summarized. There is still more room for the development of such composites and it can be said that this is a direction worth exploring.

\section{Conclusions}

This paper reviews the synthesis methods, advantages, disadvantages, and applications of MOF and its composites as gas sensing materials. The composite materials of SMOx and MOF synthesized using the template-sacrifice method can increase the specific surface area of the materials, enhance the moisture resistance of the materials, and improve the selectivity for specific gases. By compounding carbon-based materials with MOF, the dispersibility of the porous materials can be improved, the electrical conductivity of the materials can be increased, and the surface-active sites can be increased, thereby improving the adsorption and diffusion of gas molecules. Using the synergistic effect of polymer and MOF materials, the stability of the materials can be enhanced, and the gas can be detected at lower temperatures. Although there are not many reports on these composites for gas sensing, MOFs with porous structures and their composites are expected to be candidates for improving gas sensing performance.

\section{Outlook}

Although some progress has been made in gas sensors based on MOF composites, further research is still needed. Regarding the materials for the composites, we summarized the metal oxide, carbon-based materials, and polymers with MOF. For the composite of the MOF with metal oxides, the current material selection needs to be further explored. For the composites of MOF with carbon-based materials, although there are many reports, they focus on the adsorption of gases and the investigation of the sensing of gases is still a significant challenge. For the composites of MOF with polymers, the preparation 
methods still need to be improved. Finally, we hope our work can provide some ideas for developing more MOF-based composites with good gas sensing properties.

Author Contributions: Conceptualization, B.H.; methodology, B.H.; validation, B.H., Y.L. and W.Z.; formal analysis, B.H.; investigation, Y.L.; resources, W.Z.; data curation, Y.L.; writing-original draft preparation, B.H.; writing-review and editing, W.Z.; visualization, W.Z.; supervision, W.Z.; project administration, W.Z. All authors have read and agreed to the published version of the manuscript.

Funding: This research received no external funding.

Institutional Review Board Statement: Not applicable.

Informed Consent Statement: Informed consent was obtained from all subjects involved in the study.

Data Availability Statement: The data is available on the request from corresponding author.

Acknowledgments: This work was financially supported by the Graduate Scientific Research and Innovation Foundation of Chongqing, China (No. CYS20001) and the Science and Technology Research Program of Chongqing Municipal Education Commission (No. KJQN201801320).

Conflicts of Interest: The authors declare no conflict of interest.

\section{References}

1. Qiao, L.; Bing, Y.; Wang, Y.; Yu, S.; Liang, Z.; Zeng, Y. Enhanced toluene sensing performances of Pd- loaded $\mathrm{SnO}_{2} \mathrm{cubic}$ nanocages with porous nanoparticle-assembled shells. Sens. Actuators B Chem. 2017, 241, 1121-1129. [CrossRef]

2. Wei, A.; Pan, L.; Huang, W. Recent progress in the ZnO nanostructure-based sensors. Mater. Sci. Eng. B Adv. Funct. Solid State Mater. 2011, 176, 1409-1421. [CrossRef]

3. Mokoena, T.P.; Swart, H.C.; Motaung, D.E. A review on recent progress of p-type nickel oxide based gas sensors: Future perspectives. J. Alloy. Compd. 2019, 805, 267-294. [CrossRef]

4. Rydosz, A. The Use of Copper Oxide Thin Films in Gas-Sensing Applications. Coatings 2018, 8, 425. [CrossRef]

5. Yuliarto, B.; Gumilar, G.; Septiani, N.L.W. $\mathrm{SnO}_{2}$ Nanostructure as Pollutant Gas Sensors: Synthesis, Sensing Performances, and Mechanism. Adv. Mater. Sci. Eng. 2015, 2015, 694823. [CrossRef]

6. Singkammo, S.; Wisitsoraat, A.; Sriprachuabwong, C.; Tuantranont, A.; Phanichphant, S.; Liewhiran, C. Electrolytically Exfoliated Graphene-Loaded Flame-Made Ni-Doped $\mathrm{SnO}_{2}$ Composite Film for Acetone Sensing. ACS Appl. Mater. Interfaces 2015, 7, 3077-3092. [CrossRef]

7. Xu, X.L.; Chen, Y.; Ma, S.Y.; Li, W.Q.; Mao, Y.Z. Excellent acetone sensor of La-doped ZnO nanofibers with unique bead-like structures. Sens. Actuators B Chem. 2015, 213, 222-233. [CrossRef]

8. Zhou, X.; Wang, B.; Sun, H.; Wang, C.; Sun, P.; Li, X.; Hu, X.; Lu, G. Template-free synthesis of hierarchical ZnFe $2 \mathrm{O}_{4}$ yolk-shell microspheres for high-sensitivity acetone sensors. Nanoscale 2016, 8, 5446-5453. [CrossRef] [PubMed]

9. Song, P.; Wang, Q.; Yang, Z. Preparation, characterization and acetone sensing properties of Ce-doped SnO 2 hollow spheres. Sens. Actuators B Chem. 2012, 173, 839-846. [CrossRef]

10. Li, X.; Wang, C.; Guo, H.; Sun, P.; Liu, F.; Liang, X.; Lu, G. Double-Shell Architectures of $\mathrm{ZnFe}_{2} \mathrm{O}_{4}$ Nanosheets on ZnO Hollow Spheres for High-Performance Gas Sensors. ACS Appl. Mater. Interfaces 2015, 7, 17811-17818. [CrossRef] [PubMed]

11. Park, H.J.; Choi, N.-J.; Kang, H.; Jung, M.Y.; Park, J.W.; Park, K.H.; Lee, D.-S. A ppb-level formaldehyde gas sensor based on CuO nanocubes prepared using a polyol process. Sens. Actuators B Chem. 2014, 203, 282-288. [CrossRef]

12. Yao, M.-S.; Tang, W.-X.; Wang, G.-E.; Nath, B.; Xu, G. MOF Thin Film-Coated Metal Oxide Nanowire Array: Significantly Improved Chemiresistor Sensor Performance. Adv. Mater. 2016, 28, 5229-5234. [CrossRef]

13. Barsan, N.; Schweizer-Berberich, M.; Gopel, W. Fundamental and practical aspects in the design of nanoscaled $\mathrm{SnO}_{2}$ gas sensors: A status report. Fresenius J. Anal. Chem. 1999, 365, 287-304. [CrossRef]

14. Jang, S.; Song, S.; Lim, J.H.; Kim, H.S.; Phan, B.T.; Ha, K.-T.; Park, S.; Park, K.H. Application of Various Metal-Organic Frameworks (MOFs) as Catalysts for Air and Water Pollution Environmental Remediation. Catalysts 2020, 10, 195. [CrossRef]

15. Swager, T.M. Sensor Technologies Empowered by Materials and Molecular Innovations. Angew. Chem. Int. Ed. 2018, 57, 4248-4257. [CrossRef] [PubMed]

16. Lee, E.; Yoon, Y.S.; Kim, D.-J. Two-Dimensional Transition Metal Dichalcogenides and Metal Oxide Hybrids for Gas Sensing. ACS Sens. 2018, 3, 2045-2060. [CrossRef] [PubMed]

17. Park, W.; Park, J.; Jang, J.; Lee, H.; Jeong, H.; Cho, K.; Hong, S.; Lee, T. Oxygen environmental and passivation effects on molybdenum disulfide field effect transistors. Nanotechnology 2013, 24, 095202. [CrossRef] [PubMed]

18. Adhikari, B.; Majumdar, S. Polymers in sensor applications. Prog. Polym. Sci. 2004, 29, 699-766. [CrossRef]

19. Lakard, B.; Carquigny, S.; Segut, O.; Patois, T.; Lakard, S. Gas Sensors Based on Electrodeposited Polymers. Metals 2015, 5, 1371-1386. [CrossRef] 
20. Koo, W.-T.; Cha, J.-H.; Jung, J.-W.; Choi, S.-J.; Jang, J.-S.; Kim, D.-H.; Kim, I.-D. Few-Layered WS2 Nanoplates Confined in Co, N-Doped Hollow Carbon Nanocages: Abundant WS2 Edges for Highly Sensitive Gas Sensors. Adv. Funct. Mater. $2018,28$. [CrossRef]

21. Lei, J.-C.; Zhang, X.; Zhou, Z. Recent advances in MXene: Preparation, properties, and applications. Front. Phys. 2015, 10, 276-286. [CrossRef]

22. Xin, M.; Li, J.; Ma, Z.; Pan, L.; Shi, Y. MXenes and Their Applications in Wearable Sensors. Front. Chem. 2020, 8, 297. [CrossRef] [PubMed]

23. Furukawa, H.; Cordova, K.E.; O'Keeffe, M.; Yaghi, O.M. The Chemistry and Applications of Metal-Organic Frameworks. Science 2013, 341, 974. [CrossRef] [PubMed]

24. Xue, D.-X.; Wang, Q.; Bai, J. Amide-functionalized metal-organic frameworks: Syntheses, structures and improved gas storage and separation properties. Coord. Chem. Rev. 2019, 378, 2-16. [CrossRef]

25. Beheshti, S.; Safarifard, V.; Morsali, A. Isoreticular interpenetrated pillared-layer microporous metal-organic framework as a highly effective catalyst for three-component synthesis of pyrano 2, 3-d pyrimidines. Inorg. Chem. Commun. 2018, 94, 80-84. [CrossRef]

26. Hu, M.-L.; Safarifard, V.; Doustkhah, E.; Rostamnia, S.; Morsali, A.; Nouruzi, N.; Beheshti, S.; Akhbari, K. Taking organic reactions over metal-organic frameworks as heterogeneous catalysis. Microporous Mesoporous Mater. 2018, 256, 111-127. [CrossRef]

27. Wang, H.; Zhu, Q.-L.; Zou, R.; Xu, Q. Metal-Organic Frameworks for Energy Applications. Chem 2017, 2, 52-80. [CrossRef]

28. Koo, W.-T.; Jang, J.-S.; Kim, I.-D. Metal-Organic Frameworks for Chemiresistive Sensors. Chem 2019, 5, 1938-1963. [CrossRef]

29. Chernikova, V.; Yassine, O.; Shekhah, O.; Eddaoudi, M.; Salama, K.N. Highly sensitive and selective $\mathrm{SO}_{2} \mathrm{MOF}$ sensor: The integration of MFM-300 MOF as a sensitive layer on a capacitive interdigitated electrode. J. Mater. Chem. A 2018, 6, 5550-5554. [CrossRef]

30. Petit, C.; Bandosz, T.J. Engineering the surface of a new class of adsorbents: Metal-organic framework/graphite oxide composites. J. Colloid Interface Sci. 2015, 447, 139-151. [CrossRef]

31. Kuesgens, P.; Rose, M.; Senkovska, I.; Froede, H.; Henschel, A.; Siegle, S.; Kaskel, S. Characterization of metal-organic frameworks by water adsorption. Microporous Mesoporous Mater. 2009, 120, 325-330. [CrossRef]

32. Lu, Z.; Xing, H.; Sun, R.; Bai, J.; Zheng, B.; Li, Y. Water Stable Metal-Organic Framework Evolutionally Formed from a Flexible Multidentate Ligand with Acylamide Groups for Selective $\mathrm{CO}_{2}$ Adsorption. Cryst. Growth Des. 2012, 12, 1081-1084. [CrossRef]

33. Schoenecker, P.M.; Carson, C.G.; Jasuja, H.; Flemming, C.J.J.; Walton, K.S. Effect of Water Adsorption on Retention of Structure and Surface Area of Metal-Organic Frameworks. Ind. Eng. Chem. Res. 2012, 51, 6513-6519. [CrossRef]

34. Wales, D.J.; Grand, J.; Ting, V.P.; Burke, R.D.; Edler, K.J.; Bowen, C.R.; Mintova, S.; Burrows, A.D. Gas sensing using porous materials for automotive applications. Chem. Soc. Rev. 2015, 44, 4290-4321. [CrossRef] [PubMed]

35. Campbell, M.G.; Dinca, M. Metal-Organic Frameworks as Active Materials in Electronic Sensor Devices. Sensors 2017, 17, 1108. [CrossRef]

36. Yi, F.-Y.; Chen, D.; Wu, M.-K.; Han, L.; Jiang, H.-L. Chemical Sensors Based on Metal-Organic Frameworks. Chempluschem 2016, 81, 675-690. [CrossRef]

37. Yadav, B.C.; Chauhan, K.S.; Singh, S.; Sonker, R.K.; Sikarwar, S.; Kumar, R. Growth and characterization of sol-gel processed rectangular shaped nanostructured ferric oxide thin film followed by humidity and gas sensing. J. Mater. Sci. Mater. Electron. 2017, 28, 5270-5280. [CrossRef]

38. Campbell, M.G.; Liu, S.F.; Swager, T.M.; Dinca, M. Chemiresistive Sensor Arrays from Conductive 2D Metal-Organic Frameworks. J. Am. Chem. Soc. 2015, 137, 13780-13783. [CrossRef]

39. Smith, M.K.; Jensen, K.E.; Pivak, P.A.; Mirica, K.A. Direct Self-Assembly of Conductive Nanorods of Metal Organic Frameworks into Chemiresistive Devices on Shrinkable Polymer Films. Chem. Mater. 2016, 28, 5264-5268. [CrossRef]

40. Chen, E.-X.; Yang, H.; Zhang, J. Zeolitic Imidazolate Framework as Formaldehyde Gas Sensor. Inorg. Chem. 2014, 53, 5411-5413. [CrossRef] [PubMed]

41. Li, H.-Y.; Zhao, S.-N.; Zang, S.-Q.; Li, J. Functional metal-organic frameworks as effective sensors of gases and volatile compounds. Chem. Soc. Rev. 2020, 49, 6364-6401. [CrossRef] [PubMed]

42. Nasalevich, M.A.; van der Veen, M.; Kapteijn, F.; Gascon, J. Metal-organic frameworks as heterogeneous photocatalysts: Advantages and challenges. Crystengcomm 2014, 16, 4919-4926. [CrossRef]

43. Leong, C.F.; Chan, B.; Faust, T.B.; D'Alessandro, D.M. Controlling charge separation in a novel donor-acceptor metal-organic framework via redox modulation. Chem. Sci. 2014, 5, 4724-4728. [CrossRef]

44. Narayan, T.C.; Miyakai, T.; Seki, S.; Dinca, M. High Charge Mobility in a Tetrathiafulvalene-Based Microporous Metal-Organic Framework. J. Am. Chem. Soc. 2012, 134, 12932-12935. [CrossRef]

45. Zhang, G.; Jin, L.; Zhang, R.; Bai, Y.; Zhu, R.; Pang, H. Recent advances in the development of electronically and ionically conductive metal-organic frameworks. Coord. Chem. Rev. 2021, 439, 213915. [CrossRef]

46. Burtch, N.C.; Jasuja, H.; Walton, K.S. Water Stability and Adsorption in Metal-Organic Frameworks. Chem. Rev. 2014, 114, 10575-10612. [CrossRef] [PubMed]

47. Howarth, A.J.; Liu, Y.; Li, P.; Li, Z.; Wang, T.C.; Hupp, J.; Farha, O.K. Chemical, thermal and mechanical stabilities of metal-organic frameworks. Nat. Rev. Mater. 2016, 1, 1-15. [CrossRef] 
48. Kung, C.-W.; Han, P.-C.; Chuang, C.-H.; Wu, K.C.W. Electronically conductive metal-organic framework-based materials. APL Mater. 2019, 7, 110902. [CrossRef]

49. Bradshaw, D.; Garai, A.; Huo, J. Metal-organic framework growth at functional interfaces: Thin films and composites for diverse applications. Chem. Soc. Rev. 2012, 41, 2344-2381. [CrossRef]

50. Petit, C.; Mendoza, B.; O'Donnell, D.; Bandosz, T.J. Effect of Graphite Features on the Properties of Metal-Organic Framework/Graphite Hybrid Materials Prepared Using an in Situ Process. Langmuir 2011, 27, 10234-10242. [CrossRef]

51. Ge, L.; Wang, L.; Rudolph, V.; Zhu, Z. Hierarchically structured metal-organic framework/vertically-aligned carbon nanotubes hybrids for $\mathrm{CO}_{2}$ capture. RSC Adv. 2013, 3, 25360-25366. [CrossRef]

52. Zhang, X.; Zhang, Q.; Yue, D.; Zhang, J.; Wang, J.; Li, B.; Yang, Y.; Cui, Y.; Qian, G. Flexible Metal-Organic Framework-Based Mixed-Matrix Membranes: A New Platform for H2S Sensors. Small 2018, 14, 1801563. [CrossRef]

53. Liu, Y.; Wang, R.; Zhang, T.; Liu, S.; Fei, T. Zeolitic imidazolate framework-8 (ZIF-8)-coated In2O3 nanofibers as an efficient sensing material for ppb-level $\mathrm{NO}_{2}$ detection. J. Colloid Interface Sci. 2019, 541, 249-257. [CrossRef] [PubMed]

54. Lu, Y.; Zhan, W.; He, Y.; Wang, Y.; Kong, X.; Kuang, Q.; Xie, Z.; Zheng, L. MOF-Templated Synthesis of Porous Co3O ${ }_{4} \mathrm{Concave}$ Nanocubes with High Specific Surface Area and Their Gas Sensing Properties. ACS Appl. Mater. Interfaces 2014, 6, 4186-4195. [CrossRef] [PubMed]

55. Cheng, L.; He, Y.; Gong, M.; He, X.; Ning, Z.; Yu, H.; Jiao, Z. MOF-derived synthesis of $\mathrm{Co}_{3} \mathrm{O}_{4}$ nanospheres with rich oxygen vacancies for long-term stable and highly selective n-butanol sensing performance. J. Alloy. Compd. 2021, 857, 158205. [CrossRef]

56. Yin, M.; Liu, S. Preparation of $\mathrm{ZnO}$ hollow spheres with different surface roughness and their enhanced gas sensing property. Sens. Actuators B Chem. 2014, 197, 58-65. [CrossRef]

57. Wei, S.; Zhang, Y.; Zhou, M. Formaldehyde sensing properties of ZnO-based hollow nanofibers. Sens. Rev. 2014, 34, 327-334. [CrossRef]

58. Li, J.; Fan, H.; Jia, X. Multi layered ZnO Nanosheets with 3D Porous Architectures: Synthesis and Gas Sensing Application. J. Phys. Chem. C 2010, 114, 14684-14691. [CrossRef]

59. Chen, E.-X.; Fu, H.-R.; Lin, R.; Tan, Y.-X.; Zhang, J. Highly Selective and Sensitive Trimethylamine Gas Sensor Based on Cobalt Imidazolate Framework Material. ACS Appl. Mater. Interfaces 2014, 6, 22871-22875. [CrossRef] [PubMed]

60. Kang, H.; Park, K.H.; Lee, H.-K. Transformation of CuO from Cu-MOF Templates and Their Enhanced Sensing Performance for HCHO. Bull. Korean Chem. Soc. 2016, 37, 123-128. [CrossRef]

61. Le Ouay, B.; Boudot, M.; Kitao, T.; Yanagida, T.; Kitagawa, S.; Uemura, T. Nanostructuration of PEDOT in Porous Coordination Polymers for Tunable Porosity and Conductivity. J. Am. Chem. Soc. 2016, 138, 10088-10091. [CrossRef] [PubMed]

62. Chuang, C.-H.; Kung, C.-W. Metal-Organic Frameworks toward Electrochemical Sensors: Challenges and Opportunities. Electroanalysis 2020, 32, 1885-1895. [CrossRef]

63. Ahmed, I.; Jhung, S.H. Composites of metal-organic frameworks: Preparation and application in adsorption. Mater. Today 2014, 17, 136-146. [CrossRef]

64. Zheng, S.; Li, Q.; Xue, H.; Pang, H.; Xu, Q. A highly alkaline-stable metal oxide@metal-organic framework composite for high-performance electrochemical energy storage. Natl. Sci. Rev. 2020, 7, 305-314. [CrossRef]

65. Huang, X.; Yan, S.; Deng, D.; Zhang, L.; Liu, R.; Lv, Y. Novel Strategy for Engineering the Metal-Oxide@MOF Core@Shell Architecture and Its Applications in Cataluminescence Sensing. ACS Appl. Mater. Interfaces 2021, 13, 3471-3480. [CrossRef] [PubMed]

66. Moon, H.R.; Lim, D.-W.; Suh, M.P. Fabrication of metal nanoparticles in metal-organic frameworks. Chem. Soc. Rev. 2013, 42, 1807-1824. [CrossRef] [PubMed]

67. He, L.; Liu, Y.; Liu, J.; Xiong, Y.; Zheng, J.; Liu, Y.; Tang, Z. CoreShell Noble-Metal@Metal-Organic-Framework Nanoparticles with Highly Selective Sensing Property. Angew. Chem. Int. Ed. 2013, 52, 3741-3745. [CrossRef]

68. Wei, W.; Liu, Z.; Wei, R.; Han, G.-C.; Liang, C. Synthesis of MOFs/GO composite for corrosion resistance application on carbon steel. RSC Adv. 2020, 10, 29923-29934. [CrossRef]

69. Lin, L.-C.; Paik, D.; Kim, J. Understanding gas adsorption in MOF-5/graphene oxide composite materials. Phys. Chem. Chem. Phys. 2017, 19, 11639-11644. [CrossRef] [PubMed]

70. Zhang, Z.; Ha Thi Hoang, N.; Miller, S.A.; Cohen, S.M. polyMOFs: A Class of Interconvertible Polymer-Metal-Organic-Framework Hybrid Materials. Angew. Chem. Int. Ed. 2015, 54, 6152-6157. [CrossRef] [PubMed]

71. Huo, J.; Marcello, M.; Garai, A.; Bradshaw, D. MOF-Polymer Composite Microcapsules Derived from Pickering Emulsions. Adv. Mater. 2013, 25, 2717-2722. [CrossRef]

72. Fu, Y.-Y.; Yang, C.-X.; Yan, X.-P. Fabrication of ZIF-8@SiO 2 Core-Shell Microspheres as the Stationary Phase for High-Performance Liquid Chromatography. Chem. A Eur. J. 2013, 19, 13484-13491. [CrossRef] [PubMed]

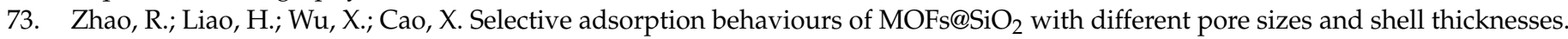
J. Solid State Chem. 2020, 292, 121693. [CrossRef]

74. Aguilera-Sigalat, J.; Bradshaw, D. Synthesis and applications of metal-organic framework-quantum dot (QD@MOF) composites. Coord. Chem. Rev. 2016, 307, 267-291. [CrossRef]

75. Wu, T.; Liu, X.; Liu, Y.; Cheng, M.; Liu, Z.; Zeng, G.; Shao, B.; Liang, Q.; Zhang, W.; He, Q.; et al. Application of QD-MOF composites for photocatalysis: Energy production and environmental remediation. Coord. Chem. Rev. 2020, 403. [CrossRef] 
76. Ji, H.; Zeng, W.; Li, Y. Gas sensing mechanisms of metal oxide semiconductors: A focus review. Nanoscale 2019, 11, 22664-22684. [CrossRef]

77. Kim, H.-J.; Lee, J.-H. Highly sensitive and selective gas sensors using p-type oxide semiconductors: Overview. Sens. Actuators $B$ Chem. 2014, 192, 607-627. [CrossRef]

78. Nair, S.S.; Illyaskutty, N.; Tam, B.; Yazaydin, A.O.; Emmerich, K.; Steudel, A.; Hashem, T.; Schoettner, L.; Woell, C.; Kohler, H.; et al. ZnO@ZIF-8: Gas sensitive core-shell hetero-structures show reduced cross-sensitivity to humidity. Sens. Actuators B Chem. 2020, 304, 127184. [CrossRef]

79. Zhang, J.; Liu, X.; Neri, G.; Pinna, N. Nanostructured Materials for Room-Temperature Gas Sensors. Adv. Mater. 2016, 28 , 795-831. [CrossRef]

80. Tian, H.; Fan, H.; Li, M.; Ma, L. Zeolitic Imidazolate Framework Coated ZnO Nanorods as Molecular Sieving to Improve Selectivity of Formaldehyde Gas Sensor. ACS Sens. 2016, 1, 243-250. [CrossRef]

81. Li, W.; Wu, X.; Han, N.; Chen, J.; Qian, X.; Deng, Y.; Tang, W.; Chen, Y. MOF-derived hierarchical hollow ZnO nanocages with enhanced low-concentration VOCs gas-sensing performance. Sens. Actuators B Chem. 2016, 225, 158-166. [CrossRef]

82. Jimenez-Cadena, G.; Riu, J.; Rius, F.X. Gas sensors based on nanostructured materials. Analyst 2007, 132, 1083-1099. [CrossRef] [PubMed]

83. Huang, X.-J.; Choi, Y.-K. Chemical sensors based on nanostructured materials. Sens. Actuators B Chem. 2007, $122,659-671$. [CrossRef]

84. Meng, Z.; Stolz, R.M.; Mendecki, L.; Mirica, K.A. Electrically-Transduced Chemical Sensors Based on Two Dimensional Nanomaterials. Chem. Rev. 2019, 119, 478-598. [CrossRef]

85. Ueda, T.; Maeda, T.; Huang, Z.; Higuchi, K.; Izawa, K.; Kamada, K.; Hyodo, T.; Shimizu, Y. Enhancement of methylmercaptan sensing response of WO3 semiconductor gas sensors by gas reactivity and gas diffusivity. Sens. Actuators B Chem. 2018, 273, 826-833. [CrossRef]

86. Comini, E. Metal oxide nano-crystals for gas sensing. Anal. Chim. Acta 2006, 568, 28-40. [CrossRef] [PubMed]

87. Khudiar, A.I.; Elttayef, A.K.; Khalaf, M.K.; Oufi, A.M. Fabrication of ZnO@ZIF-8 gas sensors for selective gas detection. Mater. Res. Express 2019, 6, 126450. [CrossRef]

88. Zhou, Y.; Zhou, T.; Zhang, Y.; Tang, L.; Guo, Q.; Wang, M.; Xie, C.; Zeng, D. Synthesis of core-shell flower-like WO3@ZIF-71 with enhanced response and selectivity to H2S gas. Solid State Ion. 2020, 350, 115278. [CrossRef]

89. Drobek, M.; Kim, J.-H.; Bechelany, M.; Vallicari, C.; Julbe, A.; Kim, S.S. MOF-Based Membrane Encapsulated ZnO Nanowires for Enhanced Gas Sensor Selectivity. ACS Appl. Mater. Interfaces 2016, 8, 8323-8328. [CrossRef] [PubMed]

90. Wu, X.; Xiong, S.; Mao, Z.; Hu, S.; Long, X. A Designed ZnO@ZIF-8 Core-Shell Nanorod Film as a Gas Sensor with Excellent Selectivity for H-2 over CO. Chem. A Eur. J. 2017, 23, 7969-7975. [CrossRef]

91. Cui, F.; Chen, W.; Jin, L.; Zhang, H.; Jiang, Z.; Song, Z. Fabrication of ZIF-8 encapsulated ZnO microrods with enhanced sensing properties for H-2 detection. J. Mater. Sci. Mater. Electron. 2018, 29, 19697-19709. [CrossRef]

92. Zhou, T.; Sang, Y.; Wang, X.; Wu, C.; Zeng, D.; Xie, C. Pore size dependent gas-sensing selectivity based on ZnO@ZIF nanorod arrays. Sens. Actuators B Chem. 2018, 258, 1099-1106. [CrossRef]

93. Dmello, M.E.; Sundaram, N.G.; Kalidindi, S.B. Assembly of ZIF-67 Metal-Organic Framework over Tin Oxide Nanoparticles for Synergistic Chemiresistive $\mathrm{CO}_{2}$ Gas Sensing. Chem. A Eur. J. 2018, 24, 9220-9223. [CrossRef] [PubMed]

94. Wu, X.; Xiong, S.; Gong, Y.; Gong, Y.; Wu, W.; Mao, Z.; Liu, Q.; Hu, S.; Long, X. MOF-SMO hybrids as a H2S sensor with superior sensitivity and selectivity. Sens. Actuators B Chem. 2019, 292, 32-39. [CrossRef]

95. Zhou, T.; Sang, Y.; Sun, Y.; Wu, C.; Wang, X.; Tang, X.; Zhang, T.; Wang, H.; Xie, C.; Zeng, D. Gas Adsorption at Metal Sites for Enhancing Gas Sensing Performance of ZnO@ZIF-71 Nanorod Arrays. Langmuir 2019, 35, 3248-3255. [CrossRef]

96. Yao, M.-S.; Cao, L.-A.; Tang, Y.-X.; Wang, G.-E.; Liu, R.-H.; Kumar, P.N.; Wu, G.-D.; Deng, W.-H.; Hong, W.-J.; Xu, G. Gas transport regulation in a MO/MOF interface for enhanced selective gas detection. J. Mater. Chem. A 2019, 7, 18397-18403. [CrossRef]

97. Zhou, T.; Chen, S.; Wang, X.; Xie, C.; Zeng, D. Catalytic Activation of Cobalt Doping Sites in ZIF-71-Coated ZnO Nanorod Arrays for Enhancing Gas-Sensing Performance to Acetone. ACS Appl. Mater. Interfaces 2020, 12, 48948-48956. [CrossRef] [PubMed]

98. Park, K.S.; Ni, Z.; Cote, A.P.; Choi, J.Y.; Huang, R.; Uribe-Romo, F.J.; Chae, H.K.; O'Keeffe, M.; Yaghi, O.M. Exceptional chemical and thermal stability of zeolitic imidazolate frameworks. Proc. Natl. Acad. Sci. USA 2006, 103, 10186-10191. [CrossRef] [PubMed]

99. Matatagui, D.; Sainz-Vidal, A.; Gracia, I.; Figueras, E.; Cane, C.; Saniger, J.M. Chemoresistive gas sensor based on ZIF-8/ZIF-67 nanocrystals. Sens. Actuators B Chem. 2018, 274, 601-608. [CrossRef]

100. Phan, A.; Doonan, C.J.; Uribe-Romo, F.J.; Knobler, C.B.; O’Keeffe, M.; Yaghi, O.M. Synthesis, Structure, and Carbon Dioxide Capture Properties of Zeolitic Imidazolate Frameworks. Acc. Chem. Res. 2010, 43, 58-67. [CrossRef]

101. Sun, J.; Sun, L.; Bai, S.; Fu, H.; Guo, J.; Feng, Y.; Luo, R.; Li, D.; Chen, A. Pyrolyzing Co/Zn bimetallic organic framework to form p-n heterojunction of $\mathrm{Co}_{3} \mathrm{O}_{4} / \mathrm{ZnO}$ for detection of formaldehyde. Sens. Actuators B Chem. 2019, 285, 291-301. [CrossRef]

102. Li, W.; Zhang, Y.; Zhang, C.; Meng, Q.; Xu, Z.; Su, P.; Li, Q.; Shen, C.; Fan, Z.; Qin, L.; et al. Transformation of metal-organic frameworks for molecular sieving membranes. Nat. Commun. 2016, 7, 1-9. [CrossRef] [PubMed]

103. Zhang, K.; Lively, R.P.; Zhang, C.; Koros, W.J.; Chance, R.R. Investigating the Intrinsic Ethanol/Water Separation Capability of ZIF-8: An Adsorption and Diffusion Study. J. Phys. Chem. C 2013, 117, 7214-7225. [CrossRef] 
104. Yin, H.; Lau, C.Y.; Rozowski, M.; Howard, C.; Xu, Y.; Lai, T.; Dose, M.E.; Lively, R.P.; Lind, M.L. Free-standing ZIF-71/PDMS nanocomposite membranes for the recovery of ethanol and 1-butanol from water through pervaporation. J. Membr. Sci. 2017, 529, 286-292. [CrossRef]

105. Zhan, W.-W.; Kuang, Q.; Zhou, J.-Z.; Kong, X.-J.; Xie, Z.-X.; Zheng, L.-S. Semiconductor@Metal-Organic Framework Core-Shell Heterostructures: A Case of ZnO@ZIF-8 Nanorods with Selective Photoelectrochemical Response. J. Am. Chem. Soc. 2013, 135, 1926-1933. [CrossRef] [PubMed]

106. Li, S.; Zhang, W.; Zhu, Y.; Zhao, Q.; Huo, F. Synthesis of MOFs and Their Composite Structures through Sacrificial-Template Strategy. Cryst. Growth Des. 2015, 15, 1017-1021. [CrossRef]

107. Julien, P.A.; Uzarevic, K.; Katsenis, A.D.; Kimber, S.A.J.; Wang, T.; Farha, O.K.; Zhang, Y.; Casaban, J.; Germann, L.S.; Etter, M.; et al. In Situ Monitoring and Mechanism of the Mechanochemical Formation of a Microporous MOF-74 Framework. J. Am. Chem. Soc. 2016, 138, 2929-2932. [CrossRef] [PubMed]

108. Flaconneche, B.; Martin, J.; Klopffer, M.H. Permeability, diffusion and solubility of gases in polyethylene, polyamide 11 and poly(vinylidene fluoride). Oil Gas Sci. Technol. Rev. D Ifp Energ. Nouv. 2001, 56, 261-278. [CrossRef]

109. Ellern, I.; Venkatasubramanian, A.; Lee, J.-H.; Hesketh, P.; Stavila, V.; Robinson, A.; Allendorf, M. HKUST-1 coated piezoresistive microcantilever array for volatile organic compound sensing. Micro Nano Lett. 2013, 8, 766-769. [CrossRef]

110. Gutierrez, I.; Diaz, E.; Vega, A.; Ordonez, S. Consequences of cavity size and chemical environment on the adsorption properties of isoreticular metal-organic frameworks: An inverse gas chromatography study. J. Chromatogr. A 2013, 1274, 173-180. [CrossRef]

111. Wang, G.; Fu, Z.; Wang, T.; Lei, W.; Sun, P.; Sui, Y.; Zou, B. A rational design of hollow nanocages $\mathrm{Ag} @ \mathrm{CuO}-\mathrm{TiO}_{2}$ for enhanced acetone sensing performance. Sens. Actuators B Chem. 2019, 295, 70-78. [CrossRef]

112. Saliba, D.; Ammar, M.; Rammal, M.; Al-Ghoul, M.; Hmadeh, M. Crystal Growth of ZIF-8, ZIF-67, and Their Mixed-Metal Derivatives. J. Am. Chem. Soc. 2018, 140, 1812-1823. [CrossRef]

113. Wang, D.; Li, Z.; Zhou, J.; Fang, H.; He, X.; Jena, P.; Zeng, J.-B.; Wang, W.-N. Simultaneous Detection and Removal of Formaldehyde at Room Temperature: Janus Au@ZnO@ZIF-8 Nanoparticles. Nano Micro Lett. 2018, 10. [CrossRef] [PubMed]

114. Bai, S.; Liu, C.; Luo, R.; Chen, A. Metal organic frameworks-derived sensing material of $\mathrm{SnO}_{2} / \mathrm{NiO}$ composites for detection of triethylamine. Appl. Surf. Sci. 2018, 437, 304-313. [CrossRef]

115. Rai, P.; Majhi, S.M.; Yu, Y.T.; Lee, J.H. Noble metal@metal oxide semiconductor core@shell nano-architectures as a new platform for gas sensor applications. RSC Adv. 2015, 5, 76229-76248. [CrossRef]

116. Jiang, H.-L.; Akita, T.; Ishida, T.; Haruta, M.; Xu, Q. Synergistic Catalysis of Au@Ag Core-Shell Nanoparticles Stabilized on Metal-Organic Framework. J. Am. Chem. Soc. 2011, 133, 1304-1306. [CrossRef] [PubMed]

117. Koo, W.-T.; Yu, S.; Choi, S.-J.; Jang, J.-S.; Cheong, J.Y.; Kim, I.-D. Nanoscale PdO Catalyst Functionalized $\mathrm{Co}_{3} \mathrm{O}_{4} \mathrm{Hollow}_{\mathrm{Nanocages}}$ Using MOF Templates for Selective Detection of Acetone Molecules in Exhaled Breath. ACS Appl. Mater. Interfaces 2017, 9 , 8201-8210. [CrossRef] [PubMed]

118. Koo, W.-T.; Jang, J.-S.; Choi, S.-J.; Cho, H.-J.; Kim, I.-D. Metal-Organic Framework Templated Catalysts: Dual Sensitization of PdO-ZnO Composite on Hollow $\mathrm{SnO}_{2}$ Nanotubes for Selective Acetone Sensors. ACS Appl. Mater. Interfaces 2017, 9, 18069-18077. [CrossRef] [PubMed]

119. Koo, W.-T.; Choi, S.-J.; Kim, S.-J.; Jang, J.-S.; Tuller, H.L.; Kim, I.-D. Heterogeneous Sensitization of Metal-Organic Framework Driven Metal@Metal Oxide Complex Catalysts on an Oxide Nanofiber Scaffold Toward Superior Gas Sensors. J. Am. Chem. Soc. 2016, 138, 13431-13437. [CrossRef] [PubMed]

120. Deng, S.; Zhu, H.; Wang, G.; Luo, M.; Shen, S.; Ai, C.; Yang, L.; Lin, S.; Zhang, Q.; Gu, L.; et al. Boosting fast energy storage by synergistic engineering of carbon and deficiency. Nat. Commun. 2020, 11, 1-11. [CrossRef] [PubMed]

121. Yang, W.; Li, X.; Li, Y.; Zhu, R.; Pang, H. Applications of Metal-Organic-Framework-Derived Carbon Materials. Adv. Mater. 2019, 31, 1804740. [CrossRef] [PubMed]

122. Wei, J.; Hu, Y.; Liang, Y.; Kong, B.; Zheng, Z.; Zhang, J.; Jiang, S.P.; Zhao, Y.; Wang, H. Graphene oxide/core-shell structured metal-organic framework nano-sandwiches and their derived cobalt/N-doped carbon nanosheets for oxygen reduction reactions. J. Mater. Chem. A 2017, 5, 10182-10189. [CrossRef]

123. Liu, P.; Gao, S.; Wang, Y.; Huang, Y.; He, W.; Huang, W.; Luo, J. Carbon nanocages with N-doped carbon inner shell and Co/N-doped carbon outer shell as electromagnetic wave absorption materials. Chem. Eng. J. 2020, 381, 122653. [CrossRef]

124. Varghese, S.S.; Lonkar, S.; Singh, K.K.; Swaminathan, S.; Abdala, A. Recent advances in graphene based gas sensors. Sens. Actuators B Chem. 2015, 218, 160-183. [CrossRef]

125. Zhang, H.; Fan, L.; Dong, H.; Zhang, P.; Nie, K.; Zhong, J.; Li, Y.; Guo, J.; Sun, X. Spectroscopic Investigation of Plasma-Fluorinated Monolayer Graphene and Application for Gas Sensing. ACS Appl. Mater. Interfaces 2016, 8, 8652-8661. [CrossRef]

126. Naguib, M.; Kurtoglu, M.; Presser, V.; Lu, J.; Niu, J.; Heon, M.; Hultman, L.; Gogotsi, Y.; Barsoum, M.W. Two-Dimensional Nanocrystals Produced by Exfoliation of Ti3AlC2. Adv. Mater. 2011, 23, 4248-4253. [CrossRef] [PubMed]

127. Schroeder, V.; Savagatrup, S.; He, M.; Ling, S.; Swager, T.M. Carbon Nanotube Chemical Sensors. Chem. Rev. 2019, 119, 599-663. [CrossRef]

128. Ingle, N.; Sayyad, P.; Deshmukh, M.; Bodkhe, G.; Mahadik, M.; Al-Gahouari, T.; Shirsat, S.; Shirsat, M.D. A chemiresistive gas sensor for sensitive detection of $\mathrm{SO}_{2}$ employing Ni-MOF modified -OH-SWNTs and -OH-MWNTs. Appl. Phys. A Mater. Sci. Process. 2021, 127. [CrossRef] 
129. Sule, R.; Mishra, A.K. MOFs-carbon hybrid nanocomposites in environmental protection applications. Environ. Sci. Pollut. Res. 2020, 27, 16004-16018. [CrossRef]

130. Liu, X.-W.; Sun, T.-J.; Hu, J.-L.; Wang, S.-D. Composites of metal-organic frameworks and carbon-based materials: Preparations, functionalities and applications. J. Mater. Chem. A 2016, 4, 3584-3616. [CrossRef]

131. Travlou, N.A.; Singh, K.; Rodriguez-Castellon, E.; Bandosz, T.J. Cu-BTC MOF-graphene-based hybrid materials as low concentration ammonia sensors. J. Mater. Chem. A 2015, 3, 11417-11429. [CrossRef]

132. Yin, Y.; Zhang, H.; Huang, P.; Xiang, C.; Zou, Y.; Xu, F.; Sun, L. Inducement of nanoscale Cu-BTC on nanocomposite of PPy-rGO and its performance in ammonia sensing. Mater. Res. Bull. 2018, 99, 152-160. [CrossRef]

133. Bhardwaj, S.K.; Mohanta, G.C.; Sharma, A.L.; Kim, K.-H.; Deep, A. A three-phase copper MOF-graphene-polyaniline composite for effective sensing of ammonia. Anal. Chim. Acta 2018, 1043, 89-97. [CrossRef] [PubMed]

134. Jafari, N.; Zeinali, S.; Shadmehr, J. Room temperature resistive gas sensor based on ZIF-8/MWCNT/AgNPs nanocomposite for VOCs detection. J. Mater. Sci. Mater. Electron. 2019, 30, 12339-12350. [CrossRef]

135. Tan, J.; Hussain, S.; Ge, C.; Zhan, M.; Liu, J.; Liu, S.; Liu, G.; Qiao, G. Construction of hierarchical trimetallic organic framework leaf-like nanostructures derived from carbon nanotubes for gas-sensing applications. J. Hazard. Mater. 2020, $400,123155$. [CrossRef] [PubMed]

136. Ingle, N.; Mane, S.; Sayyad, P.; Bodkhe, G.; Al-Gahouari, T.; Mahadik, M.; Shirsat, S.; Shirsat, M.D. Sulfur Dioxide (SO 2 ) Detection Using Composite of Nickel Benzene Carboxylic (Ni3BTC2) and OH-Functionalized Single Walled Carbon Nanotubes (OH-SWNTs). Front. Mater. 2020, 7, 93. [CrossRef]

137. Wong, D.; Abuzalat, O.; Mostafa, S.; Park, S.S.; Kim, S. Intense pulsed light-based synthesis of hybrid $\mathrm{TiO}_{2}-\mathrm{SnO}_{2} / \mathrm{MWCNT} \mathrm{doped}$ Cu-BTC for room temperature ammonia sensing. J. Mater. Chem. C 2020, 8, 7567-7574. [CrossRef]

138. Sun, Y.; Ma, M.; Tang, B.; Li, S.; Jiang, L.; Sun, X.; Que, M.; Tao, C.; Wu, Z. Graphene modified Cu-BTC with high stability in water and controllable selective adsorption of various gases. J. Alloy. Compd. 2019, 808, 151721. [CrossRef]

139. Yang, S.J.; Choi, J.Y.; Chae, H.K.; Cho, J.H.; Nahm, K.S.; Park, C.R. Preparation and Enhanced Hydrostability and Hydrogen Storage Capacity of CNT@MOF-5 Hybrid Composite. Chem. Mater. 2009, 21, 1893-1897. [CrossRef]

140. Huang, Z.-H.; Liu, G.; Kang, F. Glucose-Promoted Zn-Based Metal-Organic Framework/Graphene Oxide Composites for Hydrogen Sulfide Removal. ACS Appl. Mater. Interfaces 2012, 4, 4942-4947. [CrossRef]

141. Sofi, F.A.; Majid, K.; Mehraj, O. The visible light driven copper based metal-organic-framework heterojunction:HKUST-1@Ag$\mathrm{Ag} \mathrm{PO}_{4}$ for plasmon enhanced visible light photocatalysis. J. Alloy. Compd. 2018, 737, 798-808. [CrossRef]

142. Yu, L.; Liu, Q.; Dai, W.; Tian, N.; Ma, N. Efficient thiophene capture with a hydrophobic Cu-BTC-(n)Br adsorbent in the presence of moisture. Microporous Mesoporous Mater. 2018, 266, 7-13. [CrossRef]

143. Zhou, C.; Cao, L.; Wei, S.; Zhang, Q.; Chen, L. A first principles study of gas adsorption on charged Cu-BTC. Comput. Theor. Chem. 2011, 976, 153-160. [CrossRef]

144. Bandosz, T.J.; Petit, C. MOF/graphite oxide hybrid materials: Exploring the new concept of adsorbents and catalysts. Adsorpt. J. Int. Adsorpt. Soc. 2011, 17, 5-16. [CrossRef]

145. Petit, C.; Huang, L.; Jagiello, J.; Kenvin, J.; Gubbins, K.E.; Bandosz, T.J. Toward Understanding Reactive Adsorption of Ammonia on Cu-MOF/Graphite Oxide Nanocomposites. Langmuir 2011, 27, 13043-13051. [CrossRef]

146. Petit, C.; Mendoza, B.; Bandosz, T.J. Reactive Adsorption of Ammonia on Cu-Based MOF/Graphene Composites. Langmuir 2010, 26, 15302-15309. [CrossRef] [PubMed]

147. Watanabe, T.; Sholl, D.S. Molecular chemisorption on open metal sites in Cu-3(benzenetricarboxylate)(2): A spatially periodic density functional theory study. J. Chem. Phys. 2010, 133, 094509. [CrossRef]

148. Peterson, G.W.; Wagner, G.W.; Balboa, A.; Mahle, J.; Sewell, T.; Karwacki, C.J. Ammonia Vapor Removal by Cu-3(BTC)(2) and Its Characterization by MAS NMR. J. Phys. Chem. C 2009, 113, 13906-13917. [CrossRef] [PubMed]

149. Petit, C.; Burress, J.; Bandosz, T.J. The synthesis and characterization of copper-based metal-organic framework/graphite oxide composites. Carbon 2011, 49, 563-572. [CrossRef]

150. Lin, Z.; Lv, Z.; Zhou, X.; Xiao, H.; Wu, J.; Li, Z. Postsynthetic Strategy To Prepare ACN@Cu-BTCs with Enhanced Water Vapor Stability and $\mathrm{CO}_{2} / \mathrm{CH}_{4}$ Separation Selectivity. Ind. Eng. Chem. Res. 2018, 57, 3765-3772. [CrossRef]

151. Li, H.; Lin, Z.; Zhou, X.; Wang, X.; Li, Y.; Wang, H.; Li, Z. Ultrafast room temperature synthesis of novel composites Imi@Cu-BTC with improved stability against moisture. Chem. Eng. J. 2017, 307, 537-543. [CrossRef]

152. Yao, W.; Liu, L.; Wu, X.; Qin, C.; Xie, H.; Su, Z. Polyoxometalates/Active Carbon Thin Separator for Improving Cycle Performance of Lithium-Sulfur Batteries. ACS Appl. Mater. Interfaces 2018, 10, 35911-35918. [CrossRef] [PubMed]

153. Sakaushi, K.; Eckardt, M.; Lyalin, A.; Taketsugu, T.; Behm, R.J.; Uosaki, K. Microscopic Electrode Processes in the Four-Electron Oxygen Reduction on Highly Active Carbon-Based Electrocatalysts. Acs Catal. 2018, 8, 8162-8176. [CrossRef]

154. Deng, X.; Shi, W.; Zhong, Y.; Zhou, W.; Liu, M.; Shao, Z. Facile Strategy to Low-Cost Synthesis of Hierarchically Porous, Active Carbon of High Graphitization for Energy Storage. Acs Appl. Mater. Interfaces 2018, 10, 21573-21581. [CrossRef] [PubMed]

155. Rieter, W.J.; Taylor, K.M.L.; Lin, W. Surface modification and functionalization of nanoscale metal-organic frameworks for controlled release and luminescence sensing. J. Am. Chem. Soc. 2007, 129, 9852-9853. [CrossRef]

156. Petit, C.; Bandosz, T.J. Synthesis, Characterization, and Ammonia Adsorption Properties of Mesoporous Metal-Organic Framework (MIL(Fe))-Graphite Oxide Composites: Exploring the Limits of Materials Fabrication. Adv. Funct. Mater. 2011, 21, $2108-2117$. [CrossRef] 
157. Patel, D.G.; Walton, I.M.; Cox, J.M.; Gleason, C.J.; Butzer, D.R.; Benedict, J.B. Photoresponsive porous materials: The design and synthesis of photochromic diarylethene-based linkers and a metal-organic framework. Chem. Commun. 2014, 50, $2653-2656$. [CrossRef]

158. Zhu, P.; Sumpter, B.G.; Meunier, V. Electronic, Thermal, and Structural Properties of Graphene Oxide Frameworks. J. Phys. Chem. C 2013, 117, 8276-8281. [CrossRef]

159. Szczesniak, B.; Choma, J.; Jaroniec, M. Ultrahigh benzene adsorption capacity of graphene-MOF composite fabricated via MOF crystallization in 3D mesoporous graphene. Microporous Mesoporous Mater. 2019, 279, 387-394. [CrossRef]

160. Jabbari, V.; Veleta, J.M.; Zarei-Chaleshtori, M.; Gardea-Torresdey, J.; Villagran, D. Green synthesis of magnetic MOF@GO and MOF@CNT hybrid nanocomposites with high adsorption capacity towards organic pollutants. Chem. Eng. J. 2016, 304, 774-783. [CrossRef]

161. Wang, Y.; Hou, C.; Zhang, Y.; He, F.; Liu, M.; Li, X. Preparation of graphene nano-sheet bonded PDA/MOF microcapsules with immobilized glucose oxidase as a mimetic multi-enzyme system for electrochemical sensing of glucose. J. Mater. Chem. B 2016, 4 , 3695-3702. [CrossRef] [PubMed]

162. Yang, P.; Liu, Q.; Liu, J.; Zhang, H.; Li, Z.; Li, R.; Liu, L.; Wang, J. Interfacial growth of a metal-organic framework (UiO-66) on functionalized graphene oxide (GO) as a suitable seawater adsorbent for extraction of uranium(VI). J. Mater. Chem. A 2017, 5, 17933-17942. [CrossRef]

163. Tang, Y.; Zheng, S.; Xu, Y.; Xiao, X.; Xue, H.; Pang, H. Advanced batteries based on manganese dioxide and its composites. Energy Storage Mater. 2018, 12, 284-309. [CrossRef]

164. Dong, L.; Chen, M.; Li, J.; Shi, D.; Dong, W.; Li, X.; Bai, Y. Metal-organic framework-graphene oxide composites: A facile method to highly improve the $\mathrm{CO}_{2}$ separation performance of mixed matrix membranes. J. Membr. Sci. 2016, 520, 801-811. [CrossRef]

165. Banerjee, P.C.; Lobo, D.E.; Middag, R.; Ng, W.K.; Shaibani, M.E.; Majumder, M. Electrochemical Capacitance of Ni-Doped Metal Organic Framework and Reduced Graphene Oxide Composites: More than the Sum of Its Parts. ACS Appl. Mater. Interfaces 2015, 7, 3655-3664. [CrossRef] [PubMed]

166. Talin, A.A.; Centrone, A.; Ford, A.C.; Foster, M.E.; Stavila, V.; Haney, P.; Kinney, R.A.; Szalai, V.; El Gabaly, F.; Yoon, H.P.; et al. Tunable Electrical Conductivity in Metal-Organic Framework Thin-Film Devices. Science 2014, 343, 66-69. [CrossRef] [PubMed]

167. Jahan, M.; Bao, Q.; Yang, J.-X.; Loh, K.P. Structure-Directing Role of Graphene in the Synthesis of Metal-Organic Framework Nanowire. J. Am. Chem. Soc. 2010, 132, 14487-14495. [CrossRef] [PubMed]

168. Allendorf, M.D.; Schwartzberg, A.; Stavila, V.; Talin, A.A. A Roadmap to Implementing Metal-Organic Frameworks in Electronic Devices: Challenges and Critical Directions. Chem. A Eur. J. 2011, 17, 11372-11388. [CrossRef] [PubMed]

169. Bian, Z.; Xu, J.; Zhang, S.; Zhu, X.; Liu, H.; Hu, J. Interfacial Growth of Metal Organic Framework/Graphite Oxide Composites through Pickering Emulsion and Their $\mathrm{CO}_{2}$ Capture Performance in the Presence of Humidity. Langmuir 2015, 31, 7410-7417. [CrossRef] [PubMed]

170. Vo, T.K.; Trinh, T.P.; Nguyen, V.C.; Kim, J. Facile synthesis of graphite oxide/MIL-101(Cr) hybrid composites for enhanced adsorption performance towards industrial toxic dyes. J. Ind. Eng. Chem. 2021, 95, 224-234. [CrossRef]

171. Esfandiari, K.; Mandavi, A.R.; Ghoreyshri, A.A.; Jahanshahi, M. Optimizing parameters affecting synthetize of CuBTC using response surface methodology and development of AC@CuBTC composite for enhanced hydrogen uptake. Int. J. Hydrog. Energy 2018, 43, 6654-6665. [CrossRef]

172. Dastbaz, A.; Karimi-Sabet, J.; Moosavian, M.A. Sonochemical synthesis of novel decorated graphene nanosheets with amine functional $\mathrm{Cu}$-terephthalate MOF for hydrogen adsorption: Effect of ultrasound and graphene content. Int. J. Hydrog. Energy 2019, 44, 26444-26458. [CrossRef]

173. Zheng, Y.; Zheng, S.; Xue, H.; Pang, H. Metal-Organic Frameworks/Graphene-Based Materials: Preparations and Applications. Adv. Funct. Mater. 2018, 28, 1804950. [CrossRef]

174. Wen, P.; Gong, P.; Sun, J.; Wang, J.; Yang, S. Design and synthesis of Ni-MOF/CNT composites and rGO/carbon nitride composites for an asymmetric supercapacitor with high energy and power density. J. Mater. Chem. A 2015, 3, 13874-13883. [CrossRef]

175. Zhang, F.; Liu, L.; Tan, X.; Sang, X.; Zhang, J.; Liu, C.; Zhang, B.; Han, B.; Yang, G. Pickering emulsions stabilized by a metalorganic framework (MOF) and graphene oxide (GO) for producing MOF/GO composites. Soft Matter 2017, 13, 7365-7370. [CrossRef] [PubMed]

176. Pera-Titus, M.; Leclercq, L.; Clacens, J.-M.; De Campo, F.; Nardello-Rataj, V. Pickering Interfacial Catalysis for Biphasic Systems: From Emulsion Design to Green Reactions. Angew. Chem. Int. Ed. 2015, 54, 2006-2021. [CrossRef]

177. Zhu, H.; Zhang, Q.; Zhu, S. Assembly of a Metal-Organic Framework into 3D Hierarchical Porous Monoliths Using a Pickering High Internal Phase Emulsion Template. Chem. A Eur. J. 2016, 22, 8751-8755. [CrossRef]

178. Zhang, B.; Zhang, J.; Liu, C.; Peng, L.; Sang, X.; Han, B.; Ma, X.; Luo, T.; Tan, X.; Yang, G. High-internal-phase emulsions stabilized by metal-organic frameworks and derivation of ultralight metal-organic aerogels. Sci. Rep. 2016, 6, 21401. [CrossRef] [PubMed]

179. Zhang, B.; Zhang, J.; Sang, X.; Liu, C.; Luo, T.; Peng, L.; Han, B.; Tan, X.; Ma, X.; Wang, D.; et al. Cellular graphene aerogel combines ultralow weight and high mechanical strength: A highly efficient reactor for catalytic hydrogenation. Sci. Rep. 2016, 6, 25830. [CrossRef] [PubMed]

180. Shao, J.-J.; Lv, W.; Yang, Q.-H. Self-Assembly of Graphene Oxide at Interfaces. Adv. Mater. 2014, 26, 5586-5612. [CrossRef]

181. Levasseur, B.; Petit, C.; Bandosz, T.J. Reactive Adsorption of $\mathrm{NO}_{2}$ on Copper-Based Metal-Organic Framework and Graphite Oxide/Metal-Organic Framework Composites. ACS Appl. Mater. Interfaces 2010, 2, 3606-3613. [CrossRef] [PubMed] 
182. He, Y.; Wu, F.; Sun, X.; Li, R.; Guo, Y.; Li, C.; Zhang, L.; Xing, F.; Wang, W.; Gao, J. Factors that Affect Pickering Emulsions Stabilized by Graphene Oxide. ACS Appl. Mater. Interfaces 2013, 5, 4843-4855. [CrossRef] [PubMed]

183. Liu, S.; Sun, L.; Xu, F.; Zhang, J.; Jiao, C.; Li, F.; Li, Z.; Wang, S.; Wang, Z.; Jiang, X.; et al. Nanosized Cu-MOFs induced by graphene oxide and enhanced gas storage capacity. Energy Environ. Sci. 2013, 6, 818-823. [CrossRef]

184. Bashkova, S.; Bandosz, T.J. Insight into the role of the oxidized graphite precursor on the properties of copper-based MOF/graphite oxide composites. Microporous Mesoporous Mater. 2013, 179, 205-211. [CrossRef]

185. Ahsan, M.A.; Jabbari, V.; Islam, M.T.; Turley, R.S.; Dominguez, N.; Kim, H.; Castro, E.; Hernandez-Viezcas, J.A.; Curry, M.L.; Lopez, J.; et al. Sustainable synthesis and remarkable adsorption capacity of MOF/graphene oxide and MOF/CNT based hybrid nanocomposites for the removal of Bisphenol A from water. Sci. Total Environ. 2019, 673, 306-317. [CrossRef] [PubMed]

186. Chappanda, K.N.; Shekhah, O.; Yassine, O.; Patole, S.P.; Eddaoudi, M.; Salama, K.N. The quest for highly sensitive QCM humidity sensors: The coating of CNT/MOF composite sensing films as case study. Sens. Actuators B Chem. 2018, 257, 609-619. [CrossRef]

187. Tran Thanh, T.; Manh Trung, T.; Feller, J.-F.; Castro, M.; Truc Van, N.; Hassan, K.; Nine, M.J.; Losic, D. Graphene and metal organic frameworks (MOFs) hybridization for tunable chemoresistive sensors for detection of volatile organic compounds (VOCs) biomarkers. Carbon 2020, 159, 333-344. [CrossRef]

188. Ellis, J.E.; Zeng, Z.; Hwang, S.I.; Li, S.; Luo, T.-Y.; Burkert, S.C.; White, D.L.; Rosi, N.L.; Gassensmith, J.J.; Star, A. Growth of ZIF-8 on molecularly ordered 2-methylimidazole/single-walled carbon nanotubes to form highly porous, electrically conductive composites. Chem. Sci. 2019, 10, 737-742. [CrossRef]

189. Jian, M.; Liu, B.; Liu, R.; Qu, J.; Wang, H.; Zhang, X. Water-based synthesis of zeolitic imidazolate framework-8 with high morphology level at room temperature. RSC Adv. 2015, 5, 48433-48441. [CrossRef]

190. Lo, Y.; Lam, C.H.; Chang, C.-W.; Yang, A.-C.; Kang, D.-Y. Polymorphism/pseudopolymorphism of metalorganic frameworks composed of Zinc(II) and 2methylimidazole: Synthesis, stability, and application in gas storage. RSC Adv. 2016, 6, 89148-89156. [CrossRef]

191. Chen, C.; Li, B.; Zhou, L.; Xia, Z.; Feng, N.; Ding, J.; Wang, L.; Wan, H.; Guan, G. Synthesis of Hierarchically Structured Hybrid Materials by Controlled Self-Assembly of Metal Organic Framework with Mesoporous Silica for $\mathrm{CO}_{2}$ Adsorption. ACS Appl. Mater. Interfaces 2017, 9, 23060-23071. [CrossRef] [PubMed]

192. Li, Z.-F.; Zhang, H.; Liu, Q.; Sun, L.; Stanciu, L.; Xie, J. Fabrication of High-Surface-Area Graphene/Polyaniline Nanocomposites and Their Application in Supercapacitors. ACS Appl. Mater. Interfaces 2013, 5, 2685-2691. [CrossRef] [PubMed]

193. Mun, S.; Chen, Y.; Kim, J. Cellulose-titanium dioxide-multiwalled carbon nanotube hybrid nanocomposite and its ammonia gas sensing properties at room temperature. Sens. Actuators B Chem. 2012, 171, 1186-1191. [CrossRef]

194. Liu, J.; Wei, Y.; Li, P.; Zhao, Y.; Zou, R. Selective H2S/CO 2 Separation by Metal-Organic Frameworks Based on Chemical-Physical Adsorption. J. Phys. Chem. C 2017, 121, 13249-13255. [CrossRef]

195. Wang, H.; Qu, Z.G.; Zhang, W.; Yu, Q.N.; He, Y.L. Experimental and numerical study of $\mathrm{CO}_{2}$ adsorption on copper benzene-1,3,5tricarboxylate (Cu-BTC) metal organic framework. Int. J. Heat Mass Transf. 2016, 92, 859-863. [CrossRef]

196. Zhao, Z.; Li, Z.; Lin, Y.S. Adsorption and Diffusion of Carbon Dioxide on Metal-Organic Framework (MOF-5). Ind. Eng. Chem. Res. 2009, 48, 10015-10020. [CrossRef]

197. Gautam, S.; Cole, D. $\mathrm{CO}_{2}$ Adsorption in Metal-Organic Framework Mg-MOF-74: Effects of Inter-Crystalline Space. Nanomaterials 2020, 10, 2274. [CrossRef]

198. Barea, E.; Montoro, C.; Navarro, J.A.R. Toxic gas removal-metal-organic frameworks for the capture and degradation of toxic gases and vapours. Chem. Soc. Rev. 2014, 43, 5419-5430. [CrossRef]

199. Petit, C.; Levasseur, B.; Mendoza, B.; Bandosz, T.J. Reactive adsorption of acidic gases on MOF/graphite oxide composites. Microporous Mesoporous Mater. 2012, 154, 107-112. [CrossRef]

200. Zhao, Y.; Seredych, M.; Zhong, Q.; Bandosz, T.J. Aminated graphite oxides and their composites with copper-based metal-organic framework: In search for efficient media for $\mathrm{CO}_{2}$ sequestration. RSC Adv. 2013, 3, 9932-9941. [CrossRef]

201. Ning, H.; Yang, Z.; Yin, Z.; Wang, D.; Meng, Z.; Wang, C.; Zhang, Y.; Chen, Z. A Novel Strategy to Enhance the Performance of $\mathrm{CO}_{2}$ Adsorption Separation: Grafting Hyper-cross-linked Polyimide onto Composites of UiO-66-NH2 and GO. ACS Appl. Mater. Interfaces 2021, 13, 17781-17790. [CrossRef] [PubMed]

202. Zhao, Y.; Seredych, M.; Zhong, Q.; Bandosz, T.J. Superior Performance of Copper Based MOF and Aminated Graphite Oxide Composites as $\mathrm{CO}_{2}$ Adsorbents at Room Temperature. ACS Appl. Mater. Interfaces 2013, 5, 4951-4959. [CrossRef] [PubMed]

203. Policicchio, A.; Zhao, Y.; Zhong, Q.; Agostino, R.G.; Bandosz, T.J. Cu-BTC/Aminated Graphite Oxide Composites As HighEfficiency $\mathrm{CO}_{2}$ Capture Media. ACS Appl. Mater. Interfaces 2014, 6, 101-108. [CrossRef] [PubMed]

204. Zhao, Y.; Seredych, M.; Jagiello, J.; Zhong, Q.; Bandosz, T.J. Insight into the mechanism of $\mathrm{CO}_{2}$ adsorption on Cu-BTC and its composites with graphite oxide or aminated graphite oxide. Chem. Eng. J. 2014, 239, 399-407. [CrossRef]

205. Cavka, J.H.; Jakobsen, S.; Olsbye, U.; Guillou, N.; Lamberti, C.; Bordiga, S.; Lillerud, K.P. A new zirconium inorganic building brick forming metal organic frameworks with exceptional stability. J. Am. Chem. Soc. 2008, 130, 13850-13851. [CrossRef] [PubMed]

206. Daraee, M.; Ghasemy, E.; Rashidi, A. Synthesis of novel and engineered UiO-66/graphene oxide nanocomposite with enhanced H2S adsorption capacity. J. Environ. Chem. Eng. 2020, 8, 104351. [CrossRef]

207. McCullough, R.D. The chemistry of conducting polythiophenes. Adv. Mater. 1998, 10, 93-116. [CrossRef] 
208. Wong, Y.C.; Ang, B.C.; Haseeb, A.S.M.A.; Baharuddin, A.A.; Wong, Y.H. Review-Conducting Polymers as Chemiresistive Gas Sensing Materials: A Review. J. Electrochem. Soc. 2019, 167, 037503. [CrossRef]

209. Waghuley, S.A.; Yenorkar, S.M.; Yawale, S.S.; Yawale, S.P. Application of chemically synthesized conducting polymer-polypyrrole as a carbon dioxide gas sensor. Sens. Actuators B Chem. 2008, 128, 366-373. [CrossRef]

210. Joshi, A.; Gangal, S.A.; Gupta, S.K. Ammonia sensing properties of polypyrrole thin films at room temperature. Sens. Actuators B Chem. 2011, 156, 938-942. [CrossRef]

211. Hassanzadeh, N.; Omidvar, H.; Tabaian, S.H. Chemical synthesis of high density and long polypyrrole nanowire arrays using alumina membrane and their hydrogen sensing properties. Superlattices Microstruct. 2012, 51, 314-323. [CrossRef]

212. Su, P.-G.; Lee, C.-T.; Chou, C.-Y. Flexible NH3 sensors fabricated by in situ self-assembly of polypyrrole. Talanta 2009, 80, 763-769. [CrossRef]

213. Malkeshi, H.; Moghaddam, H.M. Ammonia gas-sensing based on polythiophene film prepared through electrophoretic deposition method. J. Polym. Res. 2016, 23, 108. [CrossRef]

214. Bai, S.; Guo, J.; Sun, J.; Tang, P.; Chen, A.; Luo, R.; Li, D. Enhancement of $\mathrm{NO}_{2}$-Sensing Performance at Room Temperature by Graphene-Modified Polythiophene. Ind. Eng. Chem. Res. 2016, 55, 5788-5794. [CrossRef]

215. Dunst, K.; Karczewski, J.; Jasinski, P. Nitrogen dioxide sensing properties of PEDOT polymer films. Sens. Actuators B Chem. 2017, 247, 108-113. [CrossRef]

216. Yoon, H.; Chang, M.; Jang, J. Formation of 1D poly(3,4-ethylenedioxythiophene) nanomaterials in reverse microemulsions and their application to chemical sensors. Adv. Funct. Mater. 2007, 17, 431-436. [CrossRef]

217. Shaik, M.; Rao, V.K.; Sinha, A.K.; Murthy, K.S.R.C.; Jain, R. Sensitive detection of nitrogen dioxide gas at room temperature using poly(3,4-ethylenedioxythiophene) nanotubes. J. Environ. Chem. Eng. 2015, 3, 1947-1952. [CrossRef]

218. Harale, N.S.; Nagare, A.B.; Mali, S.S.; Suryawanshi, M.P.; Sharma, K.K.K.; Rao, V.K.; Hong, C.K.; Kim, J.H.; Patil, P.S. Facile Synthesis of Nanofibrous Polyaniline Thin Films for Ammonia Gas Detection. J. Electron. Mater. 2020, 49, 1338-1347. [CrossRef]

219. Liu, J.; Cui, N.; Xu, Q.; Wang, Z.; Gu, L.; Dou, W. High-Performance PANI-Based Ammonia Gas Sensor Promoted by Surface Nanostructuralization. ECS J. Solid State Sci. Technol. 2021, 10, 027007. [CrossRef]

220. Abe, S.; Kijima, M.; Shirakawa, H. Effect of mesogenic cores and length of spacers on liquid crystallinity of N-substituted polypyrrole derivatives. Synth. Met. 2001, 119, 421-422. [CrossRef]

221. Goren, M.; Lennox, R.B. Nanoscale polypyrrole patterns using block copolymer surface micelles as templates. Nano Lett. 2001, 1, 735-738. [CrossRef]

222. Somani, P.R.; Marimuthu, R.; Mulik, U.P.; Sainkar, S.R.; Amalnerkar, D.P. High piezoresistivity and its origin in conducting polyaniline $/ \mathrm{TiO}_{2}$ composites. Synth. Met. 1999, 106, 45-52. [CrossRef]

223. Wang, S.X.; Tan, Z.C.; Li, Y.S.; Sun, L.X.; Zhang, T. Synthesis, characterization and thermal analysis of polyaniline $/ \mathrm{ZrO}_{2}$ composites. Thermochim. Acta 2006, 441, 191-194. [CrossRef]

224. Yuvaraja, S.; Surya, S.G.; Chernikova, V.; Vijjapu, M.T.; Shekhah, O.; Bhatt, P.M.; Chandra, S.; Eddaoudi, M.; Salama, K.N. Realization of an Ultrasensitive and Highly Selective OFET $\mathrm{NO}_{2}$ Sensor: The Synergistic Combination of PDVT-10 Polymer and Porphyrin-MOF. ACS Appl. Mater. Interfaces 2020, 12, 18748-18760. [CrossRef] [PubMed]

225. Sachdeva, S.; Soccol, D.; Gravesteijn, D.J.; Kapteijn, F.; Sudholter, E.J.R.; Gascon, J.; de Smett, L.C.P.M. Polymer-Metal Organic Framework Composite Films as Affinity Layer for Capacitive Sensor Devices. ACS Sens. 2016, 1, 1188-1192. [CrossRef]

226. Yang, S.; Karve, V.V.; Justin, A.; Kochetygov, I.; Espin, J.; Asgari, M.; Trukhina, O.; Sun, D.T.; Peng, L.; Queen, W.L. Enhancing MOF performance through the introduction of polymer guests. Coord. Chem. Rev. 2021, 427, 213525. [CrossRef]

227. Ding, N.; Li, H.; Feng, X.; Wang, Q.; Wang, S.; Ma, L.; Zhou, J.; Wang, B. Partitioning MOF-5 into Confined and Hydrophobic Compartments for Carbon Capture under Humid Conditions. J. Am. Chem. Soc. 2016, 138, 10100-10103. [CrossRef]

228. Gamage, N.-D.H.; McDonald, K.A.; Matzger, A.J. MOF-5-Polystyrene: Direct Production from Monomer, Improved Hydrolytic Stability, and Unique Guest Adsorption. Angew. Chem. Int. Ed. 2016, 55, 12099-12103. [CrossRef] [PubMed]

229. Duan, P.; Moreton, J.C.; Tavares, S.R.; Semino, R.; Maurin, G.; Cohen, S.M.; Schmidt-Rohr, K. Polymer Infiltration into MetalOrganic Frameworks in Mixed-Matrix Membranes Detected in Situ by NMR. J. Am. Chem. Soc. 2019, 141, 7589-7595. [CrossRef] [PubMed]

230. Gul-E-Noor, F.; Jee, B.; Poeppl, A.; Hartmann, M.; Himsl, D.; Bertmer, M. Effects of varying water adsorption on a Cu-3(BTC)(2) metal-organic framework (MOF) as studied by H-1 and C-13 solid-state NMR spectroscopy. Phys. Chem. Chem. Phys. 2011, 13, 7783-7788. [CrossRef]

231. Peng, Y.; Krungleviciute, V.; Eryazici, I.; Hupp, J.T.; Farha, O.K.; Yildirim, T. Methane Storage in Metal-Organic Frameworks: Current Records, Surprise Findings, and Challenges. J. Am. Chem. Soc. 2013, 135, 11887-11894. [CrossRef]

232. Carne-Sanchez, A.; Stylianou, K.C.; Carbonell, C.; Naderi, M.; Imaz, I.; Maspoch, D. Protecting Metal-Organic Framework Crystals from Hydrolytic Degradation by Spray-Dry Encapsulating Them into Polystyrene Microspheres. Adv. Mater. 2015, 27, 869-873. [CrossRef]

233. Iizuka, T.; Honjo, K.; Uemura, T. Enhanced mechanical properties of a metal-organic framework by polymer insertion. Chem. Commun. 2019, 55, 691-694. [CrossRef]

234. Yoo, D.K.; Khan, N.A.; Jhung, S.H. Polyaniline-loaded metal-organic framework MIL-101(Cr): Promising adsorbent for CO 2 capture with increased capacity and selectivity by polyaniline introduction. J. CO2 Util. 2018, 28, 319-325. [CrossRef] 
235. Xian, S.; Wu, Y.; Wu, J.; Wang, X.; Xiao, J. Enhanced Dynamic $\mathrm{CO}_{2}$ Adsorption Capacity and $\mathrm{CO}_{2} / \mathrm{CH}_{4}$ Selectivity on Polyethylenimine-Impregnated UiO-66. Ind. Eng. Chem. Res. 2015, 54, 11151-11158. [CrossRef]

236. Xian, S.; Xu, F.; Ma, C.; Wu, Y.; Xia, Q.; Wang, H.; Li, Z. Vapor-enhanced $\mathrm{CO}_{2}$ adsorption mechanism of composite PEI@ZIF-8 modified by polyethyleneimine for $\mathrm{CO}_{2} / \mathrm{N}-2$ separation. Chem. Eng. J. 2015, 280, 363-369. [CrossRef]

237. Yan, Q.; Lin, Y.; Kong, C.; Chen, L. Remarkable $\mathrm{CO}_{2} / \mathrm{CH}_{4}$ selectivity and $\mathrm{CO}_{2}$ adsorption capacity exhibited by polyaminedecorated metal-organic framework adsorbents. Chem. Commun. 2013, 49, 6873-6875. [CrossRef] [PubMed]

238. Shen, Y.; Li, Z.; Wang, L.; Ye, Y.; Liu, Q.; Ma, X.; Chen, Q.; Zhang, Z.; Xiang, S. Cobalt-citrate framework armored with graphene oxide exhibiting improved thermal stability and selectivity for biogas decarburization. J. Mater. Chem. A 2015, 3, 593-599. [CrossRef]

239. Jadhav, A.; Gupta, K.; Ninawe, P.; Ballav, N. Imparting Multifunctionality by Utilizing Biporosity in a Zirconium-Based MetalOrganic Framework. Angew. Chem. Int. Ed. 2020, 59, 2215-2219. [CrossRef] [PubMed]

240. Uemura, T.; Kadowaki, Y.; Yanai, N.; Kitagawa, S. Template Synthesis of Porous Polypyrrole in 3D Coordination Nanochannels. Chem. Mater. 2009, 21, 4096-4098. [CrossRef]

241. Mashao, G.; Modibane, K.D.; Mdluli, S.B.; Iwuoha, E.I.; Hato, M.J.; Makgopa, K.; Molapo, K.M. Polyaniline-Cobalt Benzimidazolate Zeolitic Metal-Organic Framework Composite Material for Electrochemical Hydrogen Gas Sensing. Electrocatalysis 2019, 10, 406-419. [CrossRef]

242. Zhang, Y.; Feng, X.; Li, H.; Chen, Y.; Zhao, J.; Wang, S.; Wang, L.; Wang, B. Photoinduced Postsynthetic Polymerization of a Metal-Organic Framework toward a Flexible Stand-Alone Membrane. Angew. Chem. Int. Ed. 2015, 54, 4259-4263. [CrossRef] [PubMed]

243. Sun, D.T.; Peng, L.; Reeder, W.S.; Moosavi, S.M.; Tiana, D.; Britt, D.K.; Oveisi, E.; Queen, W.L. Rapid, Selective Heavy Metal Removal from Water by a Metal-Organic Framework/Polydopamine Composite. ACS Cent. Sci. 2018, 4, 349-356. [CrossRef] [PubMed]

244. Peng, L.; Yang, S.; Sun, D.T.; Asgari, M.; Queen, W.L. MOF/polymer composite synthesized using a double solvent method offers enhanced water and $\mathrm{CO}_{2}$ adsorption properties. Chem. Commun. 2018, 54, 10602-10605. [CrossRef] [PubMed]

245. Erucar, I.; Yilmaz, G.; Keskin, S. Recent Advances in Metal-Organic Framework-Based Mixed Matrix Membranes. Chem. Asian J. 2013, 8, 1692-1704. [CrossRef] [PubMed]

246. Park, H.B.; Kamcev, J.; Robeson, L.M.; Elimelech, M.; Freeman, B.D. Maximizing the right stuff: The trade-off between membrane permeability and selectivity. Science 2017, 356, eaab0530. [CrossRef] [PubMed]

247. Robeson, L.M. Correlation of Separation Factor Versus Permeability for Polymeric Membranes. J. Membr. Sci. 1991, 62, 165-185. [CrossRef]

248. Robeson, L.M. The upper bound revisited. J. Membr. Sci. 2008, 320, 390-400. [CrossRef]

249. Adams, R.; Carson, C.; Ward, J.; Tannenbaum, R.; Koros, W. Metal organic framework mixed matrix membranes for gas separations. Microporous Mesoporous Mater. 2010, 131, 13-20. [CrossRef]

250. Sumida, K.; Rogow, D.L.; Mason, J.A.; McDonald, T.M.; Bloch, E.D.; Herm, Z.R.; Bae, T.-H.; Long, J.R. Carbon Dioxide Capture in Metal-Organic Frameworks. Chem. Rev. 2012, 112, 724-781. [CrossRef]

251. Jeazet, H.B.T.; Staudt, C.; Janiak, C. A method for increasing permeability in O-2/N-2 separation with mixed-matrix membranes made of water-stable MIL-101 and polysulfone. Chem. Commun. 2012, 48, 2140-2142. [CrossRef]

252. Lin, R.; Hernandez, B.V.; Ge, L.; Zhu, Z. Metal organic framework based mixed matrix membranes: An overview on filler/polymer interfaces. J. Mater. Chem. A 2018, 6, 293-312. [CrossRef]

253. Azizi, A.; Feijani, E.A.; Ghorbani, Z.; Tavasoli, A. Fabrication and characterization of highly efficient three component CuBTC/graphene oxide/PSF membrane for gas separation application. Int. J. Hydrogen Energy 2021, 46, 2244-2254. [CrossRef]

254. Seoane, B.; Coronas, J.; Gascon, I.; Etxeberria Benavides, M.; Karvan, O.; Caro, J.; Kapteijn, F.; Gascon, J. Metal-organic framework based mixed matrix membranes: A solution for highly efficient $\mathrm{CO}_{2}$ capture? Chem. Soc. Rev. 2015, 44, 2421-2454. [CrossRef] [PubMed]

255. Guo, X.; Huang, H.; Ban, Y.; Yang, Q.; Xiao, Y.; Li, Y.; Yang, W.; Zhong, C. Mixed matrix membranes incorporated with amine-functionalized titanium-based metal-organic framework for $\mathrm{CO}_{2} / \mathrm{CH}_{4}$ separation. J. Membr. Sci. 2015, 478, 130-139. [CrossRef]

256. Nik, O.G.; Chen, X.Y.; Kaliaguine, S. Functionalized metal organic framework-polyimide mixed matrix membranes for $\mathrm{CO}_{2} / \mathrm{CH}_{4}$ separation. J. Membr. Sci. 2012, 413, 48-61. [CrossRef]

257. Basu, S.; Cano-Odena, A.; Vankelecom, I.F.J. Asymmetric Matrimid (R)/ Cu-3(BTC)(2) mixed-matrix membranes for gas separations. J. Membr. Sci. 2010, 362, 478-487. [CrossRef]

258. Sachdeva, S.; Koper, S.J.H.; Sabetghadam, A.; Soccol, D.; Gravesteijn, D.J.; Kapteijn, F.; Sudholter, E.J.R.; Gascon, J.; de Smet, L.C.P.M. Gas Phase Sensing of Alcohols by Metal Organic Framework-Polymer Composite Materials. ACS Appl. Mater. Interfaces 2017, 9, 24926-24935. [CrossRef] [PubMed]

259. Rodenas, T.; van Dalen, M.; Serra-Crespo, P.; Kapteijn, F.; Gascon, J. Mixed matrix membranes based on NH2-functionalized MIL-type MOFs: Influence of structural and operational parameters on the $\mathrm{CO}_{2} / \mathrm{CH}_{4}$ separation performance. Microporous Mesoporous Mater. 2014, 192, 35-42. [CrossRef] 
260. Serra-Crespo, P.; Gobechiya, E.; Ramos-Fernandez, E.V.; Juan-Alcaniz, J.; Martinez-Joaristi, A.; Stavitski, E.; Kirschhock, C.E.A.; Martens, J.A.; Kapteijn, F.; Gascon, J. Interplay of Metal Node and Amine Functionality in NH2-MIL-53: Modulating Breathing Behavior through Intra-framework Interactions. Langmuir 2012, 28, 12916-12922. [CrossRef] [PubMed]

261. Moore, T.T.; Koros, W.J. Non-ideal effects in organic-inorganic materials for gas separation membranes. J. Mol. Struct. 2005, 739, 87-98. [CrossRef]

262. Burmann, P.; Zornoza, B.; Tellez, C.; Coronas, J. Mixed matrix membranes comprising MOFs and porous silicate fillers prepared via spin coating for gas separation. Chem. Eng. Sci. 2014, 107, 66-75. [CrossRef]

263. Cao, R.; Ding, H.; Kim, K.-J.; Peng, Z.; Wu, J.; Culp, J.T.; Ohodnicki, P.R.; Beckman, E.; Chen, K.P. Metal-organic framework functionalized polymer coating for fiber optical methane sensors. Sens. Actuators B Chem. 2020, 324. [CrossRef]

264. Gupta, A.; Sharma, A.L.; Deep, A. Sensitive impedimetric detection of E. coli with metal-organic framework (MIL-53) / polymer (PEDOT) composite modified screen-printed electrodes. J. Environ. Chem. Eng. 2021, 9, 104925. [CrossRef]

265. Li, C.; Zhang, L.; Chen, J.; Li, X.; Sun, J.; Zhu, J.; Wang, X.; Fu, Y. Recent development and applications of electrical conductive MOFs. Nanoscale 2021, 13, 485-509. [CrossRef] [PubMed]

266. Zahadiya, H.; Wijesundera, R.P.; Hettiarachchi, C.V.; Perera, I.R. Effect of Benzene Derivatives as Guest Molecules on Semiconductor Properties of MOF-199. Chemistryselect 2021, 6, 425-429. [CrossRef]

267. Vo Minh Huy, T.; Aguey-Zinsou, K.-F. Encapsulation of silicotungstic acid into chromium (III) terephthalate metal-organic framework for high proton conductivity membranes. Res. Chem. Intermed. 2021, 47, 61-76. [CrossRef]

268. Yao, M.-S.; Li, W.-H.; Xu, G. Metal-organic frameworks and their derivatives for electrically-transduced gas sensors. Coord. Chem. Rev. 2021, 426. [CrossRef]

269. Hansen, J.; Kharecha, P.; Sato, M.; Masson-Delmotte, V.; Ackerman, F.; Beerling, D.J.; Hearty, P.J.; Hoegh-Guldberg, O.; Hsu, S.-L.; Parmesan, C.; et al. Assessing "Dangerous Climate Change": Required Reduction of Carbon Emissions to Protect Young People, Future Generations and Nature. PLoS ONE 2013, 8, e81648. [CrossRef]

270. Mikkelsen, M.; Jorgensen, M.; Krebs, F.C. The teraton challenge. A review of fixation and transformation of carbon dioxide. Energy Environ. Sci. 2010, 3, 43-81. [CrossRef]

271. Romero-Hermida, M.I.; Romero-Enrique, J.M.; Morales-Florez, V.; Esquivias, L. Flue gas adsorption by single-wall carbon nanotubes: A Monte Carlo study. J. Chem. Phys. 2016, 145, 074701. [CrossRef] [PubMed]

272. Lackner, K.S. A guide to $\mathrm{CO}_{2}$ sequestration. Science 2003, 300, 1677-1678. [CrossRef] [PubMed]

273. Haszeldine, R.S. Carbon Capture and Storage: How Green Can Black Be? Science 2009, 325, 1647-1652. [CrossRef] [PubMed]

274. Carbon Sequestration. Science 2009, 325, 1644-1645. [CrossRef]

275. Firoozabadi, A.; Myint, P.C. Prospects for Subsurface $\mathrm{CO}_{2}$ Sequestration. AIChE J. 2010, 56, 1398-1405. [CrossRef]

276. Gao, W.H.; Butler, D.; Tomasko, D.L. High-pressure adsorption of $\mathrm{CO}_{2}$ on $\mathrm{NaY}$ zeolite and model prediction of adsorption isotherms. Langmuir 2004, 20, 8083-8089. [CrossRef]

277. Siriwardane, R.V.; Shen, M.S.; Fisher, E.P. Adsorption of $\mathrm{CO}_{2}$ on zeolites at moderate temperatures. Energy Fuels 2005, 19, 1153-1159. [CrossRef]

278. Siriwardane, R.V.; Shen, M.S.; Fisher, E.P.; Poston, J.A. Adsorption of $\mathrm{CO}_{2}$ on molecular sieves and activated carbon. Energy Fuels 2001, 15, 279-284. [CrossRef]

279. Przepiorski, J.; Skrodzewicz, M.; Morawski, A.W. High temperature ammonia treatment of activated carbon for enhancement of $\mathrm{CO}_{2}$ adsorption. Appl. Surf. Sci. 2004, 225, 235-242. [CrossRef]

280. Li, J.-R.; Ma, Y.; McCarthy, M.C.; Sculley, J.; Yu, J.; Jeong, H.-K.; Balbuena, P.B.; Zhou, H.-C. Carbon dioxide capture-related gas adsorption and separation in metal-organic frameworks. Coord. Chem. Rev. 2011, 255, 1791-1823. [CrossRef]

281. Shekhah, O.; Belmabkhout, Y.; Chen, Z.; Guillerm, V.; Cairns, A.; Adil, K.; Eddaoudi, M. Made-to-order metal-organic frameworks for trace carbon dioxide removal and air capture. Nat. Commun. 2014, 5, 1-7. [CrossRef]

282. Farha, O.K.; Bae, Y.-S.; Hauser, B.G.; Spokoyny, A.M.; Snurr, R.Q.; Mirkin, C.A.; Hupp, J.T. Chemical reduction of a diimide based porous polymer for selective uptake of carbon dioxide versus methane. Chem. Commun. 2010, 46, 1056-1058. [CrossRef] [PubMed]

283. Bae, Y.-S.; Hauser, B.G.; Farha, O.K.; Hupp, J.T.; Snurr, R.Q. Enhancement of $\mathrm{CO}_{2} / \mathrm{CH}_{4}$ selectivity in metal-organic frameworks containing lithium cations. Microporous Mesoporous Mater. 2011, 141, 231-235. [CrossRef]

284. Babarao, R.; Jiang, J. Unprecedentedly High Selective Adsorption of Gas Mixtures in rho Zeolite-like Metal-Organic Framework: A Molecular Simulation Study. J. Am. Chem. Soc. 2009, 131, 11417-11425. [CrossRef] [PubMed]

285. Li, B.; Zhang, Z.; Li, Y.; Yao, K.; Zhu, Y.; Deng, Z.; Yang, F.; Zhou, X.; Li, G.; Wu, H.; et al. Enhanced Binding Affinity, Remarkable Selectivity, and High Capacity of $\mathrm{CO}_{2}$ by Dual Functionalization of a rht-Type Metal-Organic Framework. Angew. Chem. Int. Ed. 2012, 51, 1412-1415. [CrossRef] [PubMed]

286. Bae, Y.-S.; Farha, O.K.; Spokoyny, A.M.; Mirkin, C.A.; Hupp, J.T.; Snurr, R.Q. Carborane-based metal-organic frameworks as highly selective sorbents for $\mathrm{CO}_{2}$ over methane. Chem. Commun. 2008, 4135-4137. [CrossRef] [PubMed]

287. Dietzel, P.D.C.; Besikiotis, V.; Blom, R. Application of metal-organic frameworks with coordinatively unsaturated metal sites in storage and separation of methane and carbon dioxide. J. Mater. Chem. 2009, 19, 7362-7370. [CrossRef]

288. Caskey, S.R.; Wong-Foy, A.G.; Matzger, A.J. Dramatic tuning of carbon dioxide uptake via metal substitution in a coordination polymer with cylindrical pores. J. Am. Chem. Soc. 2008, 130, 10870-10871. [CrossRef] [PubMed] 
289. Yazaydin, A.O.; Snurr, R.Q.; Park, T.-H.; Koh, K.; Liu, J.; LeVan, M.D.; Benin, A.I.; Jakubczak, P.; Lanuza, M.; Galloway, D.B.; et al. Screening of Metal-Organic Frameworks for Carbon Dioxide Capture from Flue Gas Using a Combined Experimental and Modeling Approach. J. Am. Chem. Soc. 2009, 131, 18198-18199. [CrossRef]

290. Zhang, Z.; Yao, Z.-Z.; Xiang, S.; Chen, B. Perspective of microporous metal-organic frameworks for $\mathrm{CO}_{2}$ capture and separation. Energy Environ. Sci. 2014, 7, 2868-2899. [CrossRef]

291. Zhao, Y.; Wu, H.; Emge, T.J.; Gong, Q.; Nijem, N.; Chabal, Y.J.; Kong, L.; Langreth, D.C.; Liu, H.; Zeng, H.; et al. Enhancing Gas Adsorption and Separation Capacity through Ligand Functionalization of Microporous Metal-Organic Framework Structures. Chem. A Eur. J. 2011, 17, 5101-5109. [CrossRef] [PubMed]

292. Liu, H.; Zhao, Y.; Zhang, Z.; Nijem, N.; Chabal, Y.J.; Zeng, H.; Li, J. The Effect of Methyl Functionalization on Microporous Metal-Organic Frameworks' Capacity and Binding Energy for Carbon Dioxide Adsorption. Adv. Funct. Mater. 2011, 21, 4754-4762. [CrossRef]

293. Samanta, A.; Zhao, A.; Shimizu, G.K.H.; Sarkar, P.; Gupta, R. Post-Combustion $\mathrm{CO}_{2}$ Capture Using Solid Sorbents: A Review. Ind. Eng. Chem. Res. 2012, 51, 1438-1463. [CrossRef]

294. Lin, Y.; Kong, C.; Chen, L. Direct synthesis of amine-functionalized MIL-101(Cr) nanoparticles and application for $\mathrm{CO}_{2}$ capture. RSC Adv. 2012, 2, 6417-6419. [CrossRef]

295. Zhang, Z.; Huang, S.; Xian, S.; Xi, H.; Li, Z. Adsorption Equilibrium and Kinetics of $\mathrm{CO}_{2}$ on Chromium Terephthalate MIL-101. Energy Fuels 2011, 25, 835-842. [CrossRef]

296. Zhou, X.; Huang, W.; Miao, J.; Xia, Q.; Zhang, Z.; Wang, H.; Li, Z. Enhanced separation performance of a novel composite material GrO@MIL-101 for $\mathrm{CO}_{2} / \mathrm{CH}_{4}$ binary mixture. Chem. Eng. J. 2015, 266, 339-344. [CrossRef]

297. Xian, S.; Peng, J.; Zhang, Z.; Xia, Q.; Wang, H.; Li, Z. Highly enhanced and weakened adsorption properties of two MOFs by water vapor for separation of $\mathrm{CO}_{2} / \mathrm{CH}_{4}$ and $\mathrm{CO}_{2} / \mathrm{N}-2$ binary mixtures. Chem. Eng. J. 2015, 270, 385-392. [CrossRef]

298. Seo, Y.-K.; Yoon, J.W.; Lee, J.S.; Hwang, Y.K.; Jun, C.-H.; Chang, J.-S.; Wuttke, S.; Bazin, P.; Vimont, A.; Daturi, M.; et al. EnergyEfficient Dehumidification over Hierachically Porous Metal-Organic Frameworks as Advanced Water Adsorbents. Adv. Mater. 2012, 24, 806-807. [CrossRef]

299. Akiyama, G.; Matsuda, R.; Sato, H.; Hori, A.; Takata, M.; Kitagawa, S. Effect of functional groups in MIL-101 on water sorption behavior. Microporous Mesoporous Mater. 2012, 157, 89-93. [CrossRef]

300. Yan, J.; Yu, Y.; Ma, C.; Xiao, J.; Xia, Q.; Li, Y.; Li, Z. Adsorption isotherms and kinetics of water vapor on novel adsorbents MIL-101(Cr)@GO with super-high capacity. Appl. Therm. Eng. 2015, 84, 118-125. [CrossRef]

301. Zhao, Z.; Wang, S.; Yang, Y.; Li, X.; Li, J.; Li, Z. Competitive adsorption and selectivity of benzene and water vapor on the microporous metal organic frameworks (HKUST-1). Chem. Eng. J. 2015, 259, 79-89. [CrossRef]

302. Kuwahara, Y.; Kang, D.-Y.; Copeland, J.R.; Brunelli, N.A.; Didas, S.A.; Bollini, P.; Sievers, C.; Kamegawa, T.; Yamashita, H.; Jones, C.W. Dramatic Enhancement of $\mathrm{CO}_{2}$ Uptake by Poly(ethyleneimine) Using Zirconosilicate Supports. J. Am. Chem. Soc. 2012, 134, 10757-10760. [CrossRef]

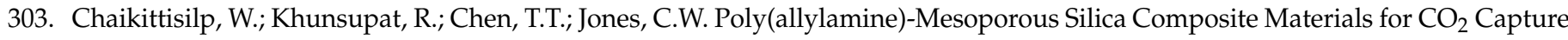
from Simulated Flue Gas or Ambient Air. Ind. Eng. Chem. Res. 2011, 50, 14203-14210. [CrossRef]

304. Espinal, L.; Green, M.L.; Fischer, D.A.; DeLongchamp, D.M.; Jaye, C.; Horn, J.C.; Sakwa-Novak, M.A.; Chaikittisilp, W.; Brunelli, N.A.; Jones, C.W. Interrogating the Carbon and Oxygen K-Edge NEXAFS of a $\mathrm{CO}_{2}$-Dosed Hyperbranched Aminosilica. J. Phys. Chem. Lett. 2015, 6, 148-152. [CrossRef]

305. Sayari, A.; Belmabkhout, Y. Stabilization of Amine-Containing $\mathrm{CO}_{2}$ Adsorbents: Dramatic Effect of Water Vapor. J. Am. Chem. Soc. 2010, 132, 6312-6314. [CrossRef] [PubMed]

306. Hiyoshi, N.; Yogo, K.; Yashima, T. Reversible adsorption of carbon dioxide on amine-modified SBA-15 from flue gas containing water vapor. In Carbon Dioxide Utilization for Global Sustainability; Studies in Surface Science and Catalysis; Park, S.E., Chang, J.S., Lee, K.W., Eds.; Elsevier: Amsterdam, The Netherlands, 2004; Volume 153, pp. 417-422. [CrossRef]

307. Huang, H.Y.; Yang, R.T.; Chinn, D.; Munson, C.L. Amine-grafted MCM-48 and silica xerogel as superior sorbents for acidic gas removal from natural gas. Ind. Eng. Chem. Res. 2003, 42, 2427-2433. [CrossRef] 